\title{
Study of Beryllium, Magnesium, and Spodium Bonds to Carbenes and Carbodiphosphoranes
}

\author{
Mirosław Jabłoński + (iD \\ Faculty of Chemistry, Nicolaus Copernicus University, 87-100 Toruń, Poland; teojab@chem.umk.pl; \\ Tel.: +48-056-611-4695 \\ † Current address: 7-Gagarina St., 87-100 Toruń, Poland.
}

Citation: Jabłoński, M. Study of

Beryllium, Magnesium, and

Spodium Bonds to Carbenes and Carbodiphosphoranes. Molecules 2021, 26, 2275. https://doi.org/ $10.3390 /$ molecules 26082275

Academic Editors: Maxim L. Kuznetsov, Carlo Gatti, David L. Cooper and Miroslav Kohout

Received: 18 March 2021

Accepted: 11 April 2021

Published: 14 April 2021

Publisher's Note: MDPI stays neutral with regard to jurisdictional claims in published maps and institutional affiliations.

\begin{abstract}
The aim of this article is to present results of theoretical study on the properties of $\mathrm{C} \cdots \mathrm{M}$ bonds, where $C$ is either a carbene or carbodiphosphorane carbon atom and $M$ is an acidic center of $\mathrm{MX}_{2}(\mathrm{M}=\mathrm{Be}, \mathrm{Mg}, \mathrm{Zn})$. Due to the rarity of theoretical data regarding the $\mathrm{C} \cdots \mathrm{Zn}$ bond (i.e., the zinc bond), the main focus is placed on comparing the characteristics of this interaction with C...Be (beryllium bond) and C..Mg (magnesium bond). For this purpose, theoretical studies $(\omega \mathrm{B} 97 \mathrm{X}-\mathrm{D} / 6-311++\mathrm{G}(2 \mathrm{df}, 2 \mathrm{p}))$ have been performed for a large group of dimers formed by $\mathrm{MX}_{2}$ $(\mathrm{X}=\mathrm{H}, \mathrm{F}, \mathrm{Cl}, \mathrm{Br}, \mathrm{Me})$ and either a carbene $\left(\left(\mathrm{NH}_{2}\right)_{2} \mathrm{C}\right.$, imidazol-2-ylidene, imidazolidin-2-ylidene, tetrahydropyrymid-2-ylidene, cyclopropenylidene) or carbodiphosphorane $\left(\left(\mathrm{PH}_{3}\right)_{2} \mathrm{C},\left(\mathrm{NH}_{3}\right)_{2} \mathrm{C}\right)$ molecule. The investigated dimers are characterized by a very strong charge transfer effect from either the carbene or carbodiphosphorane molecule to the $\mathrm{MX}_{2}$ one. This may even be over six times as strong as in the water dimer. According to the QTAIM and NCI method, the zinc bond is not very different than the beryllium bond, with both featuring a significant covalent contribution. However, the zinc bond should be definitely stronger if delocalization index is considered.
\end{abstract}

Keywords: beryllium bond; magnesium bond; zinc bond; spodium bond; carbene; carbodiphosphoranes; intermolecular interaction; beryllium; magnesium; zinc

\section{Introduction}

Undoubtedly, one can get an impression that there has been a kind of race that has been going on for over a dozen years related to the introduction of various names for various interatomic contacts. The current situation with this nomenclature has recently been well captured by Alkorta, Elguero, and Frontera in a review article in Crystals [1]. Thus, in addition to hydrogen bonds [2-16], which have been well established for a hundred years, we also now have alkali bonds [17-22], alkaline earth metal bonds [23-34], triel bonds [35-46], tetrel bonds [47-55], pnictogen bonds [55-63], chalcogen bonds [64-72], halogen bonds [73-78], and aerogen (noble gas) bonds [79-81]. Apart from the obvious hydrogen bonds, the remaining terms refer consecutively to the interaction in which a Lewis acid is an element of groups 1-2 and then 13-18 of the periodic table. In circulation, there also exist names that refer to individual elements of group 1 or 2 , namely lithium bonds [17-20] and sodium bonds [21,22] in the former case and beryllium bonds [23-30], magnesium bonds [23,29-33], and calcium bonds [34] in the latter. Interactions involving various transition metals have not been called so willingly; however, in the case of interactions in which the Lewis acid center is a metal from groups 10 or 11, the term regium bonds [82-90] is relatively common. It is worth mentioning here that for interactions involving metals from group 11, the name coinage-metal bonds was previously introduced. In the aforementioned review article, Alkorta et al. proposed that interactions involving group 12 metals be called spodium bonds [1,91-93]. Unfortunately, for the metals of this group, this name seems not very intuitive.

Due to their specific electronic structure, carbenes occupy particular position in organic chemistry [94-103]. This peculiar electronic structure of carbenes results from the fact that 
the carbene carbon atom is merely divalent and therefore forms only one $(C=R)$ or at most two $\left(C R_{1} R_{2}\right)$ covalent bonds. This chemical situation indicates that only two valence electrons are used in the bonds, whereas the other two are unbound. This is turn leads to two possible spin states, triplet and singlet [98] (Figure 1).
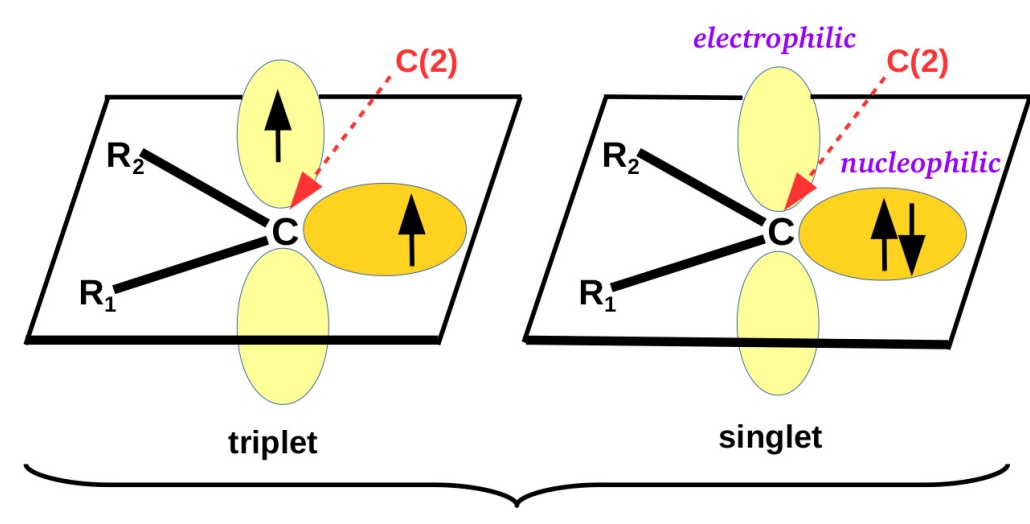

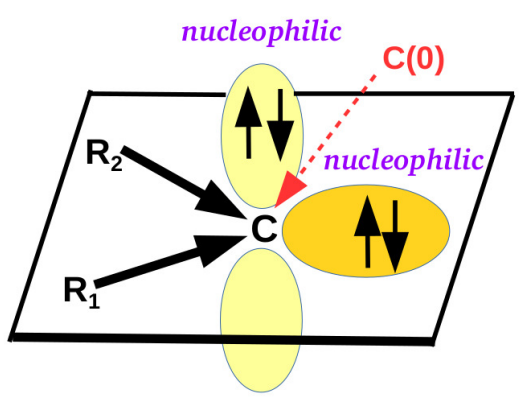

CDPs

carbenes

Figure 1. Electronic states of carbenes and carbodiphosphoranes.

In the triplet spin state, both electrons occupy perpendicular $p$ orbitals and have the same spins. In the singlet state, both electrons form a lone pair on one of the perpendicular $p$ orbitals. Due to the presence of the often readily available electron lone pair, carbenes in the singlet state are good Lewis bases; i.e., they feature strong nucleophilic properties. Indeed, the nucleophilic properties of carbenes are well known and are often used in organic and organometallic synthesis [94-103]. Consequently, it is known that carbene carbon atoms willingly form various types of interatomic connections, such as hydrogen bonds [104-111], lithium bonds [102,103,112-114], beryllium bonds [102,103,115-118], magnesium bonds [102,103,118-121], triel bonds [103,122-125], tetrel bonds [103,126-128], pnictogen bonds [103,129-131], chalcogen bonds [103,132], halogen bonds [103,133-136] (in particular to iodine [133,134]), and aerogen bonds [137]. Moreover, carbenes readily form numerous adducts with transition metals [102,119,138,139], significantly enriching the possibilities of designing syntheses in organometallic chemistry. In this case, the Nheterocyclic carbenes (NHC) are of particular importance [98,99,102,139]. In view of the title of this article, it should be mentioned that complexes for heavier transition metals, i.e., from lower rows of the periodic table, are especially common, while examples of carbenes bound to lighter transition metals, e.g., zinc $[119,121]$, are reported much less frequently. In particular, theoretical reports are missing. In the light of the aforementioned proposal of Alkorta et al. [1], the interaction between the carbene carbon atom and the zinc atom should be classified as a spodium bond.

Figure 1 clearly shows that a singlet carbene, in addition to an electron lone pair, also possesses a formally empty $p$ orbital perpendicular to the plane of the molecule, leading to the electrophilic properties of a given carbene [140-145]. Thus, carbenes can also act like a Lewis acid interacting with good electron density donors, i.e., Lewis bases. On this topic, the interactions of the carbene carbon atom with nitrogen or phosphorus were definitely the most frequently reported [141]. A practical curiosity is that the formation of phosphorus ylides was considered evidence of the presence of an empty $p$ orbital on the carbene carbon atom of singlet carbenes [98]. It is worth mentioning here that it has only recently been shown by theoretical methods that singlet carbenes can also interact with a hydridic, i.e., possessing partial negative charge, hydrogen atom of silane, leading to a particular case of a tetrel bond (although this case was announced as a hydride-carbene bond) [143-145]. 
Although Hund's rule favors the spin triplet state over the singlet one [146], the requirements that invert this relationship, i.e., make the singlet state an electronic ground state, are well known. This may happen if either some appropriate geometric requirements are met [147-149] or one or both of the substituents $R_{1}$ and $R_{2}$ are $\sigma$-electron-withdrawing or $\pi$-electron-donating [149-153]. The latter requirement is met especially in the presence of strongly electronegative atoms with lone electron pairs, such as $\mathrm{P}, \mathrm{N}, \mathrm{O}, \mathrm{F}, \mathrm{Cl}$, etc. In this case, the preference for the singlet state results from partial delocalization of the electron charge from electron lone pairs of these atoms to the unfilled $p$ orbital on the carbene carbon atom (Figure 1).

Apart from carbenes, an equally important and interesting group of organic compounds is the so-called carbodiphosphoranes (CDPs) and their amine analogues [154-172]. Their uniqueness in the electronic structure (see Figure 1) is that, unlike the previously described carbenes, in CDPs, none of the four valence electrons of the carbon atom participate in ligand binding, and therefore these electrons remain unbound. Instead of covalent bonds as in carbenes, the carbon atom in CDPs is bound to ligands via donor-acceptor $R \rightarrow C$ bonds [167]. These non-binding valence carbon electrons form two lone pairs, and not just one as in singlet carbenes. It should therefore be expected that CDPs exhibit greater nucleophilic abilities than singlet carbenes, and moreover, they should be felt not only in the plane of the molecule but also in the direction perpendicular to it.

It is understandable that so far, the vast majority of theoretical studies on beryllium and magnesium bonds have used as Lewis bases small molecules containing either some atoms with good electron-donating properties or $\pi$ bonds [23-27,29-32]. On the other hand, reports of systems containing spodium bonds [91-93], especially with zinc (they could be called zinc bonds) are very rare [91,93]. It is also quite understandable that the research on carbenes and CDPs is mostly experimental. This is of course due to their huge role in organic and organometallic synthesis, as mentioned earlier. For this reason, beryllium bonds, magnesium bonds, or spodium bonds with the zinc atom as the Lewis acid center (i.e., the zinc bonds) with the participation of either carbenes or CDPs are most often found by crystallographic methods in the solid state. In this case, both the carbene (or the CDP) and the Lewis acid interacting with it are molecules containing many different substituents and functional groups, often of considerable size, which makes the systems themselves also generally bulky.

In order to unite these two thematic areas, this article describes the result of theoretical research on a large group of dimers with a beryllium bond, magnesium bond, or zinc bond between various Lewis acids of the $\mathrm{MX}_{2}$ (where $\mathrm{M}=\mathrm{Be}, \mathrm{Mg}, \mathrm{Zn}$ and $\mathrm{X}=\mathrm{H}, \mathrm{F}, \mathrm{Cl}, \mathrm{Br}$, $\mathrm{Me})$ type and some fundamental carbenes $\left(\left(\mathrm{NH}_{2}\right)_{2} \mathrm{C}\right.$, imidazol-2-ylidene, imidazolidin-2ylidene, tetrahydropyrymid-2-ylidene, and cyclopropenylidene) and $\mathrm{CDPs}\left(\left(\mathrm{PH}_{3}\right)_{2} \mathrm{C}\right.$ and $\left.\left(\mathrm{NH}_{3}\right)_{2} \mathrm{C}\right)$ acting as a Lewis base. Therefore, the aim of this article is to present the results of theoretical research on the properties of $C \cdots M$ bonds, where $C$ is either a carbene or $\mathrm{CDP}$ carbon atom. It should be noted that due to the aforementioned scarcity of reports, in particular theoretical ones, on systems featuring a zinc bond (i.e., the spodium bond [1] with the participation of a zinc atom acting as a Lewis acid center), the reported studies on the C . . Zn bond-containing systems investigated here represent an especially considerable novelty. At the same time, the presented results on the properties of this bond and slightly similar $\mathrm{C} \cdots \mathrm{Be}$ and $\mathrm{C} \cdots \mathrm{Mg}$ bonds will contribute to increasing the knowledge of both the carbenes chemistry and the chemistry of CDPs. It is worth mentioning at this point that the presence of $X$ halogen atoms leads in some of the dimers considered here to certain symptoms that indicate interactions accompanying the leading $\mathrm{C} \cdots \mathrm{M}$ bond. Therefore, one of the sub-goals of this article is to investigate the conditions that favor these additional weak interactions.

\section{Results and Discussion}

As mentioned in the Introduction, this article describes research on systems containing a beryllium bond, a magnesium bond or a zinc bond, where the role of Lewis acids is 
played by the $\mathrm{MX}_{2}$ molecules (where $\mathrm{M}=\mathrm{Be}, \mathrm{Mg}, \mathrm{Zn}$ and $\mathrm{X}=\mathrm{H}, \mathrm{F}, \mathrm{Cl}, \mathrm{Be}, \mathrm{Me}$ ), while the role of Lewis base is played by either carbene $\left(\left(\mathrm{NH}_{2}\right)_{2} \mathrm{C}\right.$, imidazol-2-ylidene, imidazolidin2-ylidene, tetrahydropyrymid-2-ylidene, or cyclopropenylidene) or carbodiphosphorane (being either $\left(\mathrm{PH}_{3}\right)_{2} \mathrm{C}$ or $\left.\left(\mathrm{NH}_{3}\right)_{2} \mathrm{C}\right)$. The monomers themselves and their dimers, in which the described bonds occur, are presented in separate subsections.

\subsection{Investigated Systems}

\subsubsection{Monomers}

- $\mathrm{MeX}_{2}$

The considered $\mathrm{MX}_{2}$ molecules are characterized by a linear structure in which $\mathrm{M}-\mathrm{X}$ bonds are formed by overlapping of the hybridized $s p$ orbital of the metal atom with one of the orbitals of X. Due to lower electronegativity of the metal atom, this atom is endowed with a partial positive charge (Table 1), becoming electron-depleted and therefore a Lewis acid center.

Table 1. Some fundamental data characterizing $M X_{2}$ molecules: the length of the $\mathrm{M}-\mathrm{X}$ bond $\left(d_{\mathrm{MX}}\right)$, the atomic charge (Hirshfeld-, NBO- or QTAIM-based) of $\mathrm{M}(q(\mathrm{M}))$, the maximum value of the electrostatic potential on $\mathrm{M}\left(V^{\max }(\mathrm{M})\right)$.

\begin{tabular}{cccccc}
\hline \multirow{2}{*}{$\mathbf{M X}_{2}$} & \multirow{2}{*}{$\boldsymbol{d}_{\mathbf{M X}} / \mathbf{A}$} & \multicolumn{3}{c}{$\boldsymbol{q}(\mathbf{M}) / \mathbf{a u}$} & \multirow{2}{*}{$\boldsymbol{V}^{\mathbf{m a x}}(\mathbf{M}) / \mathbf{a u}$} \\
\cline { 3 - 4 } & & Hirshfeld & $\mathbf{N B O}$ & $\mathbf{Q T A I M}$ & \\
\hline $\mathrm{BeH}_{2}$ & 1.335 & 0.421 & 1.185 & 1.689 & 0.057 \\
$\mathrm{BeF}_{2}$ & 1.381 & 0.646 & 1.737 & 1.772 & 0.101 \\
$\mathrm{BeCl}_{2}$ & 1.802 & 0.478 & 1.449 & 1.724 & 0.060 \\
$\mathrm{BeBr}_{2}$ & 1.950 & 0.486 & 1.358 & 1.696 & 0.052 \\
$\mathrm{BeMe}_{2}$ & 1.683 & 0.456 & 1.467 & 1.701 & 0.037 \\
\hline $\mathrm{MgH}_{2}$ & 1.705 & 0.544 & 1.379 & 1.551 & 0.102 \\
$\mathrm{MgF}_{2}$ & 1.757 & 0.924 & 1.881 & 1.797 & 0.243 \\
$\mathrm{MgCl}_{2}$ & 2.176 & 0.776 & 1.688 & 1.724 & 0.164 \\
$\mathrm{MgBr}_{2}$ & 2.324 & 0.819 & 1.620 & 1.688 & 0.139 \\
$\mathrm{MgMe}_{2}$ & 2.088 & 0.659 & 1.532 & 1.581 & 0.087 \\
\hline $\mathrm{ZnH}_{2}$ & 1.539 & 0.354 & 1.069 & 0.794 & 0.050 \\
$\mathrm{ZnF}_{2}$ & 1.730 & 0.714 & 1.646 & 1.401 & 0.093 \\
$\mathrm{ZnCl}_{2}$ & 2.079 & 0.569 & 1.397 & 1.133 & 0.071 \\
$\mathrm{ZnBr}_{2}$ & 2.215 & 0.622 & 1.304 & 1.008 & 0.065 \\
$\mathrm{ZnMe}_{2}$ & 1.942 & 0.444 & 1.284 & 0.861 & 0.037 \\
\hline
\end{tabular}

The atomic charge values shown in Table 1 confirm the known fact that they can be very significantly dependent on the method of obtaining them in the calculations [173-176]. The atomic charges obtained by the NBO and QTAIM methods seem to be greatly exaggerated. In the context of the presented results, however, it is more important that all the methods of obtaining atomic charges used here (i.e., Hirshfeld [177-179], NBO [180,181], and QTAIM [182-184]) show that in the set of $\mathrm{MX}_{2}$ molecules for a given metal $\mathrm{M}$ the most positive charge on the $\mathrm{M}$ atom occurs when $\mathrm{X}=\mathrm{F}$. This is fully understandable due to the very high electronegativity of the fluorine atom. Conversely, the smallest positive charge on the $\mathrm{M}$ atom occurs when $\mathrm{X}=\mathrm{H}$. This result is not as expected, because, due to the positive inductive effect $(+\mathrm{I})$ of the methyl group, one would expect the smallest positive atomic charge of $\mathrm{M}_{\text {in }} \mathrm{MMe}_{2}$. It is also seen that the $\mathrm{Cl}$ and $\mathrm{Br}$ atoms lead to similar atomic charges on M. Importantly, all the methods used show that the highest positive charge occurs in $\mathrm{MgF}_{2}$, and the lowest in $\mathrm{ZnH}_{2}$. If we refer to the most reliable $[175,176]$ Hirshfeld atomic charges, then these values are 0.924 and $0.354 \mathrm{au}$, respectively. The former value suggests an extremely high polarization of the $\mathrm{Mg}-\mathrm{F}$ bond, which practically becomes the $\mathrm{Mg}^{+} \mathrm{F}^{-}$ ionic one. A practical consequence of this finding is that, assuming electrostatic reasoning, 
the $\mathrm{MgF}_{2}$ molecule should be the best Lewis acid, and therefore it should theoretically form the strongest adducts with carbenes and CDPs.

With the values of the atomic charges obtained by various theoretical methods, it is interesting to see if there are clear relationships between them. Figure 2 shows the relationships between the Hirshfeld charges and their equivalents obtained by the NBO or QTAIM method.

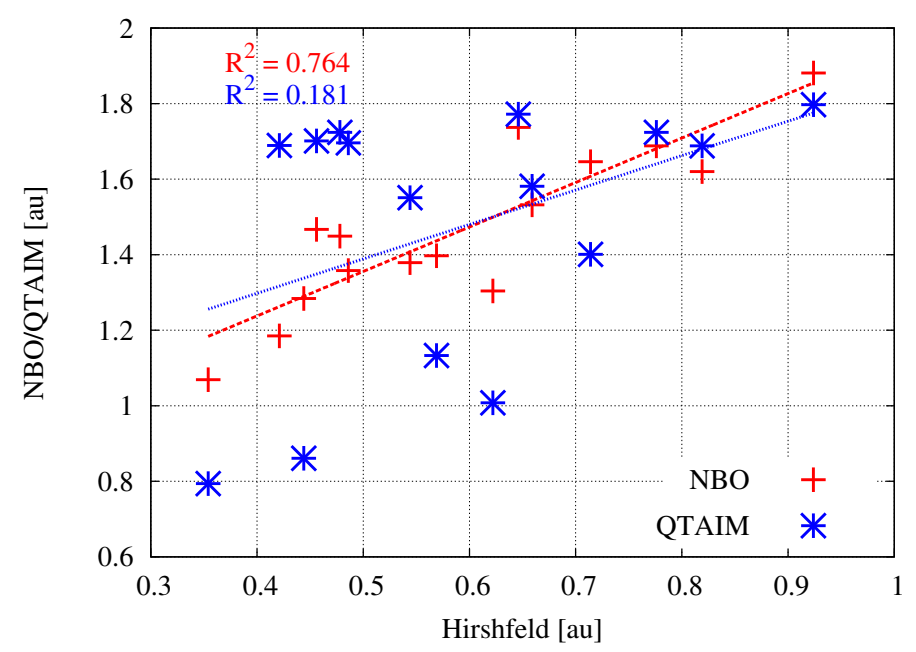

Figure 2. Relationships between the atomic charges of $\mathrm{M}(\mathrm{M}=\mathrm{Be}, \mathrm{Mg}, \mathrm{Zn}$; see Table 1) obtained by the Hirshfeld method and either NBO or QTAIM.

As can be clearly seen, the linear relationships between the Hirshfeld atomic charges and those obtained by the NBO or QTAIM method are very weak. Particularly in the case of the latter method, the obtained coefficient of determination is unacceptably low. This result shows that especially the atomic charges obtained by QTAIM should not be treated as reliable. This flaw of QTAIM-based atomic charges was attributed to irregular shapes of atomic basins, which give them multipolar moments.

The electrophilic properties of a particular metal atom, which is an acidic center in the $\mathrm{MX}_{2}$ molecule, can be nicely illustrated by means of maps of the distribution of the molecular electrostatic potential (MESP) projected onto the electron density isosurface, as shown in Figure 3.

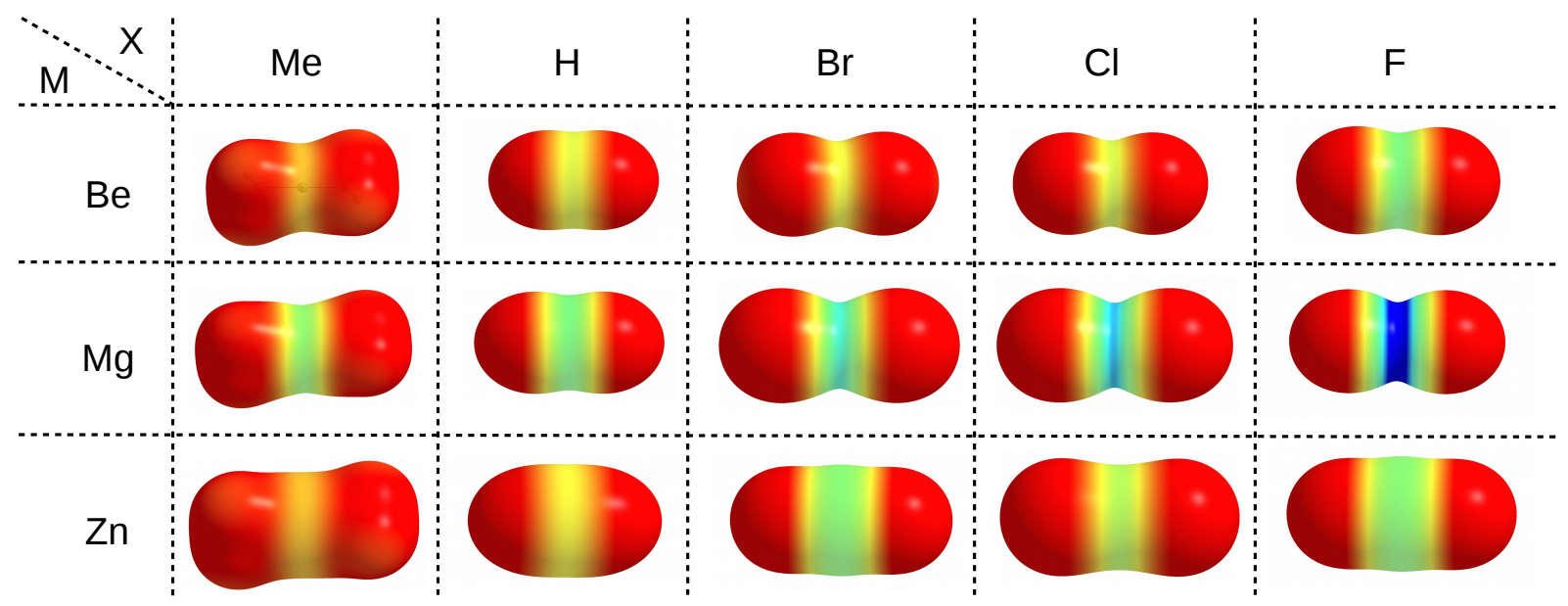

Figure 3. Maps of electrostatic potential projected on 0.001 au isodensity surfaces of $\mathrm{MX}_{2}(\mathrm{M}=\mathrm{Be}, \mathrm{Mg}, \mathrm{Zn} ; \mathrm{X}=\mathrm{Me}, \mathrm{H}, \mathrm{F}, \mathrm{Cl}$, $\mathrm{Br}$ ). A common value scale (in au) was used: 0.0—red, 0.05—yellow, 0.1—green, 0.15—cyan, 0.2—blue. 
The use of same scale of the electrostatic potential values (from 0.0 au (red) to 0.2 (blue)) for all $\mathrm{MX}_{2}$ molecules allows one to easily capture the existing relationships. It is clearly seen that, upon going in the series $\mathrm{Me} \rightarrow \mathrm{H} \rightarrow \mathrm{Br} \rightarrow \mathrm{Cl} \rightarrow \mathrm{F}$, i.e., from left to right in Figure 3, a belt of even more positive electrostatic potential develops around the central metal atom. This is of course confirmed by the corresponding values of the maximum electrostatic potential on $\mathrm{M}\left(V^{\max }(\mathrm{M})\right)$, which are provided in the last column of Table 1. For zinc compounds, these values (in au) increase in this series as follows: $0.037<0.050$ $<0.065<0.071<0.093$. Although the MESP maps for zinc molecules are very similar to those for beryllium, it is worth noting that in the former case, the corresponding MESP belt is wider and larger in diameter due to the larger atomic radius of $\mathrm{Zn}^{2+}(88 \mathrm{pm})$ compared to $\mathrm{Be}^{2+}(59 \mathrm{pm})$ [185]. Therefore, compared to beryllium, the zinc atom should be more accessible. The more important result, however, is that, for a given $X$, the belts of positive MESP are most visible when the central metal atom is magnesium. The values of $V^{\max }(\mathrm{M})$ increase monotonically quite quickly in the order given earlier, reaching a maximum value of $0.243 \mathrm{au}$ in $\mathrm{MgF}_{2}$ (Table 1). The fact that the $V^{\max }(\mathrm{M})$ values increase in this order, while $q(\mathrm{M})$ does not, suggests that $V^{\max }(\mathrm{M})$ is perhaps the more reliable parameter describing the acidic nature of the central metal atom in $\mathrm{MX}_{2}$ molecules than $q(\mathrm{M})$. Although the linear relationship between the value of $V^{\max }(\mathrm{M})$ is not very good $\left(R^{2}=0.795\right)$ either when $q(\mathrm{M})$ is computed utilizing the Hirshfeld method, it is much better than in the case of NBO- and especially QTAIM-based charges (Figure 4).

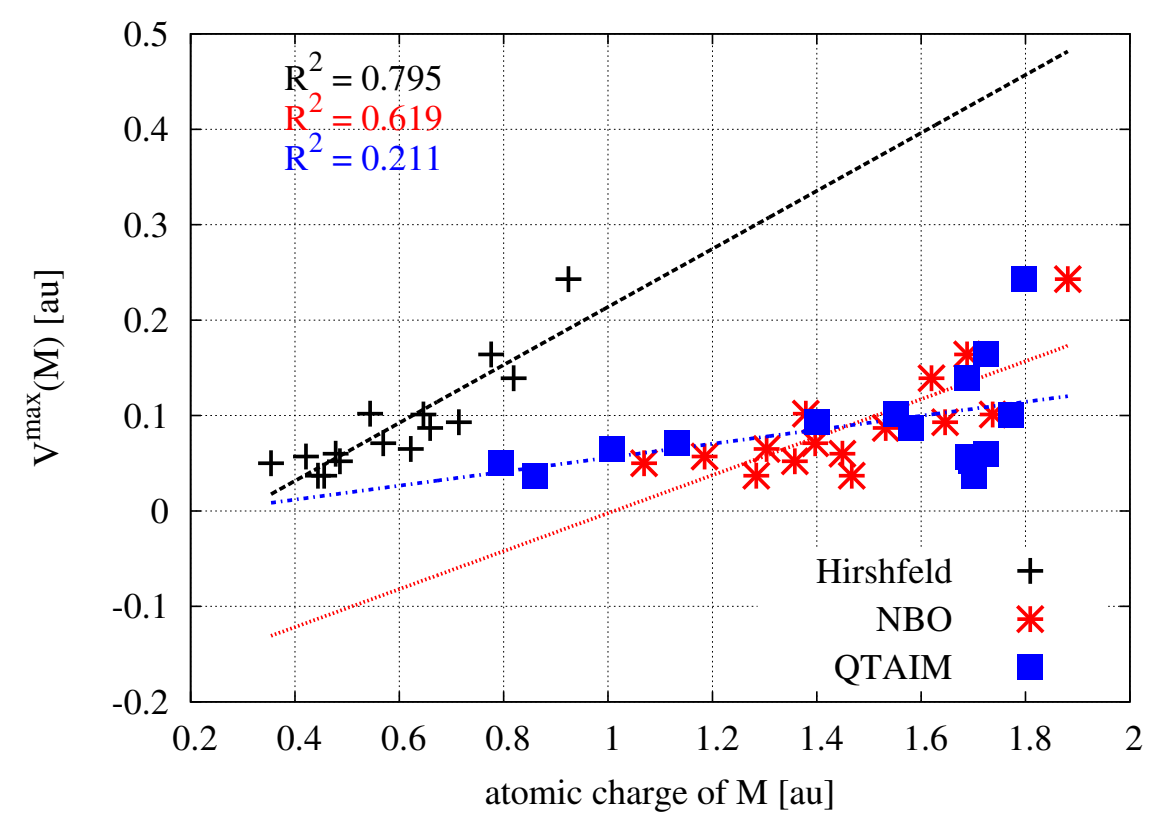

Figure 4. Relationships between the atomic charge of the $\mathrm{M}$ metal atom in $\mathrm{MX}_{2}(\mathrm{M}=\mathrm{Be}, \mathrm{Mg}, \mathrm{Zn}$; $\mathrm{X}=\mathrm{H}, \mathrm{F}, \mathrm{Cl}, \mathrm{Br}, \mathrm{Me}$ ) and the maximum value of the electrostatic potential on the surface of this atom.

\section{- $\quad$ Carbenes and CDPs}

Imidazol-2-ylidene, imidazolidin-2-ylidene, tetrahydropyrymid-2-ylidene, cyclopropenylidene, and $\left(\mathrm{NH}_{2}\right)_{2} \mathrm{C}$ have been used as model representatives of carbenes. In particular, the first two carbenes are often used in organic and organometallic chemistry and represent an important starting point in the syntheses of larger carbene compounds $[98,102,103]$. The CDPs group is represented by $\left(\mathrm{PH}_{3}\right)_{2} \mathrm{C}$ and its amino derivative $\left(\mathrm{NH}_{3}\right)_{2} \mathrm{C}$. Both are the starting molecules for more complex CDPs obtained by substituting hydrogen atoms in one or both of the $-\mathrm{PH}_{3}$ or $-\mathrm{NH}_{3}$ groups. It is worth mentioning here that the fully saturated phenyl derivative, i.e., $\left(\mathrm{PPh}_{3}\right)_{2} \mathrm{C}$ was the first synthesized CDP [154]. Some fundamental parameters characterizing the considered carbenes and CDPs are presented in Table 2. 
Table 2. Some fundamental data characterizing carbenes and CDPs: the R-C-R angle $\left(\alpha_{\mathrm{RCR}}\right)$, the atomic charge (Hirshfeld-, NBO- or QTAIM-based) of $C(q(C)$ in au), the minimum value of the electrostatic potential on $\mathrm{C}\left(V^{\mathrm{min}}(\mathrm{C})\right.$ in au), the energy of $\mathrm{HOMO}\left(E_{\mathrm{HOMO}}\right.$ in $\left.\left.\mathrm{eV}\right)\right)$.

\begin{tabular}{ccccccc}
\hline \multirow{2}{*}{ Molecule } & \multirow{2}{*}{$\boldsymbol{\alpha}_{\mathrm{RCR}}$} & \multicolumn{3}{c}{$\boldsymbol{q}(\mathrm{C})$} & \multirow{2}{*}{$\boldsymbol{V}^{\min }(\mathrm{C})$} & \multirow{2}{*}{$\boldsymbol{E}_{\text {HOMO }}$} \\
\cline { 3 - 5 } & & Hirshfeld & NBO & QTAIM & & \\
\hline$\left(\mathrm{NH}_{2}\right)_{2} \mathrm{C}$ & 113.0 & -0.139 & 0.174 & 0.945 & -0.074 & -7.86 \\
imidazol-2-ylidene & 100.7 & -0.188 & 0.104 & 0.787 & -0.077 & -8.22 \\
imidazolidin-2-ylidene & 104.7 & -0.158 & 0.191 & 0.882 & -0.079 & -7.92 \\
tetrahydropyrymid-2-ylidene & 113.9 & -0.163 & 0.170 & 0.886 & -0.081 & -7.41 \\
cyclopropenylidene & 55.8 & -0.200 & -0.108 & 0.040 & -0.072 & -8.74 \\
\hline$\left(\mathrm{PH}_{3}\right)_{2} \mathrm{C}$ & 127.8 & -0.516 & -1.536 & -2.261 & -0.067 & -7.28 \\
$\left(\mathrm{NH}_{3}\right)_{2} \mathrm{C}$ & 100.8 & -0.563 & -0.672 & -0.179 & -0.109 & -4.35 \\
\hline
\end{tabular}

When analyzing the obtained values of the atomic charge on the carbon atom, one can easily notice their great diversity, even in terms of sign. In the case of carbenes, positive QTAIM atomic charges have been obtained. Additionally, this method has given (too) large variation in the negative values on the $\mathrm{C}$ atom in $\left(\mathrm{PH}_{3}\right)_{2} \mathrm{C}$ and $\left(\mathrm{NH}_{3}\right)_{2} \mathrm{C}(-2.261$ and $-0.179 \mathrm{au}$, respectively). Both of these findings strongly suggest that atomic charges of QTAIM are highly unreliable. A similar conclusion applies to the atomic charges of $\mathrm{NBO}$, although the values themselves are not that large. It is worth mentioning that the value of the atomic charge on a carbon atom of -1.43 au in $\left(\mathrm{PPh}_{3}\right)_{2} \mathrm{C}$ was used by Tonner et al. [167] as an argument supporting the bonding scheme of CDPs presented in Figure 1. However, taking into account large dependence of the atomic charge on the method used in calculations, it seems that this argument was perhaps not entirely correct. The more reliable $[175,176]$ Hirshfeld atomic charges are negative in both carbenes and CDPs. Understandably, in the latter case they are much larger, which results from the role of the carbon atom as an acceptor in the $\mathrm{R} \rightarrow \mathrm{C}$ bonds (Figure 1 ).

Further valuable information on the nucleophilic abilities of singlet carbenes and CDPs can be obtained from the values of the minimum electrostatic potential on $C$ (the penultimate column in Table 2) and the distribution of this potential around this atom (see Figure 5).

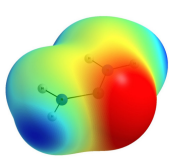

(a)

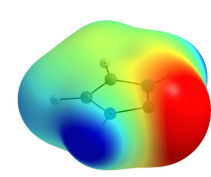

(b)

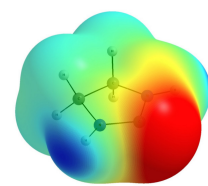

(c)

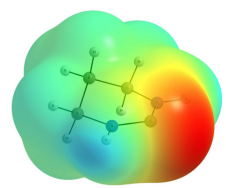

(d)

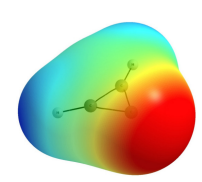

(e)

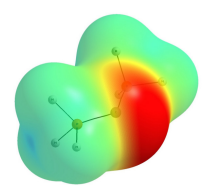

(f)

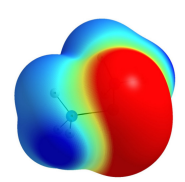

(g)

Figure 5. Maps of electrostatic potential projected on 0.001 au isodensity surfaces of carbenes $\left((\mathbf{a})\left(\mathrm{NH}_{2}\right)_{2} \mathrm{C},(\mathbf{b})\right.$ imidazol-2ylidene, (c) imidazolidin-2-ylidene, (d) tetrahydropyrymid-2-ylidene, (e) cyclopropenylidene) and carbodiphosphoranes $\left((\mathbf{f})\left(\mathrm{PH}_{3}\right)_{2} \mathrm{C},(\mathrm{g})\left(\mathrm{NH}_{3}\right)_{2} \mathrm{C}\right)$. A common value scale (in au) was used: -0.06-red, -0.03-yellow, 0.00—green, 0.03-cyan, 0.06-blue.

The electrostatic potential maps clearly show the negative potential area around the $\mathrm{C}(2)$ atom in the carbenes or the $\mathrm{C}(0)$ atom in the CDPs. On the other hand, strong positive potential concerns mainly hydrogen atoms in strongly polar $\mathrm{N}-\mathrm{H}$ bonds. While the characteristics of the negative potential distribution around the carbon atom are similar in carbenes (which is in line with the rather similar values of $V^{\mathrm{min}}(\mathrm{C})$; Table 2), there is a clear difference between $\left(\mathrm{PH}_{3}\right)_{2} \mathrm{C}$ and $\left(\mathrm{NH}_{3}\right)_{2} \mathrm{C}$. Specifically, in the latter case, this area in much clearer and much more spread around the carbon atom, which better emphasizes the great nucleophilic properties of this molecule. Both of these molecules also differ considerably in the value of $V^{\mathrm{min}}(\mathrm{C})(-0.067$ and $-0.109 \mathrm{au}$, respectively). 
Further information on the reactivity of molecules can be obtained from the Frontier Molecular Orbital theory [186,187], which has found its mathematical support in the Klopman-Salem Equation [188,189]. According to it, the electron-donating properties of the molecule can be characterized by the energy of HOMO. These energies for carbenes and CDPs are shown in the last column of Table 2. By far the least negative value of the HOMO energy obtained for $\left(\mathrm{NH}_{3}\right)_{2} \mathrm{C}(-4.35 \mathrm{eV})$ confirms that this molecule should undoubtedly be the most reactive, willingly acting as a Lewis base. It should be noted, however, that the HOMO energy, like the LUMO energy, which is also often used in the Frontier Molecular Orbital theory, is a global quantity, i.e., resulting from the electronic structure of the entire molecule, and therefore it does not necessarily correctly assess the nucleophilic and electrophilic properties of a molecule, which are most often strongly local. Moreover, these energies do not necessarily correlate well with the parameters characterizing the dimer strength. For example, as shown by Martín-Sómer et al. [24], LUMO energies correlate well with interaction energies (of some beryllium bonds) only when they are computed for acceptor molecules in their dimer geometries. For this reason, LUMO energy values for the fully optimized $\mathrm{MX}_{2}$ molecules were not exposed in Table 2. Moreover, in the case of $\mathrm{MX}_{2}$ molecules, the LUMO energy strongly depends on the X-M-X angle $\left(\alpha_{\mathrm{XMX}}\right)$, decreasing considerably with increasing deviation from the linearity of the molecule. In this way, Martín-Sómer et al. [24] explained the large non-linearity of the $\mathrm{BeH}_{2-n} \mathrm{X}_{n}(\mathrm{X}=\mathrm{F}, \mathrm{Cl}, \mathrm{Br}$; $n \leq 2)$ molecules in their dimers with ammonia. Therefore, it seems that there is nothing to prevent the same cause of $\mathrm{MX}_{2}$ bending also working for other Lewis bases, such as the carbenes and CDPs considered here. It is also worth mentioning that the electron lone pair, which in carbenes is $\mathrm{HOMO}$ (quite strongly delocalized), in the case of CDPs, i.e., $\left(\mathrm{PH}_{3}\right)_{2} \mathrm{C}$ and $\left(\mathrm{NH}_{3}\right)_{2} \mathrm{C}$, becomes $\mathrm{HOMO}-1$, while $\mathrm{HOMO}$ is the electron lone pair perpendicular to the plane of the molecule (Figure 6).

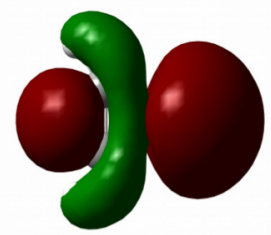

(a) $\mathrm{HOMO}$

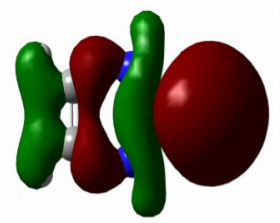

(b) $\mathrm{HOMO}$

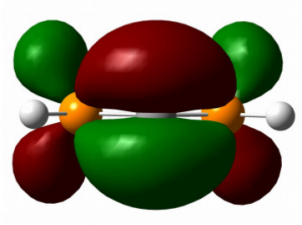

(c) $\mathrm{HOMO}$

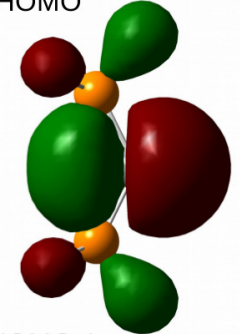

(d) HOMO-1

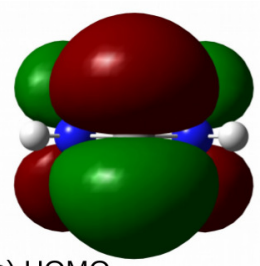

(e) $\mathrm{HOMO}$

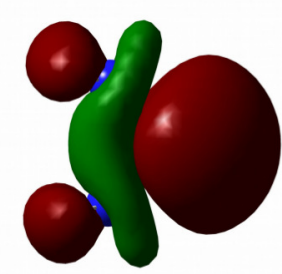

(f) HOMO-1

Figure 6. Molecular orbitals of carbenes and CDPs: (a) HOMO of cyclopropenylidene, (b) HOMO of imidazol-2-ylidene, (c) HOMO of $\left(\mathrm{PH}_{3}\right)_{2} \mathrm{C}$, (d) HOMO-1 of $\left(\mathrm{PH}_{3}\right)_{2} \mathrm{C}$, (e) HOMO of $\left(\mathrm{NH}_{3}\right)_{2} \mathrm{C}$, (f) HOMO-1 of $\left(\mathrm{NH}_{3}\right)_{2} \mathrm{C}$.

\subsubsection{Dimers}

The previous subsection has shown that in $\mathrm{MX}_{2}(\mathrm{M}=\mathrm{Be}, \mathrm{Mg}, \mathrm{Zn} ; \mathrm{X}=\mathrm{H}, \mathrm{F}, \mathrm{Cl}, \mathrm{Br}$, $\mathrm{Me}$ ) molecules, the metal atom is a relatively strong acid center, while the $\mathrm{C}(2)$ atoms in the carbenes and $\mathrm{C}(0)$ in the CDPs are strong basic regions. Moreover, these atoms are the only such regions in these molecules (see Figures 3 and 5). Due to this alignment in electronic properties, it should be expected that the $\mathrm{MX}_{2}$ molecules quite easily form a $\mathrm{M} \cdots \mathrm{C}$ bond to the $\mathrm{C}(2)$ carbon in carbenes or $\mathrm{C}(0)$ in CDPs. If so, it should lead to a particular type of beryllium, magnesium, or zinc (spodium) bond. As mentioned in the Introduction, the main purpose of this article is to describe these interactions. Nevertheless, 
the electrostatic potential distributions for $\mathrm{MX}_{2}$ (Figure 3) and carbenes and CDPs (Figure 5) suggest that other interactions accompanying the leading $\mathrm{M} \cdots \mathrm{C}$ interaction may also be possible. In particular, some symptoms of the presence of a hydrogen bond of the $\mathrm{N}-\mathrm{H} \cdots \mathrm{X}$ type (where $\mathrm{X}$ is a halogen atom, especially $\mathrm{F}$ ) are to be expected. The geometries of the fully optimized dimers are shown in Figure 7. It is convenient to describe the characteristics of the systems containing carbenes and CDPs separately.

- Carbene dimers

The basic parameters characterizing the investigated carbene-containing dimers are shown in Table 3.

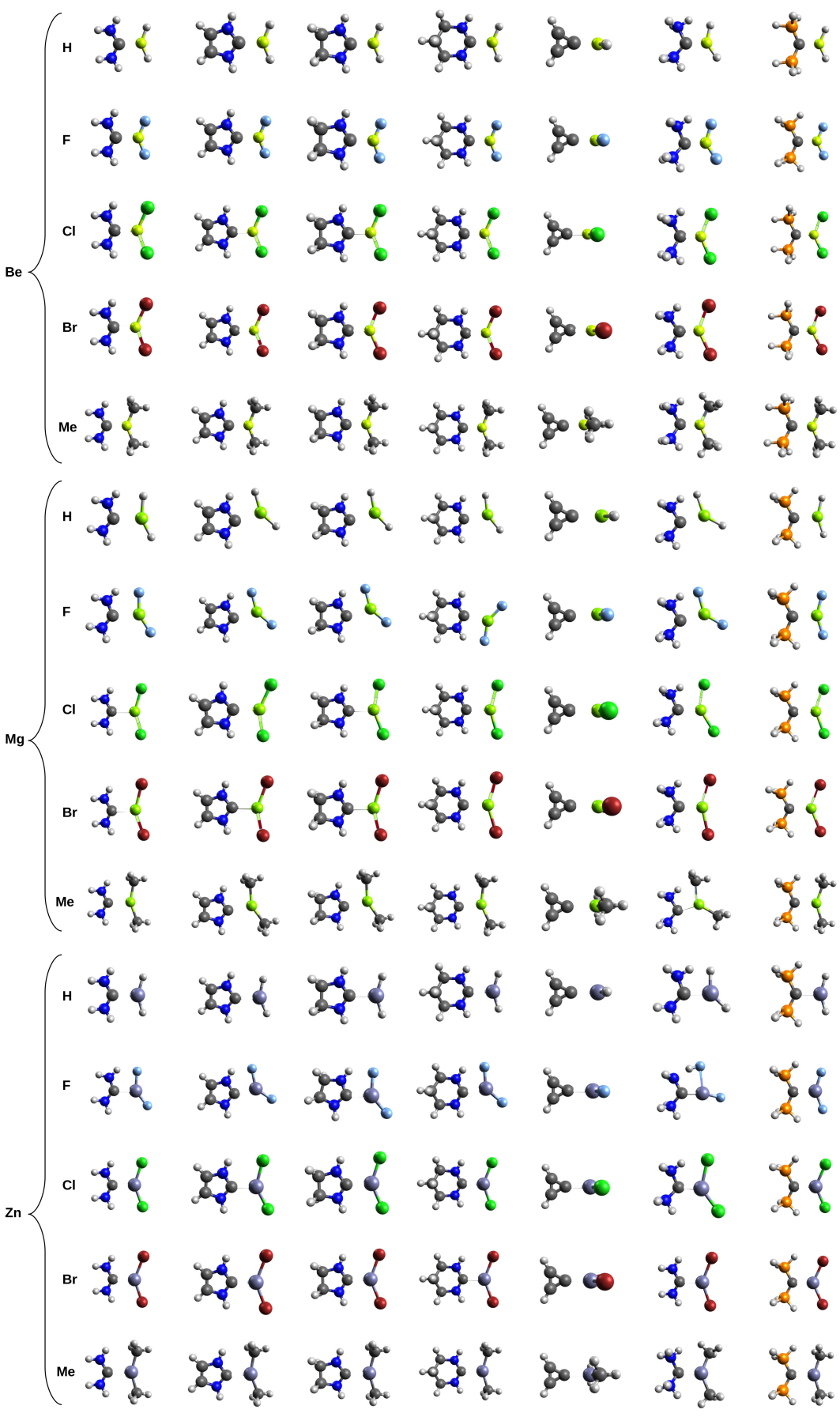

Figure 7. Geometries of the fully optimized dimers. 
Table 3. Some fundamental data characterizing carbene $\cdots M X_{2}$ dimers: $C \cdots M$ distance (in $\AA$ ), changes of MX1 and MX2 bond lengths (in $\AA$ ), XMX, CMX1, CMX2, LCL angles (in degrees), dissociation energy (in kcal/mol), charge transfer (in au).

\begin{tabular}{|c|c|c|c|c|c|c|c|c|c|c|c|c|}
\hline $\mathbf{R}_{2} \mathbf{C}$ & $\mathbf{M X}_{2}$ & $d_{\mathrm{C} \cdots \mathrm{M}}$ & $\Delta d_{\mathrm{MX} 1}$ & $\Delta d_{\mathrm{MX} 2}$ & $\Delta d_{\mathrm{MX}}^{\mathrm{av}}$ & $\alpha_{\mathrm{XMX}}$ & $\alpha_{\mathrm{CMX1}}$ & $\alpha_{\mathrm{CMX} 2}$ & $\alpha_{\mathrm{LCL}}$ & $\Delta \alpha_{\mathrm{LCL}}$ & $D_{0}$ & $\mathrm{CT}_{\mathbf{H}}$ \\
\hline \multirow{15}{*}{ 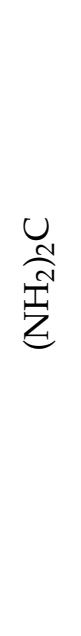 } & $\mathrm{BeH}_{2}$ & 1.820 & 0.048 & 0.048 & 0.048 & 136.4 & 111.8 & 111.8 & 118.9 & 5.9 & 34.7 & -0.381 \\
\hline & $\mathrm{BeF}_{2}$ & 1.819 & 0.060 & 0.060 & 0.060 & 135.8 & 112.1 & 112.1 & 119.6 & 6.6 & 41.0 & -0.415 \\
\hline & $\mathrm{BeCl}_{2}$ & 1.802 & 0.096 & 0.096 & 0.096 & 132.8 & 113.6 & 113.6 & 119.8 & 6.8 & 45.7 & -0.394 \\
\hline & $\mathrm{BeBr}_{2}$ & 1.800 & 0.106 & 0.106 & 0.106 & 132.0 & 114.0 & 114.0 & 119.7 & 6.7 & 47.4 & -0.435 \\
\hline & $\mathrm{BeMe}_{2}$ & 1.851 & 0.063 & 0.063 & 0.063 & 136.1 & 112.0 & 112.0 & 118.4 & 5.3 & 27.2 & -0.381 \\
\hline & $\mathrm{MgH}_{2}$ & 2.268 & 0.064 & 0.033 & 0.049 & 148.5 & 94.2 & 117.3 & 117.7 & 4.6 & 28.2 & -0.268 \\
\hline & $\mathrm{MgF}_{2}$ & 2.217 & 0.062 & 0.028 & 0.045 & 147.9 & 92.2 & 120.0 & 118.2 & 5.2 & 39.8 & -0.296 \\
\hline & $\mathrm{MgCl}_{2}$ & 2.200 & 0.062 & 0.062 & 0.062 & 149.8 & 105.1 & 105.1 & 118.5 & 5.5 & 42.1 & -0.320 \\
\hline & $\mathrm{MgBr}_{2}$ & 2.201 & 0.068 & 0.068 & 0.068 & 148.8 & 105.6 & 105.6 & 118.6 & 5.5 & 42.4 & -0.342 \\
\hline & $\mathrm{MgMe}_{2}$ & 2.278 & 0.044 & 0.034 & 0.039 & 150.9 & 101.1 & 108.0 & 117.4 & 4.3 & 26.5 & -0.301 \\
\hline & $\mathrm{ZnH}_{2}$ & 2.159 & 0.046 & 0.046 & 0.046 & 146.8 & 106.6 & 106.6 & 117.9 & 4.9 & 21.7 & -0.324 \\
\hline & $\mathrm{ZnF}_{2}$ & 2.062 & 0.123 & 0.061 & 0.092 & 137.2 & 94.0 & 128.9 & 119.6 & 6.6 & 41.3 & -0.364 \\
\hline & $\mathrm{ZnCl}_{2}$ & 2.067 & 0.090 & 0.091 & 0.091 & 141.1 & 109.7 & 109.2 & 119.6 & 6.6 & 40.7 & -0.385 \\
\hline & $\mathrm{ZnBr}_{2}$ & 2.068 & 0.095 & 0.095 & 0.095 & 140.5 & 109.8 & 109.8 & 119.8 & 6.7 & 40.5 & -0.408 \\
\hline & $\mathrm{ZnMe}_{2}$ & 2.202 & 0.054 & 0.054 & 0.054 & 150.8 & 104.6 & 104.6 & 117.6 & 4.5 & 17.1 & -0.313 \\
\hline \multirow{15}{*}{ 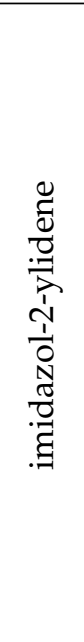 } & $\mathrm{BeH}_{2}$ & 1.793 & 0.048 & 0.048 & 0.048 & 135.3 & 112.4 & 112.4 & 103.5 & 2.7 & 35.4 & -0.402 \\
\hline & $\mathrm{BeF}_{2}$ & 1.804 & 0.061 & 0.061 & 0.061 & 134.9 & 112.5 & 112.5 & 103.8 & 3.1 & 41.1 & -0.434 \\
\hline & $\mathrm{BeCl}_{2}$ & 1.772 & 0.099 & 0.099 & 0.099 & 133.0 & 113.5 & 113.5 & 104.1 & 3.4 & 46.6 & -0.427 \\
\hline & $\mathrm{BeBr}_{2}$ & 1.765 & 0.109 & 0.109 & 0.109 & 132.9 & 113.6 & 113.6 & 104.2 & 3.5 & 48.6 & -0.464 \\
\hline & $\mathrm{BeMe}_{2}$ & 1.823 & 0.064 & 0.064 & 0.064 & 136.4 & 111.8 & 111.8 & 103.4 & 2.6 & 27.8 & -0.401 \\
\hline & $\mathrm{MgH}_{2}$ & 2.246 & 0.073 & 0.030 & 0.051 & 146.3 & 91.7 & 122.0 & 103.0 & 2.2 & 29.2 & -0.270 \\
\hline & $\mathrm{MgF}_{2}$ & 2.195 & 0.071 & 0.026 & 0.048 & 145.0 & 89.8 & 125.3 & 103.4 & 2.7 & 41.5 & -0.292 \\
\hline & $\mathrm{MgCl}_{2}$ & 2.179 & 0.080 & 0.050 & 0.065 & 146.3 & 99.0 & 114.7 & 103.4 & 2.7 & 43.3 & -0.335 \\
\hline & $\mathrm{MgBr}_{2}$ & 2.173 & 0.076 & 0.062 & 0.069 & 147.9 & 102.9 & 109.2 & 103.5 & 2.8 & 43.7 & -0.363 \\
\hline & $\mathrm{MgMe}_{2}$ & 2.263 & 0.054 & 0.028 & 0.041 & 147.2 & 97.1 & 115.7 & 102.8 & 2.0 & 27.2 & -0.302 \\
\hline & $\mathrm{ZnH}_{2}$ & 2.134 & 0.055 & 0.039 & 0.047 & 144.7 & 102.6 & 112.6 & 103.1 & 2.3 & 22.0 & -0.338 \\
\hline & $\mathrm{ZnF}_{2}$ & 2.031 & 0.137 & 0.058 & 0.097 & 134.2 & 91.4 & 134.4 & 104.3 & 3.5 & 42.7 & -0.365 \\
\hline & $\mathrm{ZnCl}_{2}$ & 2.039 & 0.110 & 0.078 & 0.094 & 138.2 & 104.2 & 117.6 & 104.1 & 3.3 & 41.4 & -0.408 \\
\hline & $\mathrm{ZnBr}_{2}$ & 2.037 & 0.097 & 0.097 & 0.097 & 139.2 & 110.4 & 110.4 & 104.2 & 3.4 & 41.2 & -0.432 \\
\hline & $\mathrm{ZnMe}_{2}$ & 2.179 & 0.061 & 0.050 & 0.056 & 149.2 & 101.3 & 109.5 & 102.9 & 2.1 & 17.2 & -0.327 \\
\hline \multirow{15}{*}{ 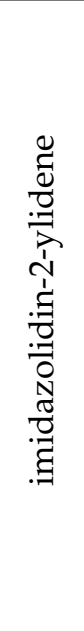 } & $\mathrm{BeH}_{2}$ & 1.815 & 0.048 & 0.048 & 0.048 & 135.1 & 112.5 & 112.5 & 107.9 & 3.2 & 34.5 & -0.396 \\
\hline & $\mathrm{BeF}_{2}$ & 1.818 & 0.059 & 0.059 & 0.059 & 134.6 & 112.7 & 112.7 & 108.2 & 3.6 & 40.7 & -0.428 \\
\hline & $\mathrm{BeCl}_{2}$ & 1.791 & 0.097 & 0.097 & 0.097 & 132.4 & 113.8 & 113.8 & 108.6 & 4.0 & 45.9 & -0.419 \\
\hline & $\mathrm{BeBr}_{2}$ & 1.785 & 0.107 & 0.107 & 0.107 & 132.0 & 114.0 & 114.0 & 108.7 & 4.1 & 47.7 & -0.457 \\
\hline & $\mathrm{BeMe}_{2}$ & 1.844 & 0.062 & 0.062 & 0.062 & 136.2 & 111.9 & 111.9 & 107.7 & 3.0 & 27.2 & -0.396 \\
\hline & $\mathrm{MgH}_{2}$ & 2.263 & 0.065 & 0.033 & 0.049 & 146.3 & 94.2 & 119.5 & 107.3 & 2.7 & 28.5 & -0.280 \\
\hline & $\mathrm{MgF}_{2}$ & 2.208 & 0.063 & 0.028 & 0.045 & 145.5 & 91.8 & 122.7 & 107.8 & 3.2 & 40.4 & -0.306 \\
\hline & $\mathrm{MgCl}_{2}$ & 2.192 & 0.066 & 0.058 & 0.062 & 147.2 & 104.2 & 108.6 & 107.9 & 3.3 & 42.8 & -0.343 \\
\hline & $\mathrm{MgBr}_{2}$ & 2.190 & 0.067 & 0.067 & 0.067 & 146.8 & 106.6 & 106.6 & 108.0 & 3.4 & 43.2 & -0.361 \\
\hline & $\mathrm{MgMe}_{2}$ & 2.279 & 0.048 & 0.030 & 0.039 & 147.8 & 98.9 & 113.3 & 107.1 & 2.4 & 26.7 & -0.307 \\
\hline & $\mathrm{ZnH}_{2}$ & 2.149 & 0.047 & 0.047 & 0.047 & 144.7 & 107.7 & 107.4 & 107.4 & 2.8 & 21.8 & -0.339 \\
\hline & $\mathrm{ZnF}_{2}$ & 2.047 & 0.124 & 0.061 & 0.093 & 135.2 & 93.6 & 131.2 & 108.8 & 4.1 & 41.9 & -0.378 \\
\hline & $\mathrm{ZnCl}_{2}$ & 2.052 & 0.092 & 0.092 & 0.092 & 138.4 & 110.8 & 110.8 & 108.7 & 4.0 & 41.4 & -0.411 \\
\hline & $\mathrm{ZnBr}_{2}$ & 2.052 & 0.096 & 0.096 & 0.096 & 138.2 & 110.9 & 110.9 & 108.7 & 4.1 & 41.1 & -0.428 \\
\hline & $\mathrm{ZnMe}_{2}$ & 2.192 & 0.054 & 0.054 & 0.054 & 149.6 & 105.2 & 105.2 & 107.2 & 2.5 & 17.2 & -0.328 \\
\hline
\end{tabular}


Table 3. Cont.

\begin{tabular}{|c|c|c|c|c|c|c|c|c|c|c|c|c|}
\hline $\mathbf{R}_{\mathbf{2}} \mathrm{C}$ & $\mathrm{MX}_{2}$ & $d_{\mathrm{C} \cdots \mathrm{M}}$ & $\Delta d_{\mathrm{MX} 1}$ & $\Delta d_{\mathrm{MX} 2}$ & $\Delta d_{\mathrm{MX}}^{\mathrm{av}}$ & $\alpha_{\mathrm{XMX}}$ & $\alpha_{\mathrm{CMX} 1}$ & $\alpha_{\mathrm{CMX} 2}$ & $\alpha_{\mathrm{LCL}}$ & $\Delta \alpha_{\mathrm{LCL}}$ & $D_{0}$ & $\mathrm{CT}_{\mathrm{H}}$ \\
\hline \multirow{15}{*}{ 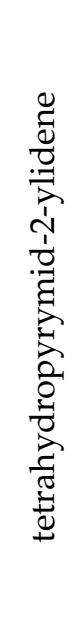 } & $\mathrm{BeH}_{2}$ & 1.806 & 0.052 & 0.052 & 0.052 & 135.5 & 112.2 & 112.2 & 117.9 & 4.0 & 38.9 & -0.392 \\
\hline & $\mathrm{BeF}_{2}$ & 1.809 & 0.063 & 0.063 & 0.063 & 134.7 & 112.7 & 112.7 & 118.4 & 4.5 & 45.3 & -0.427 \\
\hline & $\mathrm{BeCl}_{2}$ & 1.789 & 0.100 & 0.100 & 0.100 & 132.0 & 114.0 & 114.0 & 118.6 & 4.7 & 51.0 & -0.408 \\
\hline & $\mathrm{BeBr}_{2}$ & 1.787 & 0.111 & 0.111 & 0.111 & 131.3 & 114.4 & 114.4 & 118.6 & 4.7 & 52.8 & -0.451 \\
\hline & $\mathrm{BeMe}_{2}$ & 1.837 & 0.066 & 0.066 & 0.066 & 135.2 & 112.4 & 112.4 & 117.6 & 3.7 & 31.2 & -0.393 \\
\hline & $\mathrm{MgH}_{2}$ & 2.250 & 0.069 & 0.036 & 0.053 & 146.8 & 94.6 & 118.6 & 117.2 & 3.3 & 31.9 & -0.279 \\
\hline & $\mathrm{MgF}_{2}$ & 2.202 & 0.064 & 0.030 & 0.047 & 146.3 & 93.0 & 120.7 & 117.6 & 3.7 & 43.8 & -0.311 \\
\hline & $\mathrm{MgCl}_{2}$ & 2.184 & 0.066 & 0.066 & 0.066 & 148.2 & 105.9 & 105.9 & 117.8 & 3.9 & 46.7 & -0.336 \\
\hline & $\mathrm{MgBr}_{2}$ & 2.184 & 0.072 & 0.072 & 0.072 & 147.4 & 106.3 & 106.3 & 117.9 & 4.0 & 47.2 & -0.359 \\
\hline & $\mathrm{MgMe}_{2}$ & 2.258 & 0.048 & 0.037 & 0.042 & 149.2 & 101.8 & 109.0 & 116.9 & 3.0 & 29.9 & -0.314 \\
\hline & $\mathrm{ZnH}_{2}$ & 2.135 & 0.050 & 0.050 & 0.050 & 145.0 & 107.5 & 107.6 & 117.4 & 3.5 & 25.5 & -0.340 \\
\hline & $\mathrm{ZnF}_{2}$ & 2.044 & 0.129 & 0.064 & 0.096 & 134.7 & 94.6 & 130.6 & 118.7 & 4.8 & 46.3 & -0.384 \\
\hline & $\mathrm{ZnCl}_{2}$ & 2.049 & 0.096 & 0.096 & 0.096 & 139.3 & 110.3 & 110.4 & 118.6 & 4.8 & 46.2 & -0.407 \\
\hline & $\mathrm{ZnBr}_{2}$ & 2.050 & 0.100 & 0.100 & 0.100 & 138.9 & 110.5 & 110.5 & 118.7 & 4.8 & 45.9 & -0.428 \\
\hline & $\mathrm{ZnMe}_{2}$ & 2.173 & 0.059 & 0.059 & 0.059 & 148.8 & 105.6 & 105.6 & 117.1 & 3.2 & 20.6 & -0.332 \\
\hline \multirow{15}{*}{ 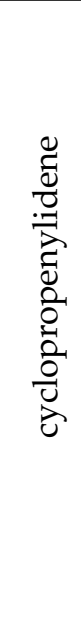 } & $\mathrm{BeH}_{2}$ & 1.743 & 0.039 & 0.039 & 0.039 & 135.1 & 112.4 & 112.4 & 56.6 & 0.8 & 29.1 & -0.317 \\
\hline & $\mathrm{BeF}_{2}$ & 1.833 & 0.050 & 0.050 & 0.050 & 135.9 & 112.0 & 112.0 & 57.2 & 1.4 & 29.4 & -0.386 \\
\hline & $\mathrm{BeCl}_{2}$ & 1.781 & 0.084 & 0.084 & 0.084 & 134.3 & 112.8 & 112.8 & 57.3 & 1.5 & 33.6 & -0.389 \\
\hline & $\mathrm{BeBr}_{2}$ & 1.764 & 0.093 & 0.093 & 0.093 & 134.5 & 112.8 & 112.8 & 57.3 & 1.5 & 35.4 & -0.414 \\
\hline & $\mathrm{BeMe}_{2}$ & 1.784 & 0.061 & 0.061 & 0.061 & 135.2 & 112.4 & 112.4 & 56.7 & 0.9 & 20.2 & -0.329 \\
\hline & $\mathrm{MgH}_{2}$ & 2.268 & 0.035 & 0.035 & 0.035 & 148.3 & 105.9 & 105.9 & 56.7 & 0.9 & 20.9 & -0.273 \\
\hline & $\mathrm{MgF}_{2}$ & 2.222 & 0.031 & 0.031 & 0.031 & 147.9 & 106.1 & 106.1 & 56.9 & 1.2 & 29.3 & -0.325 \\
\hline & $\mathrm{MgCl}_{2}$ & 2.210 & 0.047 & 0.047 & 0.047 & 145.6 & 107.2 & 107.2 & 57.0 & 1.2 & 32.0 & -0.323 \\
\hline & $\mathrm{MgBr}_{2}$ & 2.206 & 0.052 & 0.052 & 0.052 & 145.4 & 107.3 & 107.3 & 57.0 & 1.3 & 32.1 & -0.331 \\
\hline & $\mathrm{MgMe}_{2}$ & 2.288 & 0.030 & 0.030 & 0.030 & 149.1 & 105.4 & 105.4 & 56.6 & 0.8 & 19.4 & -0.275 \\
\hline & $\mathrm{ZnH}_{2}$ & 2.121 & 0.036 & 0.036 & 0.036 & 144.6 & 107.7 & 107.7 & 57.3 & 0.9 & 15.2 & -0.279 \\
\hline & $\mathrm{ZnF}_{2}$ & 2.068 & 0.072 & 0.072 & 0.072 & 138.7 & 110.6 & 110.6 & 57.3 & 1.5 & 28.7 & -0.378 \\
\hline & $\mathrm{ZnCl}_{2}$ & 2.063 & 0.078 & 0.078 & 0.078 & 137.5 & 111.3 & 111.3 & 57.3 & 1.5 & 28.6 & -0.371 \\
\hline & $\mathrm{ZnBr}_{2}$ & 2.061 & 0.083 & 0.083 & 0.083 & 137.1 & 111.5 & 111.5 & 57.3 & 1.5 & 28.2 & -0.380 \\
\hline & $\mathrm{ZnMe}_{2}$ & 2.192 & 0.048 & 0.048 & 0.048 & 149.0 & 105.5 & 105.5 & 56.6 & 0.8 & 10.3 & -0.270 \\
\hline
\end{tabular}

Due to the simple structure of the cyclopropenylidene molecule, dimers containing this carbene will be discussed first. It should be noted that the plane of the slightly bent $\mathrm{MX}_{2}$ molecule is oriented perpendicular to the plane of the cyclopropenylidene ring (Figure 7). For this reason, the interaction between $\mathrm{MX}_{2}$ and cyclopropenylidene is free from any other significant interactions than C $\cdots \mathrm{M}$. Although the earlier analysis of the values of atomic charges and electrostatic potentials on $\mathrm{M}$ and $\mathrm{C}$ suggests that the strongest $\mathrm{C} \cdots \mathrm{M}$ interaction should be present in the case of $\mathrm{MgF}_{2}$ and the weakest in the case of $\mathrm{ZnH}_{2}$, this is not in line with the values of the distance $\mathrm{C} \cdots \mathrm{M}\left(d_{\mathrm{C} \cdots \mathrm{M}}\right)$. Rather, these distances result from the radius of the metal atom, so in the case of beryllium, $d_{\mathrm{C} \cdots \mathrm{M}}$ is less than ca. $1.83 \AA$, while in the case of $\mathrm{Mg}$ and $\mathrm{Zn}$, this distance is over $2 \AA$. The penultimate column in Table 3 shows that cyclopropenylidene $\cdots \mathrm{MX}_{2}$ dimers are strongest $(32-35 \mathrm{kcal} / \mathrm{mol})$ when $\mathrm{M}$ is either Be or $\mathrm{Mg}$ and $\mathrm{X}$ is a halogen, especially $\mathrm{Cl}$ or Br. The lowest dissociation energy $(10.3 \mathrm{kcal} / \mathrm{mol})$ has been obtained in the case of $\mathrm{ZnMe}_{2}$. The weakest $\mathrm{C} \cdots \mathrm{M}$ in the presence of methyl groups has also been obtained in the case of $\mathrm{M}=\mathrm{Be}$ or $\mathrm{Mg}$ and is in line with the weak $+\mathrm{I}$ character of the methyl group. Due to the $\mathrm{C}_{2 V}$ symmetry, the following relations hold: $\Delta d_{\mathrm{MX} 1}=\Delta d_{\mathrm{MX} 2}=\Delta d_{\mathrm{MX}}^{\mathrm{av}}$ and $\alpha_{\mathrm{CMX} 1}=\alpha_{\mathrm{CMX} 2}$. The greatest elongation of the MX bond (0.093 $\AA$ ) occurs in $\mathrm{BeBr}_{2}$. Along with a similar $\mathrm{BeCl}_{2}$, in this molecule, there is also the greatest deviation from linearity ( $\alpha_{\mathrm{XMX}}$ amounts to ca. $\left.134^{\circ}\right)$. Thus, the geometric characteristics of the $\mathrm{MX}_{2}$ molecule itself and the obtained $D_{0}$ values suggest that in the cyclopropenylidene $\cdots \mathrm{MX}_{2}$ dimers, the interaction should be strongest for $\mathrm{BeBr}_{2}$ and $\mathrm{BeCl}_{2}$. It is interesting to see if similar finding also apply to dimers involving the other carbenes. 
As Figure 7 shows, the $\mathrm{MX}_{2}$ molecule lies in the same plane as the backbone atoms of the carbene molecule. This arrangement is also characteristic for dimers involving CDPs, $\left(\mathrm{PH}_{3}\right)_{2} \mathrm{C}$ and $\left(\mathrm{NH}_{3}\right)_{2} \mathrm{C}$. In at least some cases, the planar geometry of the dimer can be explained by additional beneficial interactions (as will be discussed). As was the case with cyclopropenylidene, the intermolecular distance $\mathrm{C} \cdots \mathrm{M}$ is much shorter for beryllium (ca. 1.76-1.85 $\AA$ ) than for either magnesium (ca. 2.17-2.28 $)$ or zinc (2.03-2.20 $)$ ). However, this does not mean stronger $C \cdots M$ interactions. The calculated dissociation energy values clearly show (Table 3) that, as was the case for cyclopropenylidene, the strongest intermolecular $\mathrm{C} \cdots \mathrm{M}$ interaction occurs for $\mathrm{BeBr}_{2}$ and $\mathrm{BeCl}_{2}$. Although the bond strength of the former is ca. $47-48 \mathrm{kcal} / \mathrm{mol}$, it reaches up to $53 \mathrm{kcal} / \mathrm{mol}$ when $\mathrm{BeBr}_{2}$ interacts with tetrahydropyrymid-2-ylidene. On the other hand, similar to cyclopropenylidene, the $\mathrm{C} \cdots \mathrm{M}$ interaction is the weakest (but clearly stronger than that of cyclopropenylidene) when the $\mathrm{MX}_{2}$ molecule is $\mathrm{ZnMe}_{2}$. Consequently, in the dimers considered here, the dissociation energies of $C(2) \cdots M$ have a wide range from 10 to $53 \mathrm{kcal} / \mathrm{mol}$. This result is in full accord with the recent generalization given by Alkorta and Legon that beryllium and magnesium bonds (the current results show also include the zinc bonds) are generally much stronger than hydrogen bonds, halogen bonds, etc. [29].

The LCL angle change $\left(\Delta \alpha_{\mathrm{LCL}}\right)$ values show that the interaction between $\mathrm{MX}_{2}$ and the carbene molecule leads to the opening of the latter molecule, with the effect being the greatest for $\left(\mathrm{NH}_{2}\right)_{2} \mathrm{C}$ (e.g., $\Delta \alpha_{\mathrm{LCL}}=6.8^{\circ}$ for $\left.\left(\mathrm{NH}_{2}\right)_{2} \mathrm{C} \cdots \mathrm{BeCl}_{2}\right)$. This shows that the $\alpha_{\mathrm{NCN}}$ angle in $\left(\mathrm{NH}_{2}\right)_{2} \mathrm{C}$ is more flexible than in cyclic and therefore more rigid imidazol-2-ylidene, imidazolidin-2-ylidene and tetrahydropyrymid-2-ylidene $\left(\Delta \alpha_{C C C}\right.$ in cyclopropenylidene is negligible). Although in general the $\alpha_{\mathrm{NCN}}$ angle-opening effect in the carbene molecule does not seem to be dependent on the strength of the interaction with $\mathrm{MX}_{2}$, such a relationship can be found when comparing systems with similar skeleton stiffness. Therefore, in the group of the aforementioned cyclic carbenes, the strongest effect occurs in tetrahydropyrymid-2-ylidene $\left(4.8^{\circ}\right)$. Excellent linear relationships have been found (see Figure 8 ) between the change of the opening angle $\alpha_{\mathrm{LCL}}$ and the dissociation energy of the carbene $\cdots \mathrm{MX}_{2}$ dimer as long as the carbenes and the $\mathrm{MX}_{2}$ molecules are treated separately. Note that the greater sensitivity of the opening angle in the case of the $\left(\mathrm{NH}_{2}\right)_{2} \mathrm{C}$ carbene is evident here by slightly larger slopes of the corresponding (red) lines. Moreover, the slopes of the linear fits for cyclic carbenes are similar to each other.

A characteristic effect that occurs during an interaction of the initially linear $\mathrm{MX}_{2}$ molecule with a strong Lewis base is its significant bend [23]. For example, MartínSómer et al. have reported XCX angles ( $\left.\alpha_{\mathrm{XMX}}\right)$ of $134^{\circ}-139^{\circ}$, (B3LYP $/ 6-311+\mathrm{G}(3 \mathrm{df}, 2 \mathrm{p})$ ) for dimers of $\mathrm{X}$-substituted $(\mathrm{X}=\mathrm{F}, \mathrm{Cl}, \mathrm{Br}) \mathrm{BeX}_{2}$ derivatives with ammonia [24]. This bending effect is much less $\left(138^{\circ}-149^{\circ},\right)$ in $\mathrm{BeX}_{2}(\mathrm{X}=\mathrm{H}, \mathrm{F}, \mathrm{Cl})$ dimers with ethylene or acetylene, being much weaker Lewis bases interacting via $\pi$ bonds [26]. The high sensitivity of the $\alpha_{\mathrm{XMX}}$ angle makes it particularly interesting to trace its values in the considered dimers. Due to the large number of the studied set of systems and their diversity (different acid centers $\mathrm{M}$, different $\mathrm{X}$ substituents, different carbenes), a fairly wide range of $\alpha_{\mathrm{XMX}}$ variability has been obtained, from 131 to $151^{\circ}$, i.e., as much as $20^{\circ}$. The bending effect is greatest for $\mathrm{BeCl}_{2}$ and $\mathrm{BeBr}_{2}$ and the smallest for $\mathrm{ZnMe}_{2}$. The linear correlation between the XMX angle and the dissociation energy is acceptable for $\mathrm{ZnX}_{2}$ (Figure 9, left) and the dimers of either imidazol-2-ylidene $\left(R^{2}=0.942\right)$ or imidazolidin-2-ylidene $\left(R^{2}=0.922\right)$ with $\mathrm{BeX}_{2}$ (not shown). The fitting line for cyclopropenylidene has slightly different slope than the other four cases, which may result from different (perpendicular) orientation of the interacting molecules (Figure 7). The weak linear correlation for the remaining cases of carbene $\cdots \mathrm{MX}_{2}(\mathrm{M}=\mathrm{Be}, \mathrm{Mg})$ dimers may, at least partly, result from the presence of additional interactions is some of the considered dimers, which should have some influence on the angle XMX. In the case of the dimers involving $\mathrm{ZnX}$, as a consequence of good linear relationships between $\Delta \alpha_{\mathrm{LCL}}$ and $D_{0}$ (Figure 8) and $\alpha_{\mathrm{XZnX}}$ and $D_{0}$ (Figure 9, left), one also observes good linear relationships between $\Delta \alpha_{\mathrm{LCL}}$ and $\alpha_{\mathrm{XZnZ}}$ (Figure 9, right). 

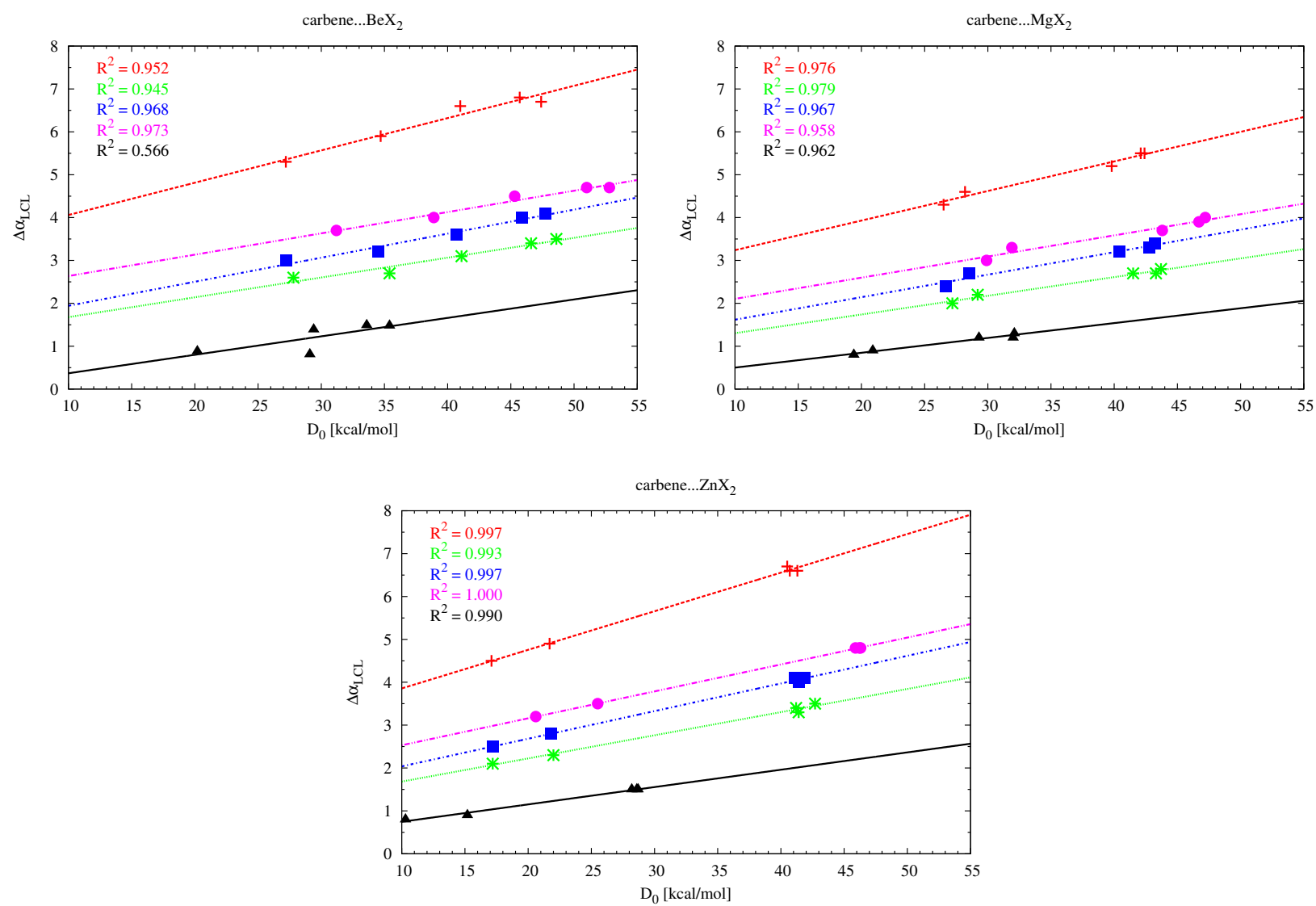

Figure 8. Relationships between the change of the LCL opening angle $\left(\Delta \alpha_{\mathrm{LCL}}\right)$ and the dissociation energy $\left(D_{0}\right)$ of the $\mathrm{L}_{2} \mathrm{C} \cdots \mathrm{MX}_{2}$ dimers, where $\mathrm{L}_{2} \mathrm{C}=\left(\mathrm{NH}_{2}\right)_{2} \mathrm{C}$ (red), imidazol-2-ylidene (green), imidazolidin-2-ylidene (blue), tetrahydropyrymid-2-ylidene (magenta), cyclopropenylidene (black).
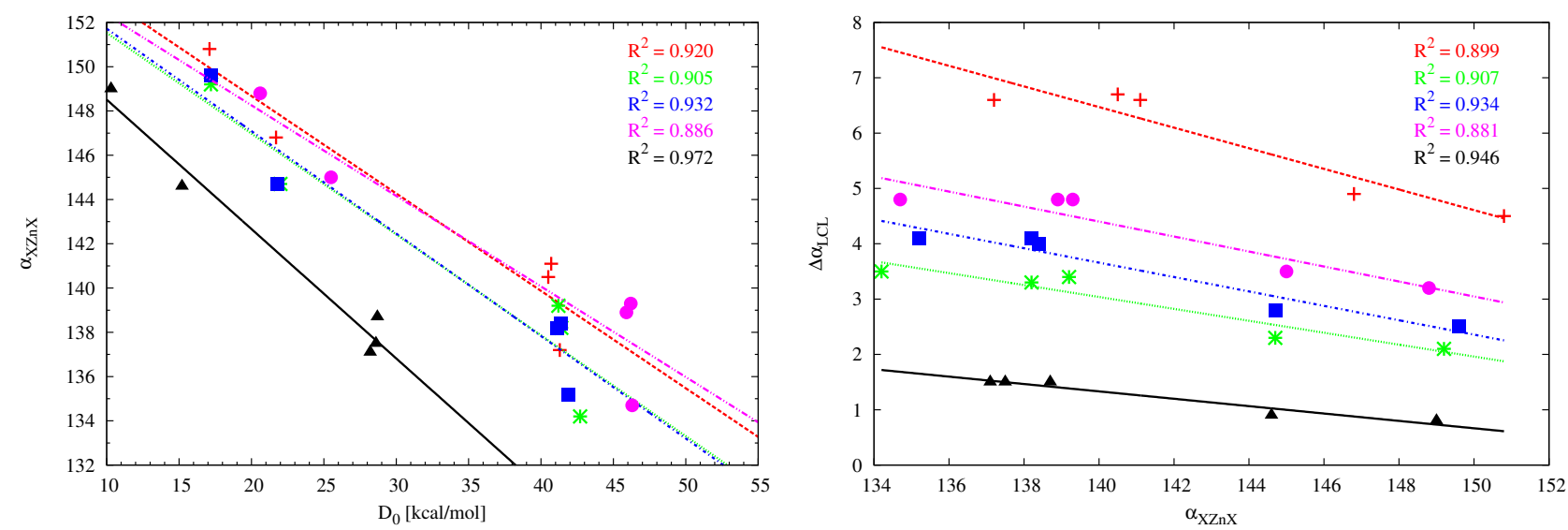

Figure 9. Relationships between either the $X Z n X$ angle $\left(\alpha_{X Z n X}\right)$ and the dissociation energy $\left(D_{0}\right)$ (left) or the change of the LCL angle $\left(\Delta \alpha_{\mathrm{LCL}}\right)$ and $\alpha_{\mathrm{XZnX}}$ (right) for the $\mathrm{L}_{2} \mathrm{C} \cdots \mathrm{ZnX}_{2}$ dimers (where $\mathrm{L}_{2} \mathrm{C}=\left(\mathrm{NH}_{2}\right)_{2} \mathrm{C}$ (red), imidazol-2-ylidene (green), imidazolidin-2-ylidene (blue), tetrahydropyrymid-2-ylidene (magenta), cyclopropenylidene (black)).

Another effect observed during the formation of the carbene $\cdots \mathrm{MX}_{2}$ dimers is a significant elongation of both MX bonds. It should be clearly underlined here that, in general, both MX bond elongations are not necessarily of equal magnitude, so it is not necessarily true that $\Delta d_{\mathrm{MX} 1}=\Delta d_{\mathrm{MX} 2}=\Delta d_{\mathrm{MX}}^{\mathrm{av}}$ (Table 3). These unsymmetrical elongations of $\mathrm{MX}$ result from the presence of certain accompanying interactions in some of the dimers studied here. 
Such cases are also clearly visible from different values of CMX1 and CMX2 angles $\left(\alpha_{\mathrm{CMX} 1}\right.$ and $\alpha_{\mathrm{CMX} 2}$, respectively) in Table 3 . In such cases, the smaller of these angles $\left(\alpha_{\mathrm{CMX} 1}\right)$ takes a value roughly about the right angle.

As already mentioned, any significant additional interactions are impossible in cyclopropenylidene dimers. In this case, the effect of MX bond elongation is therefore symmetrical, which allows for straigtforward analysis of the obtained relationships. The greatest elongation of the $\mathrm{MX}$ bonds is for $\mathrm{X}=\mathrm{Cl}$ or $\mathrm{Br}$, but only when the $\mathrm{M}$ atom is either beryllium or zinc (up to $0.093 \AA$ for $\mathrm{BeBr}_{2}$ ). Hence, the elongation effect is not entirely consistent with the strength of $C \cdots M$ if measured by $D_{0}$. On the contrary, the smallest elongation of the MX bond occurs in $\mathrm{MgMe}_{2}(0.030 \AA)$ and $\mathrm{MgF}_{2}(0.031 \AA)$. Although the relatively small magnitude of the effect in the former case can be explained by a relatively weak interaction (the largest distance C $\cdots M$ amounting to $2.288 \AA$ and the smallest bending of $149.1^{\circ}$ ), $\mathrm{BeH}_{2}$ is also characterized by a small MX bond elongation (0.039 $\AA$ ), and this molecule forms the shortest contact with cyclopropenylidene, amounting to only $1.743 \AA$. For the latter molecule, i.e., $\mathrm{MgF}_{2}$, the small effect of the $\mathrm{MgF}$ bond elongation can most likely be explained by a high polarity of the bond and therefore its considerable resistance to changes. It seems that the magnitude of the MX bond elongation does not clearly depend on $d_{\mathrm{C} \cdots \mathrm{M}}$ or the interaction strength measured by $D_{0}$.

As mentioned earlier, the asymmetry of the MX elongation effects in case of many dimers involving the remaining carbenes makes the analysis much more difficult, but mean value $\left(\Delta d_{\mathrm{MX}}^{\mathrm{av}}\right)$ provides some information. Regardless of carbene, this value for $\mathrm{BeBr}_{2}$ is always greater than $0.106 \AA$ and reaches a maximum value of $0.111 \AA$ for tetrahydropyrymid2-ylidene, thus confirming that presumably the $\mathrm{C} \cdots \mathrm{M}$ interaction is the strongest in the tetrahydropyrymid-2-ylidene $\cdots \mathrm{BeBr}_{2}$ dimer. The occurrence of the minimum values of $\Delta d_{\mathrm{MX}}^{\mathrm{av}}$ appears to be more irregular. Although $\mathrm{BeH}_{2}$ is generally characterized by low values (ca. $0.048 \AA$ ), the lowest values (ca. $0.040 \AA$ ) are nevertheless found for $\mathrm{MgMe}_{2}$ interacting with either imidazol-2-ylidene or imidazolidin-2-ylidene.

The last column in Table 3 shows values of charge transfer calculated by means of the most reliable $[175,176]$ Hirshfeld atomic charges $\left(\mathrm{CT}_{\mathrm{H}}\right)$. First, it should be noted that the obtained values are negative, which means that the formation of the carbene $\cdots \mathrm{MX}_{2}$ dimer leads to an increase in the total charge on the $\mathrm{MX}_{2}$ molecule. Secondly, the obtained values are very large. Suffice it to mention that the corresponding charge transfer values obtained (on the same level of theory) for dimers $\mathrm{HOH} \cdots \mathrm{OH}_{2}$ and $\mathrm{HOH} \cdots \mathrm{NH}_{3}$ are -0.098 and $-0.122 \mathrm{au}$, respectively. Thus, even the weakest charge transfers obtained for the investigated dimers are over two times greater (e.g., -0.270 au for cyclopropenylidene $\cdots \mathrm{ZnMe}_{2}$ ) and even reach almost four times higher values in some dimers with $\mathrm{BeBr}_{2}$ (e.g., $\mathrm{CT}_{\mathrm{H}}$ amounts to ca. - 0.46 au for imidazol-2-ylidene, imidazolidin-2-ylidene, and tetrahydropyrymid-2-ylidene). Undoubtedly, therefore, the carbene $\cdots \mathrm{MX}_{2}(\mathrm{M}=\mathrm{Be}, \mathrm{Mg}, \mathrm{Zn})$ dimers considered here are characterized by a significant charge transfer, which is particularly high in the presence of highly polarizable halogen atoms in $\mathrm{MX}_{2}$, especially $\mathrm{Br}$. This finding is also manifested by very good $\left(R^{2}=0.955\right)$ linear correlation between $\mathrm{CT}_{\mathrm{H}}$ and $\Delta d_{\mathrm{MX}}^{\mathrm{av}}$ when $\mathrm{X}=\mathrm{Br}$ and only slightly worse for $\mathrm{X}=\mathrm{Cl}\left(R^{2}=0.917\right)$, while this correlation is very weak $\left(R^{2}=0.154\right)$ for much less polarizable fluorine (Figure 10). 


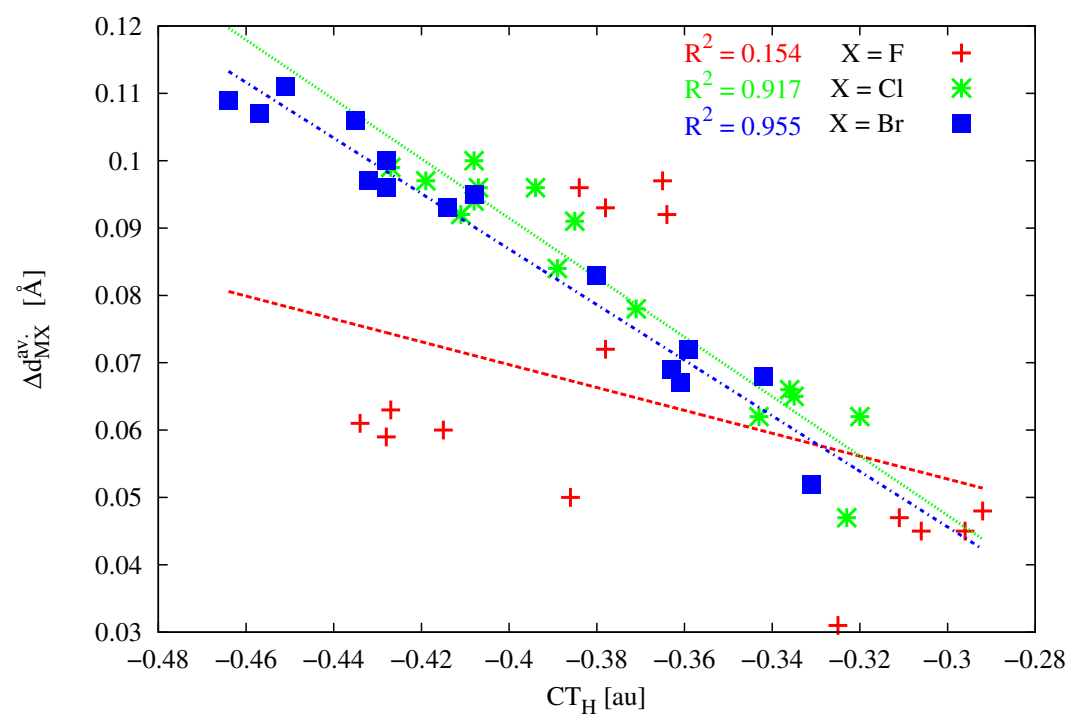

Figure 10. Relationship between charge transfer $\left(\mathrm{CT}_{\mathrm{H}}\right)$ and the averaged elongation of the $\mathrm{MX}$ bond $\left(\Delta d_{\mathrm{MX}}^{\mathrm{ax}}\right)$.

For the cyclopropenylidene $\cdots \mathrm{MX}_{2}$ dimers, there are also very good linear correlations between $\mathrm{CT}_{\mathrm{H}}$ and either $\Delta \alpha_{\mathrm{LCL}}$ or $\mathrm{D}_{0}$ (in the latter relationship, except in the case of $\mathrm{M}=\mathrm{Be}$ ) if only systems with different $\mathrm{M}$ atoms are treated separately (Figure 11).
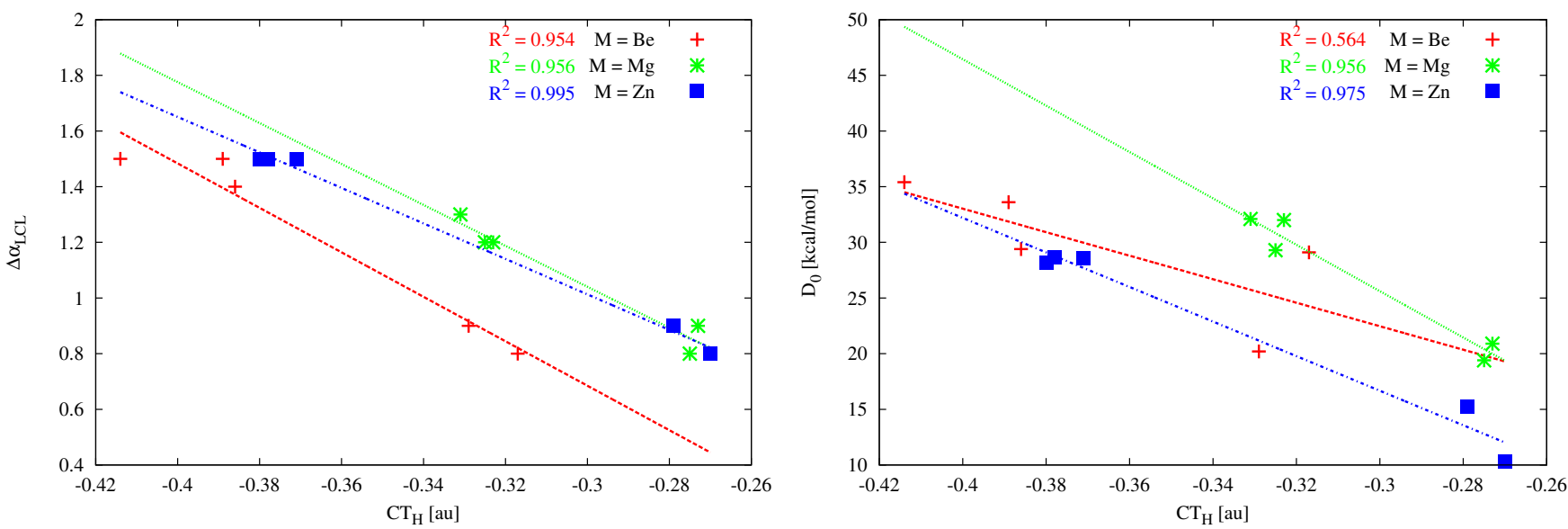

Figure 11. Relationships between charge transfer $\left(\mathrm{CT}_{\mathrm{H}}\right)$ and either the change in the LCL angle $\left(\Delta \alpha_{\mathrm{LCL}}\right)$ or the dissociation energy $\left(D_{0}\right)$ obtained for the cyclopropenylidene $\cdots \mathrm{MX}_{2}(\mathrm{M}=\mathrm{Be}, \mathrm{Mg}, \mathrm{Zn})$ dimers.

Unfortunately, similar relationships are generally much worse for other carbenes, which can be explained by the presence of additional intermolecular interactions in some of them, which to some extent affects the obtained values of the analyzed parameters.

- CDPs dimers

The fundamental data characterizing CDP $\cdots \mathrm{MX}_{2}$ dimers are included in Table 4 . 
Table 4. Some fundamental data characterizing CDP $\cdots M X_{2}$ dimers: $C \cdots M$ distance (in $\AA$ ), changes of MX1 and MX2 bond lengths (in $\AA$ ), XMX, CMX1, CMX2, LCL angles (in degrees), dissociation energy (in kcal/mol), charge transfer (in au).

\begin{tabular}{|c|c|c|c|c|c|c|c|c|c|c|c|c|}
\hline $\mathbf{R}_{\mathbf{2}} \mathbf{C}$ & $\mathrm{MX}_{2}$ & $d_{\mathrm{C} \cdots \mathrm{M}}$ & $\Delta d_{\mathrm{MX} 1}$ & $\Delta d_{\mathrm{MX} 2}$ & $\Delta d_{\mathrm{Mx}}^{\mathrm{av}}$ & $\alpha_{\mathrm{XMX}}$ & $\alpha_{\mathrm{CMX} 1}$ & $\alpha_{\mathrm{CMX} 2}$ & $\alpha_{\mathrm{LCL}}$ & $\Delta \alpha_{\mathrm{LCL}}$ & $D_{0}$ & $\mathrm{CT}_{\mathrm{H}}$ \\
\hline \multirow{15}{*}{$\frac{U_{N}^{U}}{\stackrel{D}{E}}$} & $\mathrm{BeH}_{2}$ & 1.767 & 0.058 & 0.058 & 0.058 & 132.9 & 113.5 & 113.5 & 131.3 & 3.5 & 35.5 & -0.354 \\
\hline & $\mathrm{BeF}_{2}$ & 1.792 & 0.071 & 0.071 & 0.071 & 130.9 & 114.5 & 114.5 & 128.9 & 1.2 & 40.4 & -0.407 \\
\hline & $\mathrm{BeCl}_{2}$ & 1.736 & 0.120 & 0.120 & 0.120 & 129.1 & 115.5 & 115.5 & 126.9 & -0.9 & 47.0 & -0.394 \\
\hline & $\mathrm{BeBr}_{2}$ & 1.727 & 0.133 & 0.133 & 0.133 & 128.3 & 115.9 & 115.9 & 125.4 & -2.4 & 49.3 & -0.455 \\
\hline & $\mathrm{BeMe}_{2}$ & 1.811 & 0.077 & 0.077 & 0.077 & 130.3 & 114.8 & 114.8 & 128.3 & 0.5 & 26.2 & -0.361 \\
\hline & $\mathrm{MgH}_{2}$ & 2.199 & 0.054 & 0.054 & 0.054 & 147.5 & 106.2 & 106.2 & 127.8 & 0.1 & 30.7 & -0.259 \\
\hline & $\mathrm{MgF}_{2}$ & 2.146 & 0.048 & 0.048 & 0.048 & 147.6 & 106.2 & 106.2 & 129.1 & 1.3 & 41.7 & -0.326 \\
\hline & $\mathrm{MgCl}_{2}$ & 2.143 & 0.074 & 0.074 & 0.074 & 139.8 & 110.1 & 110.1 & 124.1 & -3.7 & 45.3 & -0.315 \\
\hline & $\mathrm{MgBr}_{2}$ & 2.142 & 0.082 & 0.082 & 0.082 & 137.9 & 111.0 & 111.0 & 123.1 & -4.7 & 45.7 & -0.354 \\
\hline & $\mathrm{MgMe}_{2}$ & 2.226 & 0.046 & 0.046 & 0.046 & 143.2 & 108.4 & 108.4 & 126.6 & -1.2 & 28.4 & -0.281 \\
\hline & $\mathrm{ZnH}_{2}$ & 2.128 & 0.050 & 0.050 & 0.050 & 146.7 & 106.7 & 106.7 & 127.3 & -0.4 & 22.7 & -0.271 \\
\hline & $\mathrm{ZnF}_{2}$ & 2.026 & 0.094 & 0.094 & 0.094 & 140.1 & 110.0 & 110.0 & 129.8 & 2.0 & 42.7 & -0.384 \\
\hline & $\mathrm{ZnCl}_{2}$ & 2.025 & 0.107 & 0.107 & 0.107 & 133.1 & 113.5 & 113.5 & 125.4 & -2.3 & 43.0 & -0.367 \\
\hline & $\mathrm{ZnBr}_{2}$ & 2.025 & 0.112 & 0.112 & 0.112 & 131.3 & 114.4 & 114.4 & 124.6 & -3.2 & 42.6 & -0.409 \\
\hline & $\mathrm{ZnMe}_{2}$ & 2.182 & 0.060 & 0.060 & 0.060 & 143.9 & 108.1 & 108.1 & 125.0 & -2.7 & 17.0 & -0.265 \\
\hline \multirow{15}{*}{ 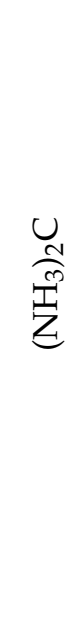 } & $\mathrm{BeH}_{2}$ & 1.655 & 0.118 & 0.060 & 0.089 & 133.2 & 103.1 & 123.8 & 111.6 & 10.8 & 64.0 & -0.527 \\
\hline & $\mathrm{BeF}_{2}$ & 1.718 & 0.118 & 0.074 & 0.096 & 129.9 & 107.5 & 122.3 & 109.5 & 8.7 & 67.0 & -0.520 \\
\hline & $\mathrm{BeCl}_{2}$ & 1.661 & 0.149 & 0.149 & 0.149 & 132.3 & 113.7 & 113.7 & 111.6 & 10.8 & 79.3 & -0.539 \\
\hline & $\mathrm{BeBr}_{2}$ & 1.643 & 0.167 & 0.167 & 0.167 & 132.9 & 113.5 & 113.5 & 112.4 & 11.5 & 83.6 & -0.610 \\
\hline & $\mathrm{BeMe}_{2}$ & 1.695 & 0.097 & 0.097 & 0.097 & 126.9 & 116.5 & 116.5 & 109.5 & 8.7 & 52.5 & -0.524 \\
\hline & $\mathrm{MgH}_{2}$ & 2.076 & 0.172 & 0.041 & 0.106 & 136.8 & 86.6 & 136.6 & 108.1 & 7.3 & 54.6 & -0.329 \\
\hline & $\mathrm{MgF}_{2}$ & 2.064 & 0.133 & 0.039 & 0.086 & 135.4 & 89.3 & 135.4 & 108.3 & 7.5 & 67.6 & -0.388 \\
\hline & $\mathrm{MgCl}_{2}$ & 2.044 & 0.152 & 0.072 & 0.112 & 140.6 & 97.0 & 122.5 & 108.7 & 7.9 & 70.0 & -0.465 \\
\hline & $\mathrm{MgBr}_{2}$ & 2.022 & 0.122 & 0.122 & 0.122 & 152.0 & 104.0 & 104.0 & 110.6 & 9.8 & 71.0 & -0.513 \\
\hline & $\mathrm{MgMe}_{2}$ & 2.086 & 0.154 & 0.037 & 0.096 & 128.8 & 97.3 & 133.9 & 108.0 & 7.2 & 48.6 & -0.377 \\
\hline & $\mathrm{ZnH}_{2}$ & 1.979 & 0.161 & 0.035 & 0.098 & 133.1 & 91.7 & 135.1 & 108.7 & 7.9 & 45.1 & -0.427 \\
\hline & $\mathrm{ZnF}_{2}$ & 1.879 & 0.660 & 0.040 & 0.350 & 109.8 & 82.1 & 167.5 & 110.9 & 10.0 & 78.8 & -0.287 \\
\hline & $\mathrm{ZnCl}_{2}$ & 1.952 & 0.212 & 0.091 & 0.151 & 130.1 & 99.7 & 130.1 & 108.8 & 8.0 & 71.1 & -0.535 \\
\hline & $\mathrm{ZnBr}_{2}$ & 1.962 & 0.142 & 0.142 & 0.142 & 139.8 & 109.8 & 109.8 & 109.2 & 8.4 & 71.3 & -0.569 \\
\hline & $\mathrm{ZnMe}_{2}$ & 2.021 & 0.087 & 0.087 & 0.087 & 136.7 & 111.7 & 111.7 & 107.3 & 6.5 & 36.3 & -0.481 \\
\hline
\end{tabular}

Its penultimate column shows that the $\mathrm{C}(0) \cdots \mathrm{M}$ interactions in the dimers formed by $\left(\mathrm{PH}_{3}\right)_{2} \mathrm{C}$ are comparable in strength to the $\mathrm{C}(2) \cdots \mathrm{M}$ bonds formed by the investigated carbenes, whereas those formed by $\left(\mathrm{NH}_{3}\right)_{2} \mathrm{C}$ are much stronger. Again, the maximum value is found for $\mathrm{BeBr}_{2}$, reaching $84 \mathrm{kcal} / \mathrm{mol}$, a value comparable to the energy of weaker covalent bonds [190]. The other dimers with high values of $D_{0}$ are $\left(\mathrm{NH}_{3}\right)_{2} \mathrm{C} \cdot \mathrm{BeCl}_{2}$ and $\left(\mathrm{NH}_{3}\right)_{2} \mathrm{C} \cdots \mathrm{ZnF}_{2}$ (ca. $\left.79 \mathrm{kcal} / \mathrm{mol}\right)$. It is worth recalling here the theoretical research by Jabłoński and Palusiak [108] on the ability of carbenes and CDPs to form hydrogen bonds. The results of those studies have shown that for the same Lewis acid (e.g., $\mathrm{HCCH}$ ), the hydrogen bond to $\left(\mathrm{NH}_{3}\right)_{2} \mathrm{C}$ is much stronger than to $\left(\mathrm{PH}_{3}\right)_{2} \mathrm{C}$ (the MP2/augcc-pVTZ-based BSSE-corrected interaction energies amount to -9.16 and $-5.31 \mathrm{kcal} / \mathrm{mol}$, respectively, [108]), which further confirms the greater basicity of the former molecule. Although the $\left(\mathrm{NH}_{3}\right)_{2} \mathrm{C} \cdot \mathrm{BeBr}_{2}$ and $\left(\mathrm{NH}_{3}\right)_{2} \mathrm{C} \cdots \mathrm{BeCl}_{2}$ dimers are characterized by short C . . Be distances (1.643 and $1.661 \AA$, respectively), the short C . B Be distance (1.655 $\AA$ ) is also present in the $\left(\mathrm{NH}_{3}\right)_{2} \mathrm{C} \cdot \cdots \mathrm{BeH}_{2}$ dimer with much weaker interaction $(64 \mathrm{kcal} / \mathrm{mol})$.

Very high bond strength of $\mathrm{C}(0) \cdots \mathrm{M}$ in the $\left(\mathrm{NH}_{3}\right)_{2} \mathrm{C} \cdots \mathrm{MX}_{2}$ dimers is in line with high values of charge transfer, which can even reach -0.610 au in the $\left(\mathrm{NH}_{3}\right)_{2} \mathrm{C} \cdots \mathrm{BeBr}_{2}$ dimer. This value is more than six times greater than that of the water dimer and exactly five times greater than that of the water-ammonia dimer. A curiosity is the relatively low $\mathrm{CT}_{\mathrm{H}}$ value $(-0.287 \mathrm{au})$ obtained for the $\left(\mathrm{NH}_{3}\right)_{2} \mathrm{C} \cdots \mathrm{ZnF}_{2}$ dimer with a simultaneous very high dissociation energy $(78.8 \mathrm{kcal} / \mathrm{mol})$. In the next subsection, however, it will be shown 
that this dimer is characterized by a highly advanced proton transfer from $\mathrm{N}$ to $\mathrm{F}$, which results in the formation of the N $\cdots \mathrm{H}-\mathrm{F}$ hydrogen bond. The formation of the H-F bond requires some removal of the electron charge from the fluorine atom.

An interesting result is that, as in the case of carbenes (Table 3), the interaction between $\mathrm{MX}_{2}$ and $\left(\mathrm{NH}_{3}\right)_{2} \mathrm{C}$ causes a significant opening of the $\alpha_{\mathrm{NCN}}$ angle, whereas in the case of $\left(\mathrm{PH}_{3}\right)_{2} \mathrm{C}$, the change in the $\alpha_{\mathrm{PNP}}$ angle is much smaller and may have different sign, most often being negative. This finding clearly differentiates the nitrogen atom from the phosphorus atom.

The comparison of the values of $\Delta d_{\mathrm{MX} 1}$ and $\Delta d_{\mathrm{MX} 2}$ as well as $\alpha_{\mathrm{CMX} 1}$ and $\alpha_{\mathrm{CMX} 2}$ shows a clear difference between the dimers with $\left(\mathrm{PH}_{3}\right)_{2} \mathrm{C}$ and the dimers with $\left(\mathrm{NH}_{3}\right)_{2} \mathrm{C}$. Specifically, the former of them are characterized by the equality of both quantities, which indicates symmetry of these dimers with respect to the axis passing through the $\mathrm{C}$ and $\mathrm{M}$ atoms (see also Figure 7). In the latter case, however, this symmetry is clearly broken in most of the dimers, which results from the presence of other interactions accompanying the leading contact C $\cdots \mathrm{M}$. As a result, the search for linear correlations between the parameters from Table 4 for systems with $\left(\mathrm{NH}_{3}\right)_{2} \mathrm{C}$ is pointless, while the search for such correlations for systems with $\left(\mathrm{PH}_{3}\right)_{2} \mathrm{C}$ seems to be justified. Indeed, some reasonable linear correlations have been found, such as, for example, between $d_{\mathrm{C} \ldots \mathrm{M}}$ and $D_{0}$ (see Figure 12) when the metal atom is either $\mathrm{Mg}\left(R^{2}=0.956\right)$ or especially $\mathrm{Zn}\left(R^{2}=0.989\right)$. On the other hand, when the acidic metal center is beryllium, the linear correlation clearly deteriorates $\left(R^{2}=0.795\right)$. At least in part, this may be due to the much shorter Be-X bond compared to the $\mathrm{Mg}-\mathrm{X}$ or $\mathrm{Zn}-\mathrm{X}$ bonds, and thus stronger, although still rather weak, intermolecular interactions of the type $-\left(\mathrm{PH}_{3}\right) \cdots \mathrm{X}$. Moreover, quite good linear relationships between $\mathrm{CT}_{\mathrm{H}}$ and $d_{\mathrm{C} \cdots \mathrm{M}}\left(R^{2}=0.901\right), \Delta d_{\mathrm{MX}}^{\mathrm{av}}\left(R^{2}=0.911\right)$ or $D_{0}\left(R^{2}=0.930\right)$ have been found for the analyzed $\left(\mathrm{PH}_{3}\right)_{2} \mathrm{C} \cdots \mathrm{ZnX}_{2}$ dimers.

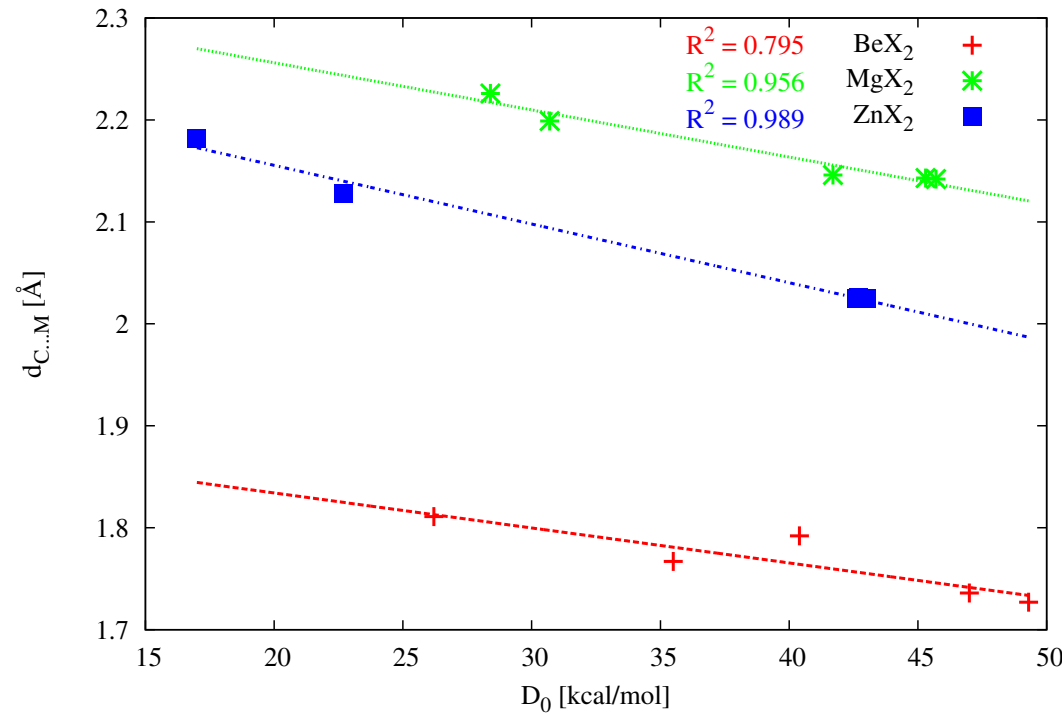

Figure 12. Relationships between $d_{\mathrm{C}} \cdots \mathrm{M}$ and $D_{0}$ obtained for $\left(\mathrm{PH}_{3}\right)_{2} \mathrm{C} \cdots \mathrm{MX}_{2}(\mathrm{X}=\mathrm{Be}, \mathrm{Mg}$, $\mathrm{Zn}$ ) dimers.

\subsection{Other Accompanying Interactions}

As mentioned earlier, some of the obtained structures of the studied dimers suggest presence of an additional intermolecular interaction that accompanies the described beryllium, magnesium, or zinc bonds to the carbene or carbodiphosphorane carbon atom. As these interactions are of various types, it is worth showing some of the more interesting examples obtained. Most of these dimers contain imidazol-2-ylidene or $\left(\mathrm{NH}_{3}\right)_{2} \mathrm{C}$; therefore, the examples shown for the reader's convenience in Figure 13 refer to these molecules. 


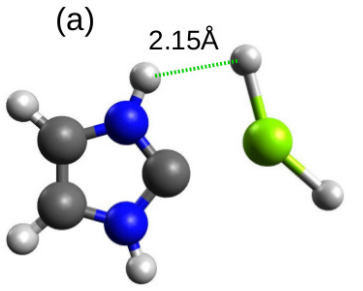

(e)

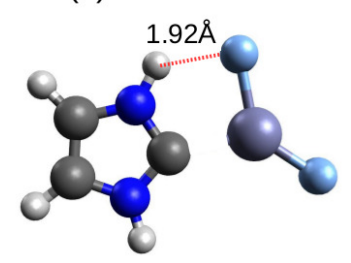

(b)

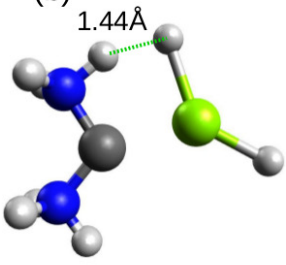

(f) $0.99 \AA$

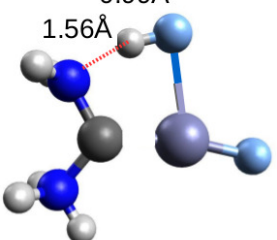

(c)

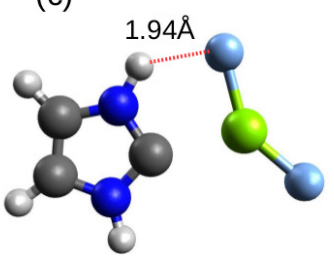

(g)

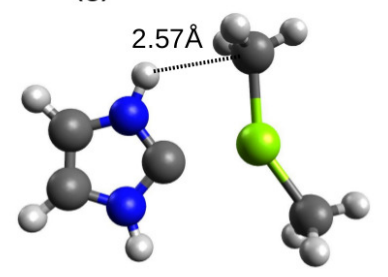

(d)

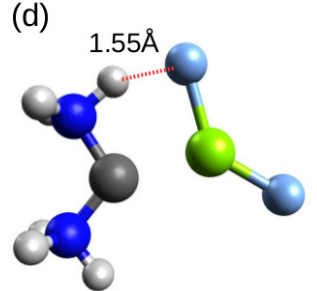

(h)

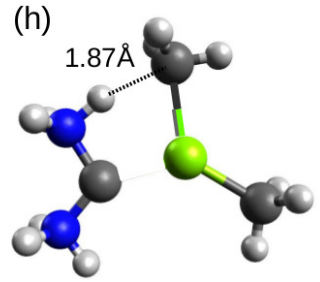

Figure 13. Structures of selected dimers containing certain intermolecular interactions accompanying the $\mathrm{C} \cdots \mathrm{M}$ bond: (a) imidazol-2-ylidene $\cdots \mathrm{MgH}_{2}$, (b) $\left(\mathrm{NH}_{3}\right)_{2} \mathrm{C} \cdots \mathrm{MgH}_{2}$, (c) imidazol-2-ylidene $\cdots \mathrm{MgF}_{2}$, (d) $\left(\mathrm{NH}_{3}\right)_{2} \mathrm{C} \cdots \mathrm{MgF}_{2}$, (e) imidazol2-ylidene $\cdots \mathrm{ZnF}_{2}$, (f) $\left(\mathrm{NH}_{3}\right)_{2} \mathrm{C} \cdots \mathrm{ZnF}_{2}$, (g) imidazol-2-ylidene $\cdots \mathrm{MgMe}_{2}$, (h) $\left(\mathrm{NH}_{3}\right)_{2} \mathrm{C} \cdots \mathrm{MgMe}_{2}$.

The fact that it is imidazol-2-ylidene and $\left(\mathrm{NH}_{3}\right)_{2} \mathrm{C}$ molecules that willingly form different interactions with $\mathrm{MX}_{2}$ than just $\mathrm{C} \cdots \mathrm{M}$ contact could have been expected from the electrostatic potential distribution map shown in Figure 5. From these maps, it is clear that both of these molecules have most acidic regions associated with the highly polar N-H bonds. It is therefore to be expected that these molecules will readily form a dihydrogen or hydrogen bond when the appropriate opportunity arises. Figure 13 shows that this is indeed the case. In cases (a) and (b), in addition to a magnesium bond to the carbon atom, there is also a dihydrogen bond. In the latter case it is very short, because the $\mathrm{H}$. . H distance is only $1.44 \AA$. It should be emphasized that it is not common for the dihydrogen bond between neutral molecules to be so short [191]. Of course, an acidic hydrogen atom from the N-H bond easily forms a hydrogen bond as well, as long as its acceptor is a strongly electronegative atom like fluorine, e.g., in $\mathrm{MgF}_{2}$ (subfigures (c) and (d)). Again, this bond is clearly shorter (1.55 $\AA$ vs. $1.94 \AA$ ) when the N-H donor bond belongs to $\left(\mathrm{NH}_{3}\right)_{2} \mathrm{C}$. In the case of imidazol-2-ylidene $\cdots \mathrm{ZnF}_{2}$ (e), the length of the $\mathrm{N}-\mathrm{H} \cdots \mathrm{F}$ hydrogen bond is $1.92 \AA$, therefore similar to imidazol-2-ylidene $\cdots \mathrm{MgF}_{2}$ (c). However, in $\left(\mathrm{NH}_{3}\right)_{2} \mathrm{C} \cdots \mathrm{ZnF}_{2}(\mathrm{f})$, the interaction between $\mathrm{H}$ and $\mathrm{F}$ is so strong that there is a highly advanced proton transfer to $\mathrm{F}$, so that the distance $\mathrm{H}$. . F becomes much shorter $(0.99 \AA)$ than $\mathrm{N}$. . H $(1.56 \AA)$. Therefore, in this case, it is more logical to speak of a hydrogen bond of the F-H - N N type. On the other hand, the dimers marked in Figure 13 as $(\mathrm{g})$ and $(\mathrm{h})$ are examples of systems with rather non-standard hydrogen bonds of the $\mathrm{N}-\mathrm{H}$. . C C type. In this pair, again, the interaction is much shorter for $\left(\mathrm{NH}_{3}\right)_{2} \mathrm{C}(1.87 \AA)$ than for imidazol-2-ylidene $(2.57 \AA)$. The discussed examples are good illustrations of the coexistence of two formally completely different intermolecular interactions. Obviously, such an occurrence makes it much more difficult to extract the characteristic features for just one of them-in this case, the magnesium or zinc (spodium) bond.

\subsection{QTAIM- and NCI-Based Characteristics}

The characteristics of the studied dimers can be further investigated using the QTAIM [182-184] and NCI [192,193] theoretical methods. In particular, the former one is one of the most frequently used in studies of various intermolecular interactions. On the other hand, the latter of these methods is much less frequently used, and, to my knowledge, has not yet been utilized in the study of beryllium, magnesium, or zinc bonds. 


\subsubsection{QTAIM}

As QTAIM has already been used previously for describing beryllium and magnesium bonds in some simple dimers [23-27], the main focus in this subsection is on the characteristics of the zinc bond and its possible differences from beryllium and magnesium bonds. For this purpose, QTAIM calculations were performed $(\omega \mathrm{B} 97 \mathrm{X}-\mathrm{D} / 6-311++\mathrm{G}(2 \mathrm{df}, 2 \mathrm{pd}))$ for the following representative dimers: cyclopropenylidene $\cdots \mathrm{MX}_{2}(\mathrm{X}=\mathrm{H}, \mathrm{Br})$, imidazol-2ylidene $\cdots \mathrm{MBr}_{2},\left(\mathrm{PH}_{3}\right)_{2} \mathrm{C} \cdots \mathrm{MBr}_{2}$, and $\left(\mathrm{NH}_{3}\right)_{2} \mathrm{C} \cdots \mathrm{MBr}_{2}$, where $\mathrm{M}=\mathrm{Be}, \mathrm{Mg}$, $\mathrm{Zn}$. These dimers were also chosen because they are examples of the dimers in which the previously described accompanying interactions either do not exist or do not have so significant influence on the C $\cdots M$ bond. Values of the most important quantities obtained by means of QTAIM are shown in Table 5.

Table 5. Some fundamental QTAIM-based parameters (in au) characterizing carbene $\cdots \mathrm{MX}_{2}$ and $\mathrm{CDP} \cdots \mathrm{MX} 2$ dimers: the electron density $\left(\rho_{\mathrm{C} \cdots \mathrm{M}}\right)$, its Laplacian $\left(\nabla^{2} \rho_{\mathrm{C} \cdots \mathrm{M}}\right)$ and the total electronic energy density $\left(H_{\mathrm{C} \cdots \mathrm{M}}\right)$ computed at the $\mathrm{C} \cdots \mathrm{M}$ bond critical point, the delocalization index of the $\mathrm{C}$ and $\mathrm{M}$ atomic basins $(\delta(\mathrm{C}, \mathrm{M}))$.

\begin{tabular}{cccrc}
\hline Dimer & $\rho_{\mathbf{C} \cdots \mathbf{M}}$ & $\nabla^{2} \rho_{\mathbf{C} \cdots \mathbf{M}}$ & $H_{\mathbf{C} \cdots \mathbf{M}}$ & $\delta(\mathbf{C}, \mathbf{M})$ \\
\hline cyclopropenylidene $\cdots \mathrm{BeH}_{2}$ & 0.076 & 0.323 & -0.022 & 0.182 \\
cyclopropenylidene $\cdots \mathrm{MgH}_{2}$ & 0.033 & 0.163 & 0.003 & 0.147 \\
cyclopropenylidene $\cdots \mathrm{ZnH}_{2}$ & 0.074 & 0.205 & -0.023 & 0.493 \\
cyclopropenylidene $\cdots \mathrm{BeBr}_{2}$ & 0.076 & 0.288 & -0.025 & 0.165 \\
cyclopropenylidene $\cdots \mathrm{MgBr}_{2}$ & 0.040 & 0.194 & 0.001 & 0.157 \\
cyclopropenylidene $\cdots \mathrm{ZnBr}_{2}$ & 0.085 & 0.236 & -0.028 & 0.519 \\
\hline imidazol-2-ylidene $\cdots \mathrm{BeBr}_{2}$ & 0.082 & 0.272 & -0.031 & 0.175 \\
imidazol-2-ylidene $\cdots \mathrm{MgBr}_{2}$ & 0.046 & 0.218 & 0.000 & 0.177 \\
imidazol-2-ylidene $\cdots \mathrm{ZnBr}_{2}$ & 0.093 & 0.249 & -0.032 & 0.548 \\
\hline$\left(\mathrm{PH}_{3}\right)_{2} \mathrm{C} \cdots \mathrm{BeBr}_{2}$ & 0.085 & 0.259 & -0.036 & 0.207 \\
$\left(\mathrm{PH}_{3}\right)_{2} \mathrm{C} \cdots \mathrm{MgBr}_{2}$ & 0.045 & 0.208 & -0.001 & 0.204 \\
$\left(\mathrm{PH}_{3}\right)_{2} \mathrm{C} \cdots \mathrm{ZnBr}_{2}$ & 0.089 & 0.209 & -0.032 & 0.629 \\
\hline$\left(\mathrm{NH}_{3}\right)_{2} \mathrm{C} \cdots \mathrm{BeBr}_{2}$ & 0.104 & 0.361 & -0.047 & 0.246 \\
$\left(\mathrm{NH}_{3}\right)_{2} \mathrm{C} \cdots \mathrm{MgBr}_{2}$ & 0.059 & 0.309 & -0.003 & 0.253 \\
$\left(\mathrm{NH}_{3}\right)_{2} \mathrm{C} \cdots \mathrm{ZnBr}_{2}$ & 0.110 & 0.276 & -0.041 & 0.732 \\
\hline
\end{tabular}

It is worth noting at the beginning that in terms of the obtained electron density $\left(\rho_{\mathrm{C} \cdots \mathrm{M}}\right)$ values or the total electronic energy density $\left(H_{\mathrm{C} \cdots \mathrm{M}}\right)$ calculated at the critical point of the $\mathrm{C} \cdots \mathrm{M}$ bond, the zinc bond does not differ much from the beryllium bond, whereas the corresponding values determined at the critical point of the magnesium bond are clearly different. For example, for the cyclopropenylidene $\cdots \mathrm{MH}_{2}$ dimer, the following values of $\rho_{\mathrm{C} \cdots \mathrm{M}}$ and $H_{\mathrm{C} \cdots \mathrm{M}}$, respectively, for $\mathrm{M}=\mathrm{Zn}, \mathrm{Be}$, and $\mathrm{Mg}$ have been obtained (in au): $0.074 \approx$ $0.076 \not \approx 0.033$ and $-0.023 \approx-0.022 \not \approx 0.003$. Similarly, the corresponding pairs of triples of values for imidazol-2-ylidene $\cdots \mathrm{MBr}_{2}$ are: $0.093 \approx 0.082 \not 0.046$ and $-0.032 \approx-0.031$ $\not \approx 0.000$ and for $\left(\mathrm{PH}_{3}\right)_{2} \mathrm{C} \cdots \mathrm{MBr}_{2}: 0.089 \approx 0.085 \not \approx 0.045$ and $-0.032 \approx-0.036 \not \approx-0.001$. The similarity in terms of $\rho_{\mathrm{C} \cdots \mathrm{M}}$ and $H_{\mathrm{C} \cdots \mathrm{M}}$ of the zinc bond to the beryllium bond found here is an important result because, unlike the beryllium bonds [23-30], the former are studied only sporadically [91,93].

For various types of interactions, the value of the electron density determined at the bond critical point of a given interaction (bond) is often treated as a measure of the strength of this interaction [182]. If so, then the zinc bonds should have a similar strength to the beryllium bonds (or even they should be slightly stronger than them), whereas the magnesium bonds should be much weaker. Comparison of the corresponding values of $\rho_{\mathrm{C} \cdots \mathrm{M}}$ for the dimers with the same $\mathrm{MBr}_{2}$ molecule suggests that cyclopropenylidene dimers should be the weakest, whereas $\left(\mathrm{NH}_{3}\right)_{2} \mathrm{C}$ dimers should be by far the strongest. The dimers 
with imidazol-2-ylidene or $\left(\mathrm{PH}_{3}\right)_{2} \mathrm{C}$ should have similar strength and intermediate between cyclopropenylidene and $\left(\mathrm{NH}_{3}\right)_{2} \mathrm{C}$. For example, in the case of $\mathrm{ZnBr}_{2}$, the $\rho_{\mathrm{C} \cdots \mathrm{M}}$ values (in $\mathrm{au}$ ) for cyclopropenylidene, $\left(\mathrm{PH}_{3}\right)_{2} \mathrm{C}$, imidazol-2-ylidene, and $\left(\mathrm{NH}_{3}\right)_{2} \mathrm{C}$ are, respectively, $0.085 \lesssim 0.089 \lesssim 0.093 \ll 0.110$. It is interesting to see if there is a good linear correlation between the calculated values of dissociation energies $\left(D_{0}\right)$ and the $\rho_{C \ldots \mathrm{M}}$ values shown in Table 5. The corresponding relationships are shown in Figure 14 (left). They illustrate that, indeed, the relationships between $\rho_{\mathrm{C} \cdots \mathrm{M}}$ and $D_{0}$ are very good $\left(R^{2}>0.975\right)$, as long as the dimers with different $M$ are treated separately.
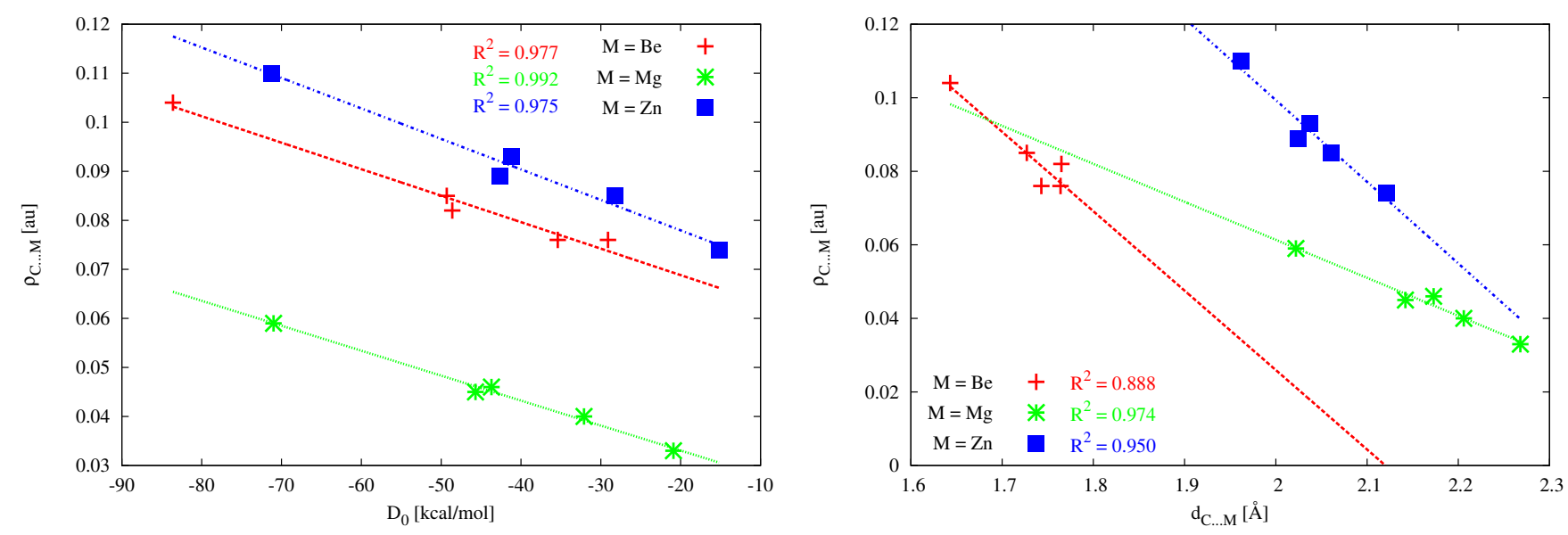

Figure 14. The relationships between the electron density at the bond critical point of the $\mathrm{C} \cdots \mathrm{M}$ interaction $\left(\rho_{\mathrm{C} \cdots \mathrm{M}}\right)$ and either the dimer dissociation energy (left) or the C $\cdots$ M distance (right) determined for the dimers in Table 5.

It should also be interesting to check the quality of the linear relationship between the values of $\rho_{\mathrm{C} \cdots \mathrm{M}}$ and $d_{\mathrm{C} \cdots \mathrm{M}}$. This relationship for the different $\mathrm{M}$ atoms is also shown in Figure 14 (right). For $\mathrm{Mg}$ and $\mathrm{Zn}$, the coefficients of determination are very good (0.974 and 0.950 , respectively), whereas the linear correlation is clearly worse for Be (0.888). This may result from much shorter $\mathrm{C} \cdots \mathrm{M}$ distances, and thus stronger intermolecular interactions. It is worth noting here similar slopes of the fitting lines for Be and $\mathrm{Zn}$, which again supports the previously shown similarity of the beryllium and zinc bonds in the systems considered. On the other hand, the slope of the appropriate linear fit for $\mathrm{Mg}$ is much smaller, thus showing a much weaker relationship between the $\mathrm{C} \cdots \mathrm{M}$ distance and $\rho_{\mathrm{C} \cdots \mathrm{M}}$ in the analyzed group of dimers.

The positive values (Table 5) of the Laplacian of the electron density at the bond critical point of $\mathrm{C} \cdots \mathrm{M}\left(\nabla^{2} \rho_{\mathrm{C} \cdots \mathrm{M}}\right)$ show that this interaction is of closed-shell type [182]. However, all the complexes with $\mathrm{Zn}$ or Be taken into account in Table 5 feature a significantly negative value of the total electronic energy density at the bond critical point of $\mathrm{C} \cdots \mathrm{M}$ (i.e., $H_{\mathrm{C} \cdots \mathrm{M}}$ ), which characterizes interactions with high degree of electron sharing, which in turn reflects a high degree of the C $\cdots$ M bond covalency [194]. On the other hand, the dimers with a magnesium atom feature $H_{\mathrm{C} \cdots \mathrm{M}}$ values close to zero.

A very important QTAIM parameter often used to describe the A-B bond strength [195] is the so-called delocalization index $\delta(\mathrm{A}, \mathrm{B})$, which defines the exchange of the electrons in the basins of atoms A and B [182-184]. Interestingly, particularly high values of $\delta(\mathrm{C}, \mathrm{M})$ characterize the zinc bond, especially in $\left(\mathrm{NH}_{3}\right)_{2} \mathrm{C} \cdots \mathrm{ZnBr}_{2}(0.732 \mathrm{au})$ and $\left(\mathrm{PH}_{3}\right)_{2} \mathrm{C} \cdots \mathrm{ZnBr}_{2}$ $(0.629 \mathrm{au})$, i.e., the systems in which CDP acts as the carbon atom donor. In a clear contrast, the $\delta(\mathrm{C}, \mathrm{M})$ values for the dimers involving magnesium are similar to the $\delta(\mathrm{C}, \mathrm{M})$ values for the dimers containing beryllium and are significantly lower than those for the dimers with zinc. Thus, surprisingly, the zinc bond to a carbene or CDP carbon atom should be much stronger than the corresponding magnesium or beryllium bond, of course, provided that the delocalization index is indeed a good measure of bond strength [195]. It is worth checking at this point whether there are strong linear relationships between the determined 
$\delta(\mathrm{C}, \mathrm{M})$ values and other parameters describing the $\mathrm{C} \cdots \mathrm{M}$ bond strength, such as $D_{0}$, $d_{\mathrm{C} \cdots \mathrm{M}}$ and $\rho_{\mathrm{C} \cdots \mathrm{M}}$. These relationships are shown in Figure 15.
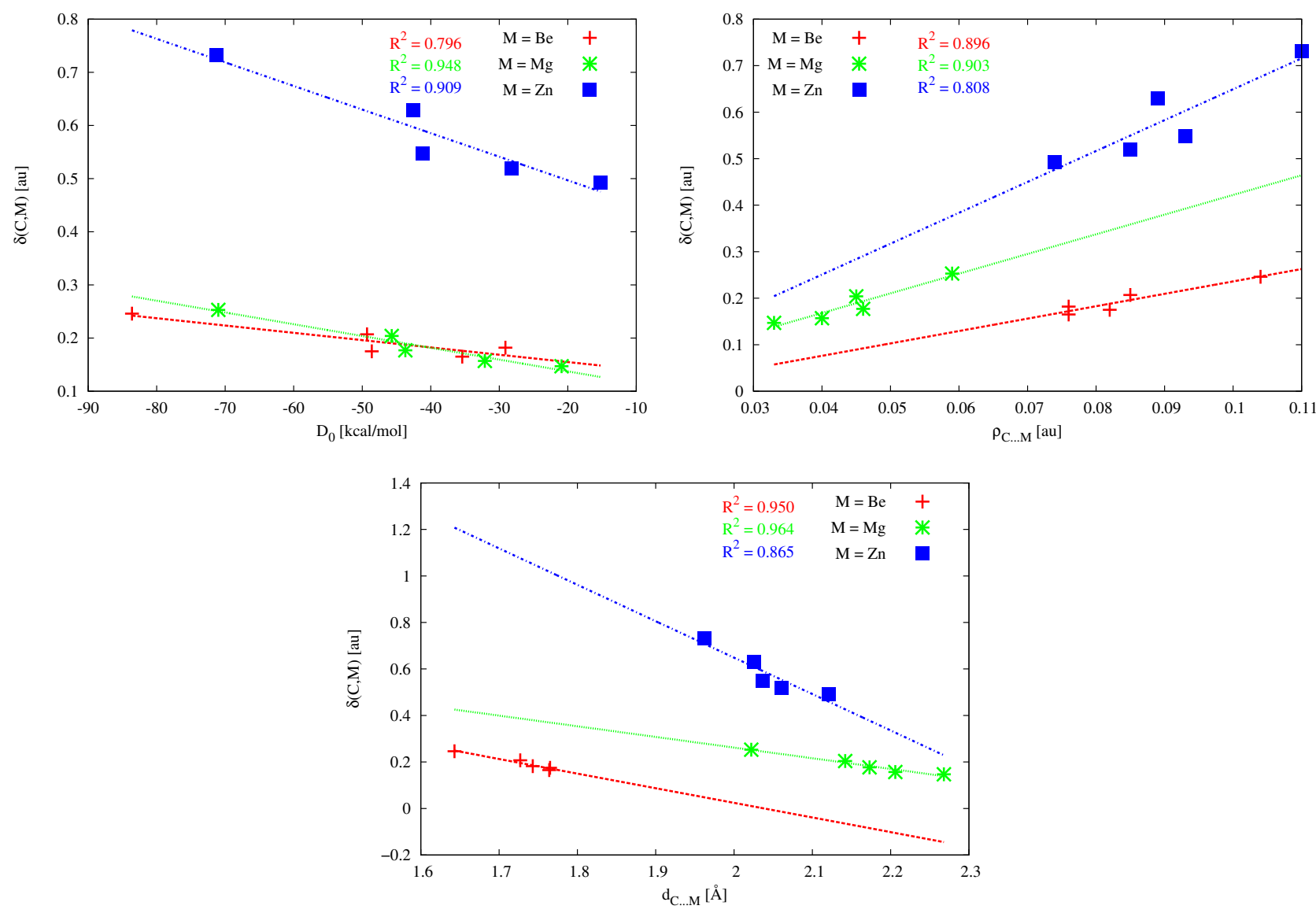

Figure 15. Relationships between the delocalization index of the $C$ and $M$ atomic basins $(\delta(C, M))$ and the dimer dissociation energy $\left(D_{0}\right)$, the electron density at the bond critical point of the $\mathrm{C} \cdots \mathrm{M}$ interaction $\left(\rho_{\mathrm{C} \cdots \mathrm{M}}\right)$, or the $\mathrm{C} \cdots \mathrm{M}$ bond distance $\left(d_{\mathrm{C} \cdots \mathrm{M}}\right)$ determined for the dimers in Table 5.

The quality of the obtained linear correlations clearly depends on both the correlated parameters and the type of the metal atom in the $\mathrm{MX}_{2}$ molecule. In the case of the relationship between $\delta(\mathrm{C}, \mathrm{M})$ and $D_{0}$, the obtained linear correlations are reasonable for $\mathrm{Mg}$ and $\mathrm{Zn}\left(R^{2}\right.$ is 0.948 and 0.909 , respectively), whereas the correlation for Be is rather weak $\left(R^{2}=0.796\right)$. For the relationship between $\delta(\mathrm{C}, \mathrm{M})$ and $\rho_{\mathrm{C} \cdots \mathrm{M}}$, the linear correlations are not great, especially for $\mathrm{Zn}$ ( $R^{2}$ is ca. 0.9 for Be and $\mathrm{Mg}$ and 0.8 for $\mathrm{Zn}$ ). In the case of the relationship $\delta(\mathrm{C}, \mathrm{M})$ vs. $d_{\mathrm{C} \cdots \mathrm{M}}$ the $R^{2}$ values for Be and $\mathrm{Mg}$ are pretty good $(0.950$ and 0.964 , respectively), whereas for $\mathrm{Zn}$, the linear correlation is clearly worse $\left(R^{2} 0.865\right)$. It is worth noting that the obtained fitting lines for $\mathrm{Zn}$ are characterized by greater slopes, which of course results from the greater range of $\delta(\mathrm{C}, \mathrm{M})$ values, from 0.493 au to 0.732 au (Table 5), thus ca. 0.24 au. In the case of Be and $\mathrm{Mg}$, the range is only $0.08-0.10 \mathrm{au}$. This result indicates a greater number of electrons shared between $\mathrm{C}$ and $\mathrm{Zn}$ atomic basins than between $\mathrm{C}$ and either $\mathrm{Mg}$ or Be. Moreover, the amount is more dependent on the type of carbene or CDP.

\subsubsection{NCI}

Most of the QTAIM-based parameters are determined at critical points (e.g., of the C.. M bond), and therefore these parameters are local, i.e., they provide information about the properties at a particular point in space. One way out of this limitation is the NCI method [192,193], which is based on the value of the reduced electron density gradient, 
$s=1 /\left(2\left(3 \pi^{2}\right)^{1 / 3}\right)|\nabla \rho| / \rho^{4 / 3}$. Then, various interactions (especially those corresponding to low-density and low-gradient values) can be isolated by using appropriate cutoffs on the electron density values and its gradient. By means of the electron density gradient isosurfaces, individual interactions (especially non-covalent ones - hence the name of the method) show themselves as certain broad regions of real space rather than simply as a bond critical point between a pair of atoms [192]. In order to further investigate the difference between the zinc bond to the carbene or CDP carbon atom and its beryllium or magnesium counterpart, the electron density gradient isosurfaces were determined for the dimers of cyclopropenylidene, imidazol-2-ylidene, $\left(\mathrm{PH}_{3}\right)_{2} \mathrm{C}$, and $\left(\mathrm{NH}_{3}\right)_{2} \mathrm{C}$ with $\mathrm{MBr}_{2}$, where $\mathrm{M}=\mathrm{Be}, \mathrm{Mg}$ and $\mathrm{Zn}$ (Figure 16).

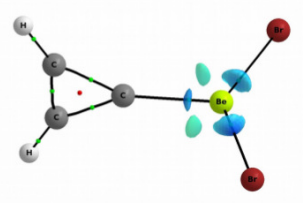

(a1)

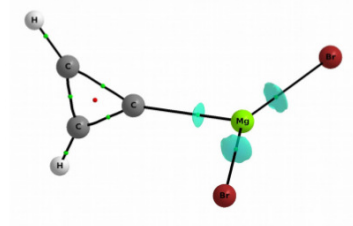

(a2)

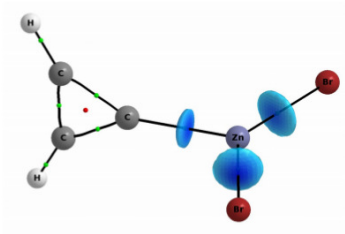

(a3)

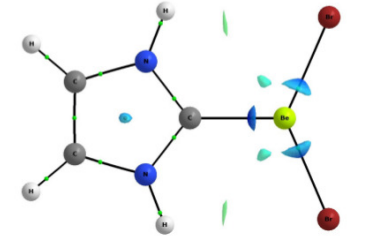

(b1)

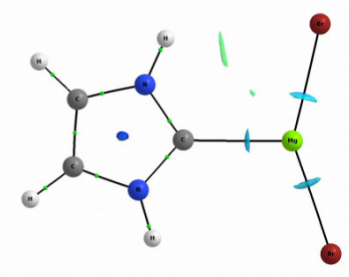

(b2)

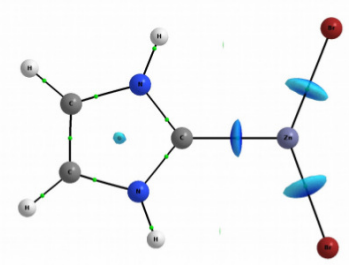

(b3)

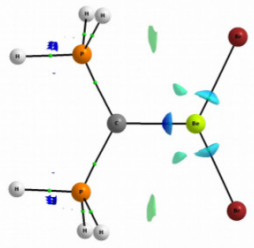

(c1)

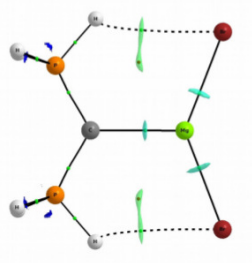

(c2)

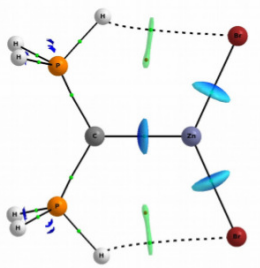

(c3)

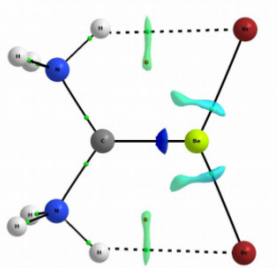

(d1)

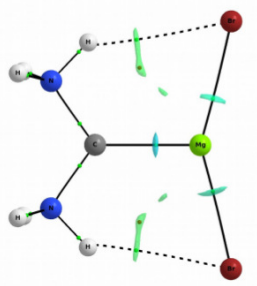

(d2)

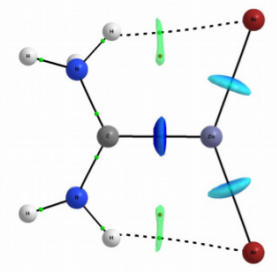

(d3)

Figure 16. Reduced gradient density isosurfaces $(s=0.3 \mathrm{au})$ for dimers involving (a) cyclopropenylidene, (b) imidazol-2ylidene, (c) $\left(\mathrm{PH}_{3}\right)_{2} \mathrm{C}$, (d) $\left(\mathrm{NH}_{3}\right)_{2} \mathrm{C}$ and (1) $\mathrm{BeBr}_{2}$, (2) $\mathrm{MgBr}_{2}$, (3) $\mathrm{ZnBr}_{2}$. Colors are coded according to a common electron density scale (in au): 0.00—green, 0.05—cyan, 0.10—blue. A cutoff of 0.12 au was used for the electron density.

The subfigure (a3) shows that the zinc bond in the cyclopropenylidene $\cdots \mathrm{ZnBr}_{2}$ dimer does not differ significantly from both $\mathrm{Zn}-\mathrm{Br}$ bonds and should be stronger than the beryllium and magnesium bonds in its counterpart dimers with $\operatorname{BeBr}_{2}$ (a1) and $\mathrm{MgBr}_{2}$ (a2), respectively. It is worth noting that in the former of these cases, i.e., in the cyclopropenylidene $\cdots \mathrm{BeBr}_{2}$ dimer, two symmetrically located areas of weak interaction appear in the antibonding regions of the Be-Br bonds. This should lead to some elongation of both Be-Br bonds. The interaction picture in the case of imidazol-2-ylidene (b1-b3) is practically similar. In the case of the systems with $\mathrm{MgBr}_{2}(\mathrm{~b} 2)$ and $\mathrm{BeBr}_{2},(\mathrm{~b} 1)$ one and two regions of very weak $\mathrm{N}-\mathrm{H} \cdots \mathrm{Br}$ hydrogen bonds are visible, respectively, which are not followed by the presence of the respective bond paths. It has been shown that the presence or absence of a bond path generally has little to do with the interaction strength $[30,196,197]$. Furthermore, in the case of complexes with either $\left(\mathrm{PH}_{3}\right)_{2} \mathrm{C}$ or $\left(\mathrm{NH}_{3}\right)_{2} \mathrm{C}$, representing the group of carbodiphosphoranes, the characteristics of changes in the areas of weak interactions caused by the change of the $\mathrm{Zn}$ atom to $\mathrm{Mg}$ or Be are similar. Specificially, in the case of the presence of the $\mathrm{ZnBr}_{2}$ molecule (c3 and $\mathrm{d} 3$ ), the area for the $\mathrm{C} \cdots \mathrm{Zn}$ bond is 
similar to the area for both $\mathrm{Zn}-\mathrm{Br}$ bonds, although it is distinguished by higher electron density values, especially in $\left(\mathrm{NH}_{3}\right)_{2} \mathrm{C}$. In the $\left(\mathrm{PH}_{3}\right)_{2} \mathrm{C} \cdots \mathrm{BeBr}_{2}(\mathrm{c} 1)$ and $\left(\mathrm{NH}_{3}\right)_{2} \mathrm{C} \cdots \mathrm{MgBr}_{2}$ (d2) dimers, small areas of weaker interaction develop in the antibonding zones of the metal atom and in the $\left(\mathrm{NH}_{3}\right)_{2} \mathrm{C} \cdots \mathrm{BeBr}_{2}(\mathrm{~d} 1)$ dimer, these regions merge with the regions that characterize $\mathrm{Be}-\mathrm{Br}$ bonds. These interactions, however, are clearly weaker than $\mathrm{C} \cdots \mathrm{M}$, especially when the metal atom is Be. It can also be seen that in all the CDP-mediated dimers, there are two symmetrical $\mathrm{P} / \mathrm{N}-\mathrm{H} \cdots \mathrm{Br}$ hydrogen bonding regions, which are or are not (case c1) followed by bond paths. However, they should be much weaker than the C... Zn and C... Be bonds.

Summing up, it can be concluded that the analysis based on the NCI method shows that the zinc bond is the strongest, and although the beryllium bond should only be slightly weaker than it, the latter is related to the presence of additional areas of weaker interaction in the antibonding regions of the Be atom. The high strength of the $\mathrm{C} \cdots \mathrm{Zn}$ bond (competing even with the $\mathrm{Zn}-\mathrm{Br}$ bond) is reflected in high values of $\rho_{\mathrm{C} \cdots \mathrm{M}}$ and $\delta(\mathrm{C}, \mathrm{M})$, but also in negative values of $H_{\mathrm{C} \cdots \mathrm{M}}$.

\section{Theoretical Methods}

Geometries of monomers and dimers were fully optimized on the $\omega \mathrm{B} 97 \mathrm{X}-\mathrm{D} / 6-$ $311++\mathrm{G}(2 \mathrm{df}, 2 \mathrm{p})$ level of theory, that is utilizing the $\omega \mathrm{B} 97 \mathrm{X}-\mathrm{D}$ exchange-correlation functional [198] of Density Functional Theory (DFT) [199-201] and the 6-311++G(2df,2p) basis set [202-206], which includes both polarization and diffuse functions. By testing 200 different exchange-correlation functionals, the $\omega$ B97X-D functional has recently been shown [207] to be one of the best for general purposes. To increase the accuracy of the optimization procedure and numerical integration, cutoffs on forces and step size that are used to determine convergence were additionally tightened $(0.000015$ and 0.000010 for maximum force and its root mean square, respectively, and 0.000060 and 0.000040 for maximum displacement and its root mean square, respectively) and integration grid was increased to the $(99,590)$ one (UltraFine) having 99 radial shells and 590 angular points per shell. All the obtained systems were subjected to vibration analysis in order to check whether they correspond to the real minima on the potential energy hypersurface. There were no imaginary frequencies. Both geometry optimization and vibration analysis were performed by means of Gaussian 09 [208]. NBO-based [180,181] atomic charges were computed by means of NBO6.0 program [209] implemented in Gaussian 09. Calculations based on the QTAIM [182-184] and NCI [192] methods were made with the AIMAll program [210].

\section{Conclusions}

To date, the vast majority of theoretical studies on beryllium and magnesium bonds have used as Lewis bases small molecules, and the research on zinc (spodium) bonds is very rare. On the other hand, the research on carbenes and carbodiphosphoranes is mostly experimental. This article presents the results of theoretical research on the properties of beryllium, magnesium, and zinc bonds in a large group of dimers formed by the $\mathrm{MX}_{2}$ molecule (where $\mathrm{M}=\mathrm{Be}, \mathrm{Mg}, \mathrm{Zn}$ and $\mathrm{X}=\mathrm{H}, \mathrm{F}, \mathrm{Cl}, \mathrm{Br}, \mathrm{Me}$ ) and either carbene $\left(\left(\mathrm{NH}_{2}\right)_{2} \mathrm{C}\right.$, imidazol-2-ylidene, imidazolidin-2-ylidene, tetrahydropyrymid-2-ylidene, cyclopropenylidene) or carbodiphosphorane $\left(\left(\mathrm{PH}_{3}\right)_{2} \mathrm{C},\left(\mathrm{NH}_{3}\right)_{2} \mathrm{C}\right)$. Due to the rarity of theoretical studies of zinc bonds, the main focus in this article is placed on comparing them with both the beryllium bond and the magnesium bond.

The general characteristics of the presented dimers showed that the dissociation energies of the $C(2) \cdots M$ intermolecular interaction have wide range, from 10 to $53 \mathrm{kcal} / \mathrm{mol}$, and this interaction is the strongest for the $\mathrm{BeBr}_{2}$ and $\mathrm{BeCl}_{2}$ Lewis acids. Although the $\mathrm{C}(0) \cdots \mathrm{M}$ bonds formed by $\left(\mathrm{PH}_{3}\right)_{2} \mathrm{C}$ are similar in strength to the $\mathrm{C}(2) \cdots \mathrm{M}$ bonds formed by carbenes, $\left(\mathrm{NH}_{3}\right)_{2} \mathrm{C}$ forms much stronger complexes, with a bond strength of up to $84 \mathrm{kcal} / \mathrm{mol}$ for the dimer with $\mathrm{BeBr}_{2}$. The interaction between $\mathrm{MX}_{2}$ and either carbene or carbodiphosphorane leads to a significant bend of the $\mathrm{MX}_{2}$ molecule, elongation of the $\mathrm{MX}$ bonds, and opening of the LCL angle (with a few exceptions). 
Importantly, it has been shown that the investigated systems are characterized by very high charge transfer effect from the carbene or carbodiphosphorane molecule to the $\mathrm{MX}_{2}$ one. Even the weakest effect is more than twice as high as in the water dimer, while it is more than six times as strong in the $\left(\mathrm{NH}_{3}\right)_{2} \mathrm{C} \cdots \mathrm{BeBr}_{2}$ dimer.

Theoretical studies based on the QTAIM and NCI methods have shown that the zinc bond is not very different from the beryllium bond; both should be of similar strength, while the magnesium bond should be weaker. Both are also characterized by a high degree of covalence. The determined values of the delocalization index show, however, that the zinc bond should be definitely stronger than the beryllium and magnesium bonds.

A large number of tested dimers as well as parameters characterizing both the interacting subsystems and the $\mathrm{C} \cdots \mathrm{M}$ bond itself allowed for the study of many linear relationships between the parameters. In general, they are good as long as systems with different $\mathrm{M}$ metal atoms are treated separately. The linear correlations for the zinc atom are usually slightly better than for the other atoms.

In addition to the dominant $\mathrm{C} \cdots \mathrm{M}$ interaction, some of the studied dimers also have various additional interactions, such as, e.g., the $\mathrm{N}-\mathrm{H} \cdots \mathrm{F}, \mathrm{N}-\mathrm{H} \cdots \mathrm{C}$ and $\mathrm{F}-\mathrm{H} \cdots \mathrm{N}$ hydrogen bonds, or $\mathrm{N}-\mathrm{H} \cdots \mathrm{H}-\mathrm{Mg}$ dihydrogen bond. In the latter case, it may be extremely short, such as $1.44 \AA$ in $\left(\mathrm{NH}_{3}\right)_{2} \mathrm{C} \cdots \mathrm{MgH}_{2}$. These interactions, however, are much weaker than the beryllium, magnesium, and zinc bonds that are the main topic of the research.

A side result of the presented research is that the atomic charges obtained by the QTAIM method are highly unreliable. While more reliable than these, the NBO-based atomic charges also appear to be questionable. In contrast, the Hirshfeld atomic charges appear to be chemically sound.

Funding: This research received no external funding.

Conflicts of Interest: The authors declare no conflict of interest.

Sample Availability: Optimized geometries of all considered systems are available from the author on request.
Abbreviations
The following abbreviations are used in this manuscript:
CDPs Carbodiphosphoranes
MESP Molecular electrostatic potential
NBO Natural Bond Orbital
QTAIM Quantum Theory of Atoms in Molecules
NCI Noncovalent Interactions (method)

\section{References}

1. Alkorta, I.; Elguero, J.; Frontera, A. Not Only Hydrogen Bonds: Other Noncovalent Interactions. Crystals 2020, 10, 180. [CrossRef]

2. Pauling, L. The Nature of the Chemical Bond; Cornell University Press: New York, NY, USA, 1960.

3. Pimentel, G.C.; McClellan, A.L. The Hydrogen Bond; W.H. Freeman \& Co.: San Francisco, CA, USA, 1960.

4. Hamilton, W.C.; Ibers, J.A. Hydrogen Bonding in Solids; W. A. Benjamin: New York, NY, USA, 1968.

5. Vinogradov, S.N.; Linnell, R.H. Hydrogen Bonding; Van Nostrand-Reinhold: Princeton, NJ, USA, 1971.

6. Schuster, P.; Zundel, G.; Sandorfy, C. (Eds.) The Hydrogen Bond. Recent Developments in Theory and Experiments; North Holland: Amsterdam, The Netherlands, 1976; Volume I-III.

7. Schuster, P. Intermolecular Interactions: From Diatomics to Biopolymers; Pullman, B., Ed.; J. Wiley: New York, NY, USA, 1978.

8. Jeffrey, G.A.; Saenger, W. Hydrogen Bonding in Biological Structures; Springer: Berlin, Germany, 1991.

9. Hadži, D. (Ed.) Theoretical Treatments of Hydrogen Bonding; J. Wiley: Chichester, UK, 1997.

10. Jeffrey, G.A. An Introduction to Hydrogen Bonding; Oxford University Press: New York, NY, USA, 1997.

11. Scheiner, S. (Ed.) Molecular Interactions. From van der Waals to Strongly Bound Complexes; Wiley: Chichester, UK, 1997.

12. Scheiner, S. Hydrogen Bonding: A Theoretical Perspective; Oxford University Press: New York, NY, USA, 1997.

13. Desiraju, G.R.; Steiner, T. The Weak Hydrogen Bond in Structural Chemistry and Biology; Oxford University Press: New York, NY, USA, 1999.

14. Grabowski, S.J. (Ed.) Hydrogen Bonding—New Insights; Springer: Dordrecht, The Netherlands, 2006.

15. Maréchal, Y. The Hydrogen Bond and the Water Molecule; Elsevier: Amsterdam, The Netherlands, 2007. 
16. Gilli, G.; Gilli, P. The Nature of the Hydrogen Bond. Outline of a Comprehensive Hydrogen Bond Theory; Oxford University Press: Oxford, UK, 2009.

17. Kollman, P.A.; Liebman, J.F.; Allen, L.C. The lithium bond. J. Am. Chem. Soc. 1970, 92, 1142-1150. [CrossRef]

18. Del Bene, J.E.; Alkorta, I.; Elguero, J. Characterizing Complexes with F-Li $\cdots \mathrm{N}, \mathrm{H}-\mathrm{Li} \cdots \mathrm{N}$, and CH $\mathrm{CH}_{3} \mathrm{Li} \cdots \mathrm{N}$ Lithium Bonds: Structures, Binding Energies, and Spin-Spin Coupling Constants. J. Phys. Chem. A 2009, 113, 10327-10334. [CrossRef]

19. Li, Q.; Hu, T.; An, X.; Li, W.; Cheng, J.; Gong, B.; Sun, J. Theoretical Study of the Interplay between Lithium Bond and Hydrogen Bond in Complexes Involved with HLi and HCN. ChemPhysChem 2009, 10, 3310-3315. [CrossRef]

20. Ford, T.A. An Ab Initio Study Prop. Some Lithium-Bond. Complexes - Comp. Their Hydrog.-Bond. Analogues. J. Mol. Struct. 2013, 1044, 46-54. [CrossRef]

21. Esrafili, M.D.; Mohammadirad, N. Halogen bond interactions enhanced by sodium bonds-Theoretical evidence for cooperative and substitution effects in NCX $\cdots$ NCNa $\cdots$ NCY complexes (X = F, Cl, Br, I; Y = H, F, OH). Can. J. Chem. 2014, 92, 653-658. [CrossRef]

22. Solimannejad, M.; Rabbani, M.; Ahmadi, A.; Esrafili, M.D. Cooperative and diminutive interplay between the sodium bonding with hydrogen and dihydrogen bondings in ternary complexes of $\mathrm{NaC}_{3} \mathrm{~N}$ with $\mathrm{HMgH}$ and $\mathrm{HCN}$ (HNC). Mol. Phys. 2014, 112, 2017-2022. [CrossRef]

23. Yáñez, M.; Sanz, P.; Mó, O.; Alkorta, I.; Elguero, J. Beryllium Bonds, Do They Exists? J. Chem. Theory Comput. 2009, 5, $2763-2771$. [CrossRef]

24. Martín-Sómer, A.; Lamsabhi, A.M.; Mó, O.; Yáñez, M. The importance of deformation on the strength of beryllium bonds. Comput. Theor. Chem. 2012, 998, 74-79. [CrossRef]

25. Eskandari, K. Characteristics of beryllium bonds: A QTAIM study. J. Mol. Model 2012, 18, 3481-3487. [CrossRef]

26. Villanueva, E.F.; Mó, O.; Manuel Yáñez, M. On the existence and characteristics of $\pi$-beryllium bonds. Phys. Chem. Chem. Phys. 2014, 16, 17531-17536. [CrossRef]

27. Eskandari, K. Nature of beryllium bonds in view of interacting quantum atoms and natural energy decomposition analysis. Comput. Theor. Chem. 2016, 1090, 74-79. [CrossRef]

28. Montero-Campillo, M.M.; Mó, O.; Yáñez, M.; Alkorta, I.; Elguero, J. The beryllium bond. Adv. Inorg. Chem. 2019, 73, 73-121.

29. Alkorta, I.; Legon, A.C. Non-Covalent Interactions Involving Alkaline-Earth Atoms and Lewis Bases B: An ab Initio Investigation of Beryllium and Magnesium Bonds, $\mathrm{B} \cdots \mathrm{MR}_{2}\left(\mathrm{M}=\mathrm{Be}\right.$ or $\mathrm{Mg}$, and $\mathrm{R}=\mathrm{H}$, F or $\left.\mathrm{CH}_{3}\right)$. Inorganics 2019, 7, 35. [CrossRef]

30. Jabłoński, M. On the Uselessness of Bond Paths Linking Distant Atoms and on the Violation of the Concept of Privileged Exchange Channels. ChemistryOpen 2019, 8, 497-507. [CrossRef]

31. Yang, X.; Li, Q.; Cheng, J.; Li, W. A new interaction mechanism of $\mathrm{LiNH}_{2}$ with $\mathrm{MgH}_{2}$ : Magnesium bond. J. Mol. Model. 2013, 19, 247-253. [CrossRef]

32. Xu, H.L.; Li, Q.Z.; Scheiner, S. Effect of magnesium bond on the competition between hydrogen and halogen bonds and the induction of proton and halogen transfer. ChemPhysChem 2018, 19, 1456-1464. [CrossRef]

33. Sanz, P.; Montero-Campillo, M.M.; Mó, O.; Yáñez, M.; Alkorta, I.; Elguero, J. Intramolecular magnesium bonds in malonaldehydelike systems: A critical view of the resonance-assisted phenomena. Theor. Chem. Acc. 2018, 137, 97. [CrossRef]

34. Montero-Campillo, M.M.; Sanz, P.; Mó, O.; Yáñez, M.; Alkorta, I.; Elguero, J. Alkaline-earth (Be, Mg and Ca) bonds at the origin of huge acidity enhancements. Phys. Chem. Chem. Phys. 2018, 20, 2413-2420. [CrossRef]

35. Jonas, V.; Frenking, G.; Reetz, M.T. Comparative Theoretical Study of Lewis Acid-Base Complexes of $\mathrm{BH}_{3}, \mathrm{BF}_{3}, \mathrm{BCl}_{3}, \mathrm{AlCl}_{3}$, and $\mathrm{SO}_{2}$. J. Am. Chem. Soc. 1994, 116, 8141-8753. [CrossRef]

36. Fau, S.; Frenking, G. Theoretical investigation of the weakly bonded donor-acceptor complexes $\mathrm{X}_{3} \mathrm{~B}-\mathrm{H}_{2}, \mathrm{X}_{3} \mathrm{~B}-\mathrm{C}_{2} \mathrm{H}_{4}$, and $\mathrm{X}_{3} \mathrm{~B}-\mathrm{C}_{2} \mathrm{H}_{2}(\mathrm{X}=\mathrm{H}, \mathrm{F}, \mathrm{Cl})$. Mol. Phys. 1999, 96, 519-527.

37. Czerw, M.; Goldman, A.S.; Krogh-Jespersen, K. Addition of Ammonia to $\mathrm{AlH}_{3}$ and $\mathrm{BH}_{3}$. Why Does Only Aluminum Form 2:1 Adducts? Inorg. Chem. 2000, 39, 363-369. [CrossRef]

38. Jabłoński, M. Binding of X-H to the lone-pair vacancy: Charge-inverted hydrogen bond. Chem. Phys. Lett. 2009, 477, 374-376. [CrossRef]

39. Grabowski, S.J. Boron and other Triel Lewis Acid Centers: From Hypovalency to Hypervalency. ChemPhysChem 2014, 15, 2985-2993. [CrossRef]

40. Grabowski, S.J. $\pi$-Hole Bonds: Boron and Aluminum Lewis Acid Centers. ChemPhysChem 2015, 16, 1470-1479. [CrossRef] [PubMed]

41. Grabowski, S.J. Triel Bonds, $\pi$-Hole- $\pi$-Electrons Interactions in Complexes of Boron and Aluminium Trihalides and Trihydrides with Acetylene and Ethylene. Molecules 2015, 20, 11297-11316. [CrossRef] [PubMed]

42. Grabowski, S.J. Triel bonds-complexes of boron and aluminum trihalides and trihydrides with benzene. Struct. Chem. 2017, 28, 1163-1171. [CrossRef]

43. Yourdkhani, S.; Jabłoński, M. Revealing the Physical Nature and the Strength of Charge-Inverted Hydrogen Bonds by SAPT(DFT), MP2, SCS-MP2, MP2C, and CCSD(T) Methods. J. Comput. Chem. 2017, 38, 773-780. [CrossRef] [PubMed]

44. Jabłoński, M. Hydride-Triel Bonds. J. Comput. Chem. 2018, 39, 1177-1191. [CrossRef]

45. Jabłoński, M. Ten years of charge-inverted hydrogen bonds. Struct. Chem. 2020, 31, 61-80. [CrossRef]

46. Grabowski, S.J. The Nature of Triel Bonds, a Case of B and Al Centres Bonded with Electron Rich Sites. Molecules 2020, 25, 2703. [CrossRef] 
47. Bauzá, A.; Mooibroek, T.J.; Frontera, A. Tetrel-Bonding Interaction: Rediscovered Supramolecular Force? Angew. Chem. Int. Ed. 2013, 52, 12317-12321. [CrossRef] [PubMed]

48. Grabowski, S.J. Tetrel bond $-\sigma$-hole bond as a preliminary stage of the $\mathrm{S}_{\mathrm{N}} 2$ reaction. Phys. Chem. Chem. Phys. 2014, 16, 1824-1834. [CrossRef]

49. Servati Gargari, M.; Stilinović, V.; Bauzá, A.; Frontera, A.; McArdle, P.; van Derveer, D.; Ng, S.W.; Mahmoudi, G. Design of Lead(II) Metal-Organic Frameworks Based on Covalent and Tetrel Bonding. Chem. Eur. J. 2015, 21, 17951-17958. [CrossRef] [PubMed]

50. Yourdkhani, S.; Korona, T.; Hadipour, N.L. Interplay between Tetrel and Triel Bonds in $\mathrm{RC}_{6} \mathrm{H}_{4} \mathrm{CN} \cdots \mathrm{MF}_{3} \mathrm{CN} \cdots \mathrm{BX}_{3} \mathrm{Complexes:}$ A Combined Symmetry-Adapted Perturbation Theory, Møller-Plesset, and Quantum Theory of Atoms-in-Molecules Study. J. Comput. Chem. 2015, 36, 2412-2428. [CrossRef]

51. Bauzá, A.; Mooibroek, T.J.; Frontera, A. Tetrel Bonding Interactions. Chem. Rec. 2016, 16, 473-487. [CrossRef]

52. Scheiner, S. Systematic Elucidation of Factors That Influence the Strength of Tetrel Bonds. J. Phys. Chem. A 2017, 121, 5561-5568. [CrossRef]

53. Grabowski, S.J. Tetrel bonds, penta- and hexa-coordinated tin and lead centres. Appl. Organomet. Chem. 2017, 31, e3727. [CrossRef]

54. Wei, Y.; Li, Q.; Yang, X.; McDowell, S.A.C. Intramolecular Si . . O Tetrel Bonding: Tuning of Substituents and Cooperativity. ChemistrySelect 2017, 2, 11104-11112. [CrossRef]

55. Grabowski, S.J. Pnicogen and tetrel bonds-tetrahedral Lewis acid centres. Struct. Chem. 2019, 30, 1141-1151. [CrossRef]

56. Zahn, S.; Frank, R.; Hey-Hawkins, E.; Kirchner, B. Pnicogen Bonds: A New Molecular Linker? Chem. Eur. J. 2011, 17, 6034-6038. [CrossRef]

57. Scheiner, S. A new noncovalent force: Comparison of P $\cdots$ N interaction with hydrogen and halogen bonds. J. Chem. Phys. 2011, 134, 094315. [CrossRef]

58. Del Bene, J.E.; Alkorta, I.; Sánchez-Sanz, G.; Elguero, J. ${ }^{31} \mathrm{P} \_{ }^{31} \mathrm{P}$ spin-spin coupling constants for pnicogen homodimers. Chem. Phys. Lett. 2011, 512, 184-187. [CrossRef]

59. Scheiner, S. The Pnicogen Bond: Its Relation to Hydrogen, Halogen, and Other Noncovalent Bonds. Acc. Chem. Res. 2013, 46, 280-288. [CrossRef]

60. Del Bene, J.E.; Alkorta, I.; Elguero, J. Properties of Complexes $\mathrm{H}_{2} \mathrm{C}=(\mathrm{X}) \mathrm{P}: \mathrm{PXH}_{2}$, for $\mathrm{X}=\mathrm{F}, \mathrm{Cl}, \mathrm{OH}, \mathrm{CN}, \mathrm{NC}, \mathrm{CCH}, \mathrm{H}, \mathrm{CH} 3$, and $\mathrm{BH}_{2}:$ P. . P Pnicogen Bonding at $\sigma$-Holes and $\pi$-Holes. J. Phys. Chem. A 2013, 117, 11592-11604. [CrossRef]

61. Del Bene, J.E.; Alkorta, I.; Elguero, J. The Pnicogen Bond in Review: Structures, Binding Energies, Bonding Properties, and Spin-Spin Coupling Constants of Complexes Stabilized by Pnicogen Bonds. In Noncovalent Forces. Challenges and Advances in Computational Chemistry and Physics; Scheiner, S., Ed.; Springer: Basel, Switzerland, 2015; Volume 19, pp. 191-264.

62. Sarkar, S.; Pavan, M.S.; Row, T.N.G. Experimental validation of 'Pnicogen Bonding' in Nitrogen from charge density analysis. Phys. Chem. Chem. Phys. 2015, 17, 2330-2334. [CrossRef]

63. Zierkiewicz, W.; Michalczyk, M.; Wysokiński, R.; Scheiner, S. On the ability of pnicogen atoms to engage in both $\sigma$ and $\pi$-hole complexes. Heterodimers of $\mathrm{ZF}_{2} \mathrm{C}_{6} \mathrm{H}_{5}(\mathrm{Z}=\mathrm{P}, \mathrm{As}, \mathrm{Sb}, \mathrm{Bi})$ and $\mathrm{NH}_{3}$. J. Mol. Model. 2019, 25, 152. [CrossRef]

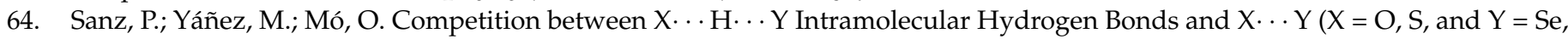
Te) Chalcogen-Chalcogen Interactions. J. Phys. Chem. A 2002, 106, 4661-4668. [CrossRef]

65. Bleiholder, C.; Werz, D.B.; Köppel, H.; Gleiter, R. Theoretical Investigations on Chalcogen-Chalcogen Interactions: What Makes These Nonbonded Interactions Bonding? J. Am. Chem. Soc. 2006, 128, 2666-2674. [CrossRef]

66. Wang, W.; Ji, B.; Zhang, Y. Chalcogen Bond: A Sister Noncovalent Bond to Halogen Bond. J. Phys. Chem. A 2009, 113, 8132-8135. [CrossRef]

67. Mahmudov, K.T.; Kopylovich, M.N.; Guedes da Silva, M.F.C.; Pombeiro, A.J.L. Chalcogen bonding in synthesis, catalysis and design of materials. Dalton Trans. 2016, 46, 10121-10138. [CrossRef]

68. Gleiter, R.; Haberhauer, G.; Werz, D.B.; Rominger, F.; Bleiholder, C. From Noncovalent Chalcogen-Chalcogen Interactions to Supramolecular Aggregates: Experiments and Calculations. Chem. Rev. 2018, 118, 2010-2041. [CrossRef] [PubMed]

69. Vogel, L.; Wonner, P.; Huber, S.M. Chalcogen Bonding: An Overview. Angew. Chem. Int. Ed. 2019, 58, 1880-1891. [CrossRef] [PubMed]

70. Scilabra, P.; Terraneo, G.; Resnati, G. The Chalcogen Bond in Crystalline Solids: A World Parallel to Halogen Bond. Acc. Chem. Res. 2019, 52, 1313-1324. [CrossRef] [PubMed]

71. Fellowes, T.; Harris, B.L.; White, J.M. Experimental evidence of chalcogen bonding at oxygen. Chem.Commun. 2020, 56, 3313-3316. [CrossRef]

72. Ibrahim, M.A.A.; Telb, E.M.Z. $\sigma$-Hole and Lone-Pair Hole Interactions in Chalcogen-Containing Complexes: A Comparative Study. ACS Omega 2020, 5, 21631-21640. [CrossRef]

73. Metrangolo, P.; Resnati, G. Halogen Bonding: Fundamentals and Applications. In Structure and Bonding; Mingos, D.M.P., Ed.; Springer: Berlin/Heidelberg, Germany, 2008; Volume 126.

74. Metrangolo, P.; Resnati, G. Halogen Bonding: A Paradigm in Supramolecular Chemistry. Chem. Eur. J. 2001, 7, 2511-2519. [CrossRef]

75. Voth, A.R.; Khuu, P.; Oishi, K.; Ho, P.S. Halogen bonds as orthogonal molecular interactions to hydrogen bonds. Nat. Chem. 2009, 1, 74-79. [CrossRef]

76. Fourmigué, M. Halogen bonding: Recent advances. Curr. Opin. Solid State Mater. Sci. 2009, 13, 36-45. [CrossRef] 
77. Wang, H.; Wang, W.; Jin, W.J. $\sigma$-Hole Bond vs. $\pi$-Hole Bond: A Comparison Based on Halogen Bond. Chem. Rev. 2016, 116, 5072-5104.

78. Varadwaj, P.R.; Varadwaj, A.; Marques, H.M. Halogen Bonding: A Halogen-Centered Noncovalent Interaction Yet to Be Understood. Inorganics 2019, 7, 40. [CrossRef]

79. Bauzá, A.; Frontera, A. Aerogen Bonding Interactions: A New Supramolecular Force? Angew. Chem. Int. Ed. 2015, 54, 7340-7343. [CrossRef] [PubMed]

80. Makarewicz, E.; Lundell, J.; Gordon, A.J.; Berski, S. On the nature of interactions in the $\mathrm{F}_{2} \mathrm{OXe} \cdots \mathrm{NCCH}_{3} \mathrm{complex}_{\mathrm{N}} \mathrm{Is}$ there the Xe(IV)-N bond? J. Comput. Chem. 2016, 37, 1876-1886. [CrossRef]

81. Bauzá, A.; Frontera, A. $\sigma / \pi$-Hole noble gas bonding interactions: Insights from theory and experiment. Coord. Chem. Rev. 2020, 404, 213112. [CrossRef]

82. Sánchez-Sanz, G.; Alkorta, I.; Elguero, J.; Yáñez, M.; Mó, O. Strong interactions between copper halides and unsaturated systems: New metallocycles? Or the importance of deformation. Phys. Chem. Chem. Phys. 2012, 14, 11468-11477. [CrossRef] [PubMed]

83. Forfar, L.C.; Zeng, D.; Green, M.; McGrady, J.E.; Russell, C.A. Probing the Structure, Dynamics, and Bonding of Coinage Metal Complexes of White Phosphorus. Chem. Eur. J. 2016, 22, 5397-5403. [CrossRef] [PubMed]

84. Radenković, S.; Antić, M.; Savić, N.D.; Glišić, B.D. The nature of the Au-N bond in gold(III) complexes with aromatic nitrogencontaining heterocycles: The influence of $\mathrm{Au}(\mathrm{III})$ ions on the ligand aromaticity. New J. Chem. 2017, 41, 12407-12415. [CrossRef]

85. Legon, A.C.; Walker, N.R. What's in a name? 'Coinage-metal' non-covalent bonds and their definition. Phys. Chem. Chem. Phys. 2018, 20, 19332-19338. [CrossRef]

86. Frontera, A.; Bauzá, A. Regium- $\pi$ bonds: An Unexplored Link between Noble Metal Nanoparticles and Aromatic Surfaces. Chem. Eur. J. 2018, 24, 7228-7234. [CrossRef] [PubMed]

87. Bauzá, A.; Frontera, A. Regium- $\pi$ Vs. Cation- Interact. $\mathrm{M}_{2} \mathrm{MCl}(\mathrm{M}=\mathrm{Cu}, \mathrm{Ag} \mathrm{Au})$ Complexes Small Aromat. Syst. Ab Initio Study. Inorganics 2018, 6, 64. [CrossRef]

88. Wang, R.; Yang, S.; Li, Q. Coinage-Metal Bond between [1.1.1]Propellane and $\mathrm{M} 2 / \mathrm{MCl} / \mathrm{MCH}_{3}(\mathrm{M}=\mathrm{Cu}, \mathrm{Ag}$, and $\mathrm{Au})$ : Cooperativity and Substituents. Molecule 2019, 24, 2601. [CrossRef]

89. Sánchez-Sanz, G.; Trujillo, C.; Alkorta, I.; Elguero, J. Understanding Regium Bonds and their Competition with Hydrogen Bonds in $\mathrm{Au}_{2}: \mathrm{HX}$ Complexes. ChemPhysChem 2019, 20, 1572-1580. [CrossRef]

90. Terrón, A.; Buils, J.; Mooibroek, T.J.; Barceló-Oliver, M.; García-Raso, A.; Fiol, J.J.; Frontera, A. Synthesis, X-ray characterization and regium bonding interactions of a trichlorido-(1-hexylcytosine)gold(III) complex. Chem. Commun. 2020, 56, $3524-3527$. [CrossRef]

91. Lupinetti, A.J.; Jonas, V.; Thiel, W.; Strauss, S.H.; Frenking, G. Trends in Molecular Geometries and Bond Strengths of the Homoleptic $\mathrm{d}^{10}$ Metal Carbonyl Cations $\left[\mathrm{M}(\mathrm{CO})_{n}\right]^{x+}\left(\mathrm{M}^{x+}=\mathrm{Cu}^{+}, \mathrm{Ag}^{+}, \mathrm{Au}^{+}, \mathrm{Zn}^{2+}, \mathrm{Cd}^{2+}, \mathrm{Hg}^{2+} ; n=1-6\right)$ : A Theoretical Study. Chem. Eur. J. 1999, 5, 2573-2583. [CrossRef]

92. Joy, J.; Jemmis, E.D. Contrasting Behavior of the Z Bonds in X-Z ‥ Y Weak Interactions: Z = Main Group Elements Versus the Transition Metals. Inorg. Chem. 2017, 56, 1132-1143. [CrossRef]

93. Wang, S.R.; Arrowsmith, M.; Braunschweig, H.; Dewhurst, R.D.; Dömling, M.; Mattock, J.D.; Pranckevicius, C.; Vargas, A. Monomeric 16-Electron $\pi$-Diborene Complexes of $\mathrm{Zn}(\mathrm{II})$ and Cd(II). J. Am. Chem. Soc. 2017, 139, 10661-10664. [CrossRef] [PubMed]

94. Kirmse, W. Carbene Chemistry; Academic Press: Cambridge, MA, USA, 1964.

95. Hubert, A.J. Catalysis in $C_{1}$ Chemistry; Springer: Dordrecht, The Netherlands, 1983.

96. Schubert, U. Advances in Metal Carbene Chemistry; Springer: Dordrecht, The Netherlands, 1989.

97. Bertrande, G. Carbene Chemistry: From Fleeting Intermediates to Powerful Reagents; FontisMedia S.A. (Lausanne) and Marcel Dekker, Inc.: Basel, Switzerland, 2002.

98. Moss, R.A.; Platz, M.S.; Jones, M., Jr. (Eds.) Reactive Intermediate Chemistry; John Wiley \& Sons, Inc.: Hoboken, NJ, USA, 2005.

99. Nolan, S.P. N-Heterocyclic Carbenes in Synthesis; Wiley-VCH: Weinheim, Germany, 2006.

100. Carey, F.A.; Sundberg, R.J. Carbenes, Part B: Reactions and Synthesis. Advanced Organic Chemistry; Springer: New York, NY, USA, 2007.

101. Moss, R.A.; Doyle, M.P. Contemporary Carbene Chemistry; John Wiley \& Sons, Inc.: Hoboken, NJ, USA, 2013.

102. Bellemin-Laponnaz, S.; Dagorne, S. Group 1 and 2 and Early Transition Metal Complexes Bearing N-Heterocyclic Carbene Ligands: Coordination Chemistry, Reactivity, and Applications. Chem. Rev. 2014, 114, 8747-8774. [CrossRef] [PubMed]

103. Nesterov, V.; Reiter, D.; Bag, P.; Frisch, P.; Holzner, R.; Porzelt, A.; Inoue, S. NHCs in Main Group Chemistry. Chem. Rev. 2018, 118, 9678-9842. [CrossRef] [PubMed]

104. Pople, J.A.; Raghavachari, K.; Frisch, M.J.; Binkley, J.S.; Schleyer, P.V.R. Comprehensive Theoretical Study of Isomers and Rearrangement Barriers of Even-Electron Polyatomic Molecules $\mathrm{H}_{m} \mathrm{ABH}_{n}(\mathrm{~A}, \mathrm{~B}=\mathrm{C}, \mathrm{N}, \mathrm{O}$, and F). J. Am. Chem. Soc. 1983, 105, 6389-6398. [CrossRef]

105. Pople, J.A. A theoretical search for the methylenefluoronium ylide. Chem. Phys. Lett. 1986, 132, 144-146. [CrossRef]

106. Arduengo, A.J., III; Gamper, S.F.; Tamm, M.; Calabrese, J.C.; Davidson, F.; Craig, H.A. A Bis(carbene)-Proton Complex: Structure of a C-H-C Hydrogen Bond. J. Am. Chem. Soc. 1995, 117, 572-573. [CrossRef]

107. Alkorta, I.; Elguero, J. Carbenes and Silylenes as Hydrogen Bond Acceptors. J. Phys. Chem. 1996, 100, 19367-19370. [CrossRef] 
108. Jabłoński, M.; Palusiak, M. Divalent carbon atom as the proton acceptor in hydrogen bonding. Phys. Chem. Chem. Phys. 2009, 11, 5711-5719. [CrossRef]

109. Giffin, N.A.; Makramalla, M.; Hendsbee, A.D.; Robertson, K.N.; Sherren, C.; Pye, C.C.; Masuda, J.D.; Clyburne, J.A.C. Anhydrous TEMPO-H: Reactions of a good hydrogen atom donor with low-valent carbon centres. Org. Biomol. Chem. 2011, 9, 3672-3680. [CrossRef]

110. Gerbig, D.; Ley, D. Computational methods for contemporary carbene chemistry. WIREs Comput. Mol. Sci. 2013, 3, $242-272$. [CrossRef]

111. Samanta, R.C.; De Sarkar, S.; Fröhlich, R.; Grimme, S.; Studer, A. N-Heterocyclic carbene (NHC) catalyzed chemoselective acylation of alcohols in the presence of amines with various acylating reagents. Chem. Sci. 2013, 4, 2177-2184. [CrossRef]

112. Li, Q.; Wang, H.; Liu, Z.; Li, W.; Cheng, J.; Gong, B.; Sun, J. Ab Initio Study of Lithium-Bonded Complexes with Carbene as an Electron Donor. J. Phys. Chem. A 2009, 113, 14156-14160. [CrossRef] [PubMed]

113. Wang, Y.; Xie, Y.; Abraham, M.Y.; Wei, P.; Schaefer, H.F., III; Schleyer, P.v.R.; Robinson, G.H. A Viable Anionic N-Heterocyclic Dicarbene. J. Am. Chem. Soc. 2010, 132, 14370-14372. [CrossRef] [PubMed]

114. Zhi-Feng, L.; Sheng, Y.; Hui-Xue, L. Theoretical prediction characters of unconventional weak bond with carbene as electron donors and $\mathrm{Li}-\mathrm{Y}(\mathrm{Y}=\mathrm{OH}, \mathrm{H}, \mathrm{F}, \mathrm{NC}$ and CN) as electron acceptors. J. Mol. Struct. THEOCHEM 2010, 952, 56-60. [CrossRef]

115. Herrmann, W.A.; Runte, O.; Artus, G. Synthesis and structure of an ionic beryllium-“Carbene” complex. J. Organomet. Chem. 1995, 501, Cl-C4. [CrossRef]

116. Gilliard, R.J., Jr.; Abraham, M.Y.; Wang, Y.; Wei, P.; Xie, Y.; Quillian, B.; Schaefer, H.F., III; Schleyer, P.v.R.; Robinson, G.H. Carbene-Stabilized Beryllium Borohydride. J. Am. Chem. Soc. 2012, 134, 9953-9955.

117. Arrowsmith, M.; Hill, M.S.; Kociok-Köhn, G.; MacDougall, D.J.; Mahon, M.F. Beryllium-Induced C-N Bond Activation and Ring Opening of an N-Heterocyclic Carbene. Angew. Chem. Int. Ed. 2012, 51, 2098-2100. [CrossRef] [PubMed]

118. Walley, J.E.; Wong, Y.-O.; Freeman, L.A.; Dickie, D.A.; Gilliard, R.J., Jr. N-Heterocyclic Carbene-Supported Aryl- and Alk- oxides of Beryllium and Magnesium. Catalysts 2019, 9, 934. [CrossRef]

119. Arduengo, A.J., III; Dias, H.V.R.; Davidson, F.; Harlow, R.L. Carbene adducts of magnesium and zinc. J. Organomet. Chem. 1993, 462, 13-18. [CrossRef]

120. Arrowsmith, M.; Hill, M.S.; MacDougall, D.J.; Mahon, M.F. A Hydride-Rich Magnesium Cluster. Angew. Chem. Int. Ed. 2009, 48, 4013-4016. [CrossRef] [PubMed]

121. Arnold, P.L.; Casely, I.J.; Turner, Z.R.; Bellabarba, R.; Tooze, R.B. Magnesium and zinc complexes of functionalised, saturated $\mathrm{N}$-heterocyclic carbene ligands: Carbene lability and functionalisation, and lactide polymerisation catalysis. Dalton Trans. 2009, 7236-7247. [CrossRef] [PubMed]

122. Arduengo, A.J., III; Dias, H.V.R.; Calabrese, J.C.; Davidson, F. A Stable Carbene-Alane Adduct. J. Am. Chem. Soc. 1992, 114, 9724-9725. [CrossRef]

123. Li, X.-W.; Su, J.; Robinson, G.H. Syntheses and molecular structure of organo-group 13 metal carbene complexes. Chem. Commun. 1996, 23, 2683-2684. [CrossRef]

124. Hibbs, D.E.; Hursthouse, M.B.; Jones, C.; Smithies, N.A. Synthesis, crystal and molecular structure of the first indium trihydride complex, [InH3CN(Pri)C2Me2N(Pri)]. Chem. Commun. 1998, 8, 869-870. [CrossRef]

125. Merceron, N.; Miqueu, K.; Baceiredo, A.; Bertrand, G. Stable (Amino)(phosphino)carbenes: Difunctional Molecules. J. Am. Chem. Soc. 2002, 124, 6806-6807. [CrossRef]

126. Wang, Y.; Robinson, G.H. Unique homonuclear multiple bonding in main group compounds. Chem. Commun. 2009, 5201-5213. [CrossRef] [PubMed]

127. Del Bene, J.E.; Alkorta, I.; Elguero, J. Carbon-Carbon Bonding between Nitrogen Heterocyclic Carbenes and $\mathrm{CO}_{2}$. J. Phys. Chem. A 2017, 121, 8136-8146. [CrossRef]

128. Liu, M.; Li, Q.; Li, W.; Cheng, J. Carbene tetrel-bonded complexes. Struct. Chem. 2017, 28, 823-831. [CrossRef]

129. Wang, Y.; Xie, Y.; Abraham, M.Y.; Gilliard, R.J., Jr.; Wei, P.; Schaefer, H.F., III; Schleyer, P.V.R.; Robinson, G.H. Carbene-Stabilized Parent Phosphinidene. Organometallics 2010, 29, 4778-4780. [CrossRef]

130. Abraham, M.Y.; Wang, Y.; Xie, Y.; Wei, P.; Schaefer, H.F., III; Schleyer, P.V.R.; Robinson, G.H. Carbene Stabilization of Diarsenic: From Hypervalency to Allotropy. Chem. Eur. J. 2010, 16, 432-435. [CrossRef]

131. Patel, D.S.; Bharatam, P.V. Divalent N(I) Compounds with Two Lone Pairs on Nitrogen. J. Phys. Chem. A 2011, 115, 7645-7655. [CrossRef]

132. Zhao, Q.; Feng, D.; Sun, Y.; Hao, J.; Cai, Z. Theoretical Investigations on the Weak Nonbonded C $=S \cdot \cdots \mathrm{CH}_{2}$ Interactions: Chalcogen-Bonded Complexes With Singlet Carbene as an Electron Donor. Int. J. Quant. Chem. 2011, 111, 3881-3887. [CrossRef]

133. Arduengo, A.J., III; Kline, M.; Calabrese, J.C.; Davidson, F. Synthesis of a Reverse Ylide from a Nucleophilic Carbene. J. Am. Chem. Soc. 1991, 113, 9704-9705. [CrossRef]

134. Kuhn, N.; Kratz, T.; Henkel, G. A Stable Carbene Iodine Adduct: Secondary Bonding in 1,3-Diethyl-2-iodo-4,5-dimethylimidazolium Iodide. J. Chem. Soc. Chem. Commun. 1993, 1778-1779. [CrossRef]

135. Li, Q.; Wang, Y.; Liu, Z.; Li, W.; Cheng, J.; Gong, B.; Sun, J. An unconventional halogen bond with carbene as an electron donor: An ab initio study. Chem. Phys. Lett. 2009, 469, 48-51. [CrossRef]

136. Esrafili, M.D.; Mohammadirad, N. Insights into the strength and nature of carbene $\cdots$ halogen bond interactions: A theoretical perspective. J. Mol. Model. 2013, 19, 2559-2566. [CrossRef] 
137. Esrafili, M.D.; Sabouri, A. Carbene-aerogen bonds: An ab initio study. Mol. Phys. 2017, 115, 971-980. [CrossRef]

138. Frenking, G.; Solà, M.; Vyboishchikov, S.F. Chemical bonding in transition metal carbene complexes. J. Organomet. Chem. 2005, 690, 6178-6204. [CrossRef]

139. Scott, N.M.; Nolan, S.P. Stabilization of Organometallic Species Achieved by the Use of N-Heterocyclic Carbene (NHC) Ligands. Eur. J. Inorg Chem. 2005, 1815-1828. [CrossRef]

140. Schoeller, W.W. Electrophilicity and nucleophilicity in singlet carbenes. II. Electrophilic selectivity. Tetrahedron Lett. 1980, 21, 1509-1510. [CrossRef]

141. Goumri-Magnet, S.; Polishchuck, O.; Gornitzka, H.; Marsden, C.J.; Baceiredo, A.; Bertrand, G. The Electrophilic Behavior of Stable Phosphanylcarbenes Towards Phosphorus Lone Pairs. Angew. Chem. Int. Ed. 1999, 38, 3727-3729. [CrossRef]

142. Moss, R.A.; Wang, L.; Cang, H.; Krogh-Jespersen, K. Extremely reactive carbenes: Electrophiles and nucleophiles. J. Phys. Org. Chem. 2017, 30, e3555. [CrossRef]

143. Jabłoński, M. The first theoretical proof of the existence of a hydride-carbene bond. Chem. Phys. Lett. 2018, 710, 78-83. [CrossRef]

144. Jabłoński, M. In search for a hydride-carbene bond. J. Phys. Org. Chem. 2019, 32, e3949. [CrossRef]

145. Yourdkhani, S.; Jabłoński, M. Physical nature of silane - * carbene dimers revealed by state-of-the-art ab initio calculations. J. Comput. Chem. 2019, 40, 2643-2652. [CrossRef]

146. Piela, L. Ideas of Quantum Chemistry; Elsevier: Amsterdam, The Netherlands, 2020.

147. Hoffmann, R.; Zeiss, G.D.; Van Dine, G.W. The Electronic Structure of Methylenes. J. Am. Chem. Soc. 1968, 90, 1485-1499. [CrossRef]

148. Gleiter, R.; Hoffmann, R. On Stabilizing a Singlet Methylene. J. Am. Chem. Soc. 1968, 90, 5457-5460. [CrossRef]

149. Baird, N.C.; Taylor, K.F. Multiplicity of the Ground State and Magnitude of the $\mathrm{T}_{1}-\mathrm{S}_{0}$ Gap in Substituted Carbenes. J. Am. Chem. Soc. 1978, 100, 1333-1338. [CrossRef]

150. Harrison, J.F.; Liedtke, R.C.; Liebman, J.F. The Multiplicity of Substituted Acyclic Carbenes and Related Molecules. J. Am. Chem. Soc. 1979, 101, 7162-7168. [CrossRef]

151. Mueller, P.H.; Rondan, N.G.; Houk, K.N.; Harrison, J.F.; Hooper, D.; Willen, B.H.; Liebman, J.F. Carbene Singlet-Triplet Gaps. Linear Correlations with Substituent $\pi$ Donation. J. Am. Chem. Soc. 1981, 103, 5049-5052. [CrossRef]

152. Boehme, C.; Frenking, G. Electronic Structure of Stable Carbenes, Silylenes, and Germylenes. J. Am. Chem. Soc. 1996, 118, 2039-2046. [CrossRef]

153. Alkorta, I.; Elguero, J. A LFER analysis of the singlet-triplet gap in a series of sixty-six carbenes. Chem. Phys. Lett. 2018, 691, 33-36. [CrossRef]

154. Ramirez, F.; Desai, N.B.; Hansen, B.; McKelvie, N. Hexaphenylcarbodiphosporane, $\left(\mathrm{C}_{6} \mathrm{H}_{5}\right)_{3} \mathrm{PCP}\left(\mathrm{C}_{6} \mathrm{H}_{5}\right)_{3}$. J. Am. Chem. Soc. 1961, 83, 3539-3540. [CrossRef]

155. Kaska, W.C.; Mitchell, D.K.; Reichelderfer, R.F. Transition metal complexes of hexaphenylcarbodiphosphorane. J. Organomet. Chem. 1973, 47, 391-402. [CrossRef]

156. Gasser, O.; Schmidbaur, H. Bis(trimethylphosphoranylidene)methane, $\left(\mathrm{CH}_{3}\right)_{3} \mathrm{PCP}\left(\mathrm{CH}_{3}\right)_{3}$. J. Am. Chem. Soc. 1975, 97, 6281-6282. [CrossRef]

157. Bestmann, H.J. Phosphacumulene Ylides and Phosphaallene Ylides. Angew. Chem. Int. Ed. Engl. 1977, 16, 349-364. [CrossRef]

158. Hardy, G.E.; Zink, J.I.; Kaska, W.C.; Baldwin, J.C. Structure and triboluminescence of polymorphs of hexaphenylcarbodiphosphorane. J. Am. Chem. Soc. 1978, 100, 8001-8002. [CrossRef]

159. Schmidbaur, H. Carbodiphosphorane. Nachr. Chem. Tech. Lab. 1979, 27, 620-622. [CrossRef]

160. Schmidbaur, H.; Costa, T.; Milewski-Mahrla, B.; Schubert, U. Ring-Strained Carbodiphosphoranes. Angew. Chem. Int. Ed. Engl. 1980, 19, 555-556. [CrossRef]

161. Schmidbaur, H. Phosphorus Ylides in the Coordination Sphere of Transition Metals: An Inventory. Angew. Chem. Int. Ed. Engl. 1983, 22, 907-927. [CrossRef]

162. Johnson, A.W. (Ed.) Ylides and Imines of Phosphorus; Wiley: New York, NY, USA, 1993.

163. Kolodiazhnyi, O.I. C-element-substituted phosphorus ylids. Tetrahedron 1996, 52, 1855-1929. [CrossRef]

164. Kolodiazhnyi, O.I. Phosphorous Ylides: Chemistry and Application in Organic Synthesis; Wiley-VCH: Weinheim, Germany, 1999.

165. Vicente, J.; Singhal, A.R.; Jones, P.G. New Ylide-, Alkynyl-, and Mixed Alkynyl/Ylide-Gold(I) Complexes. Organometallics 2002, 21, 5887-5900. [CrossRef]

166. Jones, N.D.; Cavell, R.G. Phosphorus-substituted carbene complexes: Chelates, pincers and spirocycles. J. Organomet. Chem. 2005, 690, 5485-5496. [CrossRef]

167. Tonner, R.; Öxler, F.; Neumüller, B.; Petz, W.; Frenking, G. Carbodiphosphoranes: The Chemistry of Divalent Carbon(0). Angew. Chem. Int. Ed. 2006, 45, 8038-8042. [CrossRef] [PubMed]

168. Schmidbaur, H. Réplique: A New Concept for Bonding in Carbodiphosphoranes? Angew. Chem. Int. Ed. 2007, 46, 2984-2985. [CrossRef] [PubMed]

169. Frenking, G.; Neumüller, B.; Petz, W.; Tonner, R.; Öxler, F. Reply to Réplique: A New Concept for Bonding in Carbodiphosphoranes? Angew. Chem. Int. Ed. 2007, 46, 2986-2987. [CrossRef]

170. Tonner, R.; Frenking, G. C(NHC) 2 : Divalent Carbon(0) Compounds with N-Heterocyclic Carbene Ligands-Theoretical Evidence for a Class of Molecules with Promising Chemical Properties. Angew. Chem. Int. Ed. 2007, 46, 8695-8698. [CrossRef] [PubMed] 
171. Tonner, R.; Frenking, G. Divalent Carbon(0) Chemistry, Part 1: Parent Compounds. Chem. Eur. J. 2008, 14, 3260-3272. [CrossRef] [PubMed]

172. Tonner, R.; Frenking, G. Divalent Carbon(0) Chemistry, Part 2: Protonation and Complexes with Main Group and Transition Metal Lewis Acids. Chem. Eur. J. 2008, 14, 3273-3289. [CrossRef] [PubMed]

173. Wiberg, K.B.; Rablen, P.R. Comparison of Atomic Charges Derived via Different Procedures. J. Comput. Chem. 1993, 14, 1504-1518. [CrossRef]

174. Martin, F.; Zipse, H. Charge Distribution in the Water Molecule-A Comparison of Methods. J. Comput. Chem. 2005, 26, 97-105. [CrossRef]

175. Wiberg, K.B.; Rablen, P.R. Atomic Charges. J. Org. Chem. 2018, 83, 15463-15469. [CrossRef]

176. Jabłoński, M.; Krygowski, T.M. Study of the influence of intermolecular interaction on classical and reverse substituent effects in Para-Substituted Phenylboranes. New J. Chem. 2020, 44, 9656-9670. [CrossRef]

177. Hirshfeld, F.L. Bonded-Atom Fragments for Describing Molecular Charge Densities. Theor. Chim. Acta 1977, 44, 129-138. [CrossRef]

178. Ritchie, J.P. Electron Density Distribution Analysis for Nitromethane, Nitromethide, and Nitramide. J. Am. Chem. Soc. 1985, 107, 1829-1837. [CrossRef]

179. Ritchie, J.P.; Bachrach, S.M. Some Methods and Applications of Electron Density Distribution Analysis. J. Comput. Chem. 1987, 8, 499-509. [CrossRef]

180. Reed, A.E.; Curtiss, L.A.; Weinhold, F. Intermolecular Interactions from a Natural Bond Orbital, Donor-Acceptor Viewpoint. Chem. Rev. 1988, 88, 899-926. [CrossRef]

181. Weinhold, F.; Landis, C.R. Valency and Bonding-A Natural Bond Orbital Donor-Acceptor Perspective; Cambridge University Press: Cambridge, UK, 2005.

182. Bader, R.F.W. Atoms in Molecules: A Quantum Theory; Oxford University Press: New York, NY, USA, 1990.

183. Popelier, P.L.A. Atoms in Molecules. An Introduction; Longman: Singapore, 2000.

184. Matta, C.F.; Boyd, R.J. The Quantum Theory of Atoms in Molecules; Wiley-VCH: Weinheim, Germany, 2007.

185. Shannon, R.D. Revised Effective Ionic Radii and Systematic Studies of Interatomie Distances in Halides and Chaleogenides. Acta Cryst. 1976, A32, 751-767. [CrossRef]

186. Fukui, K.; Yonezawa, T.; Shingu, H. A Molecular Orbital Theory of Reactivity in Aromatic Hydrocarbons. J. Chem. Phys. 1952, 20, 722-725. [CrossRef]

187. Fleming, I. Frontier Orbitals and Organic Chemical Reactions; Wiley: London, UK, 1978.

188. Klopman, G. Chemical reactivity and the concept of charge- and frontier-controlled reactions. J. Am. Chem. Soc. 1968, 90, 223-234. [CrossRef]

189. Salem, L. Intermolecular orbital theory of the interaction between conjugated systems. I. General theory. J. Am. Chem. Soc. 1968, 90, 543-552. [CrossRef]

190. Frenking, G.; Shaik, S. (Eds.) The Chemical Bond; Wiley-VCH Verlag GmbH \& Co.: Weinheim, Germany, 2014.

191. Grabowski, S.J.; Sokalski, W.A.; Leszczynski, J. Wide spectrum of H ․ H interactions: Van der Waals contacts, dihydrogen bonds and covalency. Chem. Phys. 2007, 337, 68-76. [CrossRef]

192. Johnson, E.R.; Keinan, K.; Mori-Sánchez, P.; Contreras-García, J.; Cohen, A.J.; Yang, W. Revealing Noncovalent Interactions, J. Am. Chem. Soc. 2010, 132, 6498-6506.

193. Contreras-García, J.; Johnson, E.R.; Keinan, S.; Chaudret, R.; Piquemal, J.-P.; Beratan, D.N.; Yang, W. NCIPLOT: A Program for Plotting Noncovalent Interaction Regions. J. Chem. Theory Comput. 2011, 7, 625-632. [CrossRef]

194. Cremer, D.; Kraka, E. Chemical Bonds without Bonding Electron Density-Does the Difference Electron-Density Analysis Suffice for a Description of the Chemical Bond? Angew. Chem. Int. Ed. Engl. 1984, 23, 627-628. [CrossRef]

195. García-Revilla, M.; Francisco, E.; Popelier, P.L.A.; Pendás, A.M. Domain-Averaged Exchange-Correlation Energies as a Physical Underpinning for Chemical Graphs. ChemPhysChem 2013, 14, 1211-1218. [CrossRef] [PubMed]

196. Jabłoński, M. Bond Paths Between Distant Atoms Do Not Necessarily Indicate Dominant Interactions. J. Comput. Chem. 2018, 39, 2183-2195. [CrossRef] [PubMed]

197. Jabłoński, M. Counterintuitive bond paths: An intriguing case of the $\mathrm{C}\left(\mathrm{NO}_{2}\right)_{3}^{-}$ion. Chem. Phys. Lett. 2020, 759, 137946. [CrossRef]

198. Chai, J.-D.; Head-Gordon, M. Long-range corrected hybrid density functionals with damped atom-atom dispersion corrections. Phys. Chem. Chem. Phys. 2008, 10, 6615-6620. [CrossRef]

199. Hohenberg, P.; Kohn, W. Inhomogeneous Electron Gas. Phys. Rev. 1964, 136, B864-B871. [CrossRef]

200. Kohn, W.; Sham, L.J. Self-Consistent Equations Including Exchange and Correlation Effects. Phys. Rev. 1965, 140, A1133-A1138. [CrossRef]

201. Parr, R.G.; Yang, W. Density-Functional Theory of Atoms and Molecules; Oxford University Press: New York, NY, USA, 1989.

202. Krishnan, R.; Binkley, J.S.; Seeger, R.; Pople, J.A. Self-consistent molecular orbital methods. XX. A basis set for correlated wave functions. J. Chem. Phys. 1980, 72, 650-654. [CrossRef]

203. McLean, A.D.; Chandler, G.S. Contracted Gaussian basis sets for molecular calculations. I. second row atoms, Z=11-18. J. Chem. Phys. 1980, 72, 5639-5648. [CrossRef]

204. Curtiss, L.A.; McGrath, M.P.; Blandeau, J.-P.; Davis, N.E.; Binning, R.C., Jr.; Radom, L. Extension of Gaussian-2 theory to molecules containing third-row atoms Ga-Kr. J. Chem. Phys. 1995, 103, 6104-6113. [CrossRef] 
205. Frisch, M.J.; Pople, J.A.; Binkley, J.S. Self-consistent molecular orbital methods 25. Supplementary functions for Gaussian basis sets. J. Chem. Phys. 1984, 80, 3265-3269. [CrossRef]

206. Clark, T.; Chandrasekhar, J.; Spitznagel, G.W.; Schleyer, P.V.R. Efficient Diffuse Function-Augmented Basis Sets for Anion Calculations. III. The 3-21+G Basis Set for First-Row Elements, Li-F. J. Comput. Chem. 1983, 4, 294-301. [CrossRef]

207. Mardirossian, N.; Head-Gordon, M. Thirty years of density functional theory in computational chemistry: An overview and extensive assessment of 200 density functionals. Mol. Phys. 2017, 19, 2315-2372. [CrossRef]

208. Frisch, M.J.; Trucks, G.W.; Schlegel, H.B.; Scuseria, G.E.; Robb, M.A.; Cheeseman, J.R.; Scalmani, G.; Barone, V.; Mennucci, B.; Petersson, G.A.; et al. Gaussian 09; Gaussian, Inc.: Wallingford, CT, USA, 2013.

209. Glendening, E.D.; Badenhoop, J.K.; Reed, A.E.; Carpenter, J.E.; Bohmann, J.A.; Morales, C.M.; Landis, C.R.; Weinhold, F. NBO 6.0; Theoretical Chemistry Institute, University of Wisconsin: Madison, WI, USA, 2013. Available online: http://nbo6.chem.wisc.edu/ (accessed on 12 April 2021).

210. Keith, T.A. TK Gristmill Software, Version 15.05.18; AIMAll: Overland Park, KS, USA, 2015. Available online: aim.tkgristmill.com (accessed on 12 April 2021). 